\title{
PhD Thesis
}

Investigation of protein-ligand interactions of targets with solvent-exposed binding sites

\section{Edit Wéber}

Supervisor

Dr. Tamás Martinek

University of Szeged

Institute of Pharmaceutical Chemistry 


\section{Table of Contents}

Table of Contents........................................................................................................................

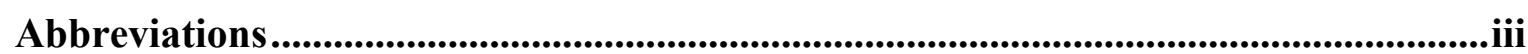

List of publications and lectures ...........................................................................................

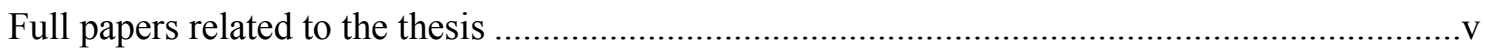

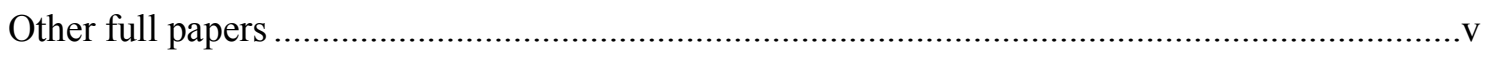

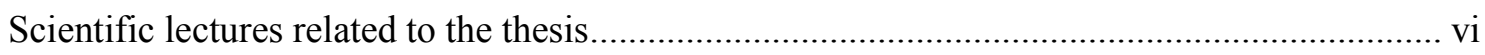

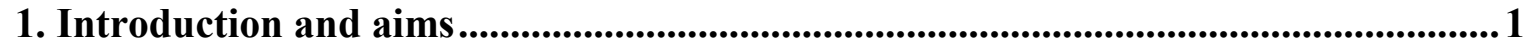

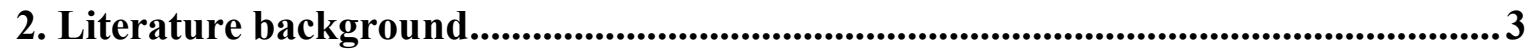

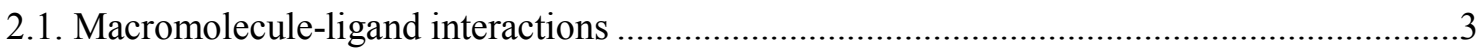

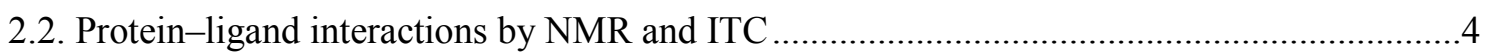

2.2.1. Basic concepts of NMR-based ligand-binding tests ....................................................

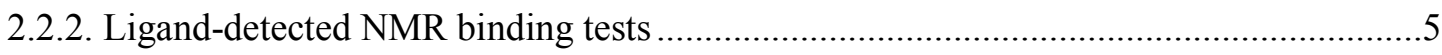

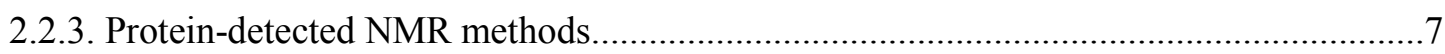

2.2.4. Characterization of protein-ligand interactions by ITC …........................................... 10

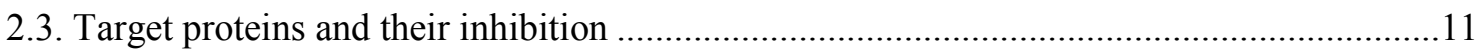

2.3.1. Galectin-1: $\beta$-sandwich homodimer involved in immune regulation and tumour metastasis

2.3.2. Amyloid- $\beta(\mathrm{A} \beta)$ peptide aggregates in Alzheimer's disease .......................................13

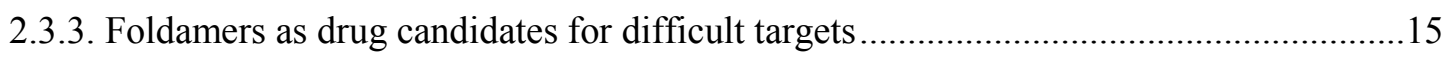

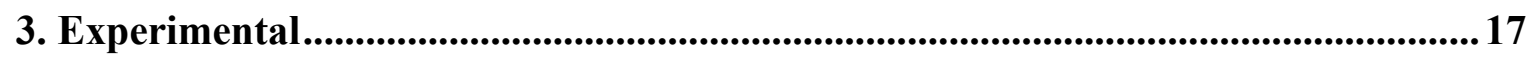

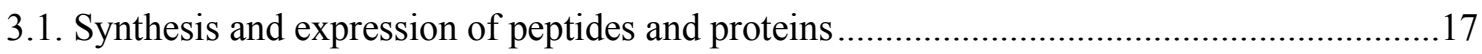

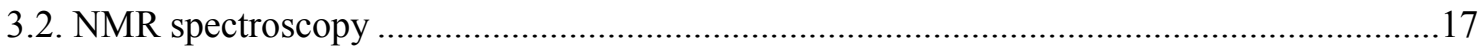

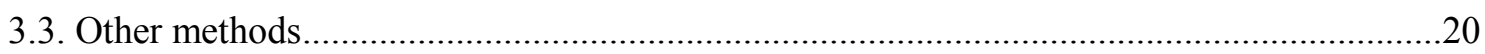

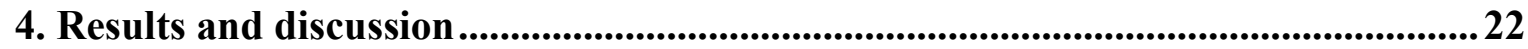

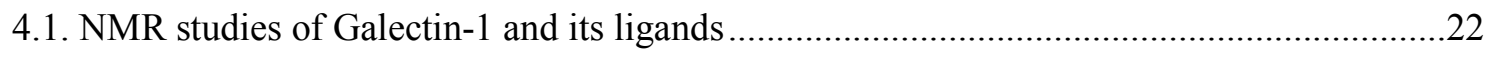

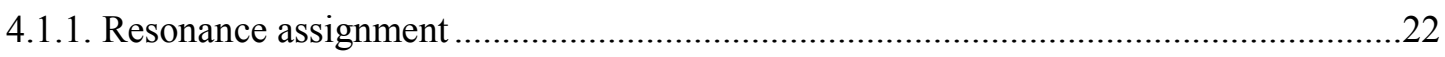

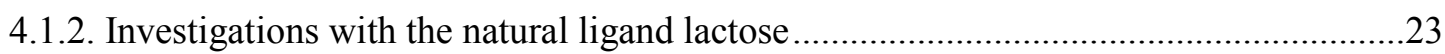

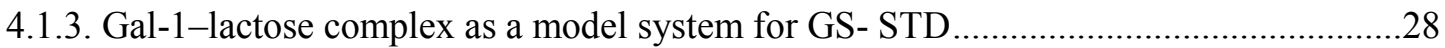

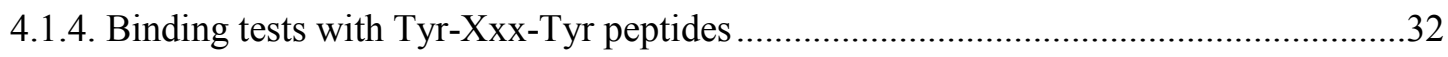

4.2. Binding of neuroprotective peptides and foldamers to $A \beta 1-42$ aggregates.............................36

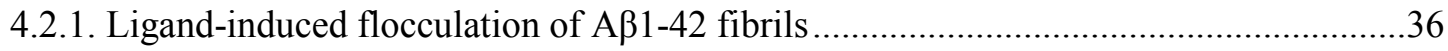

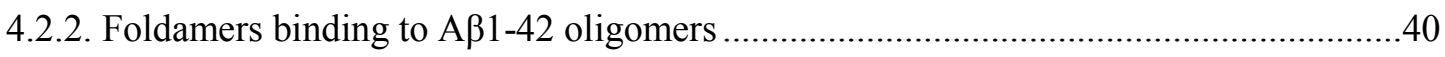

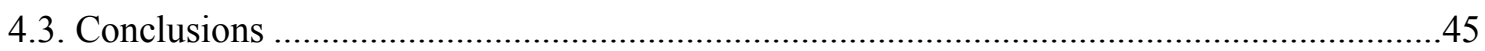

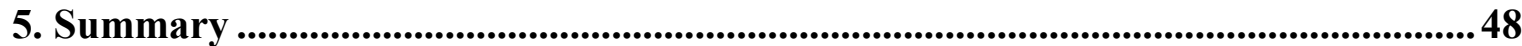




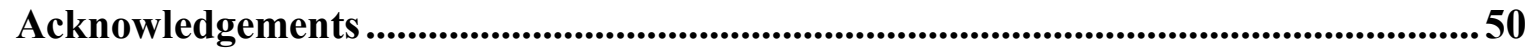

References .......................................................................................................................551

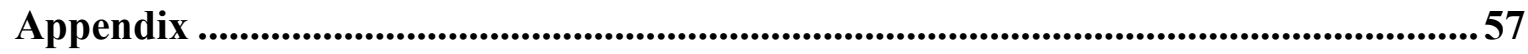




\section{Abbreviations}

2D: two-dimensional

3D: three-dimensional

A $\beta 1-42$ : Amyloid $\beta 1-42$

ACHC: 2-aminocyclohexanecarboxylic acid

ACPC: 2-aminocyclopentanecarboxylic acid

AD: Alzheimer's disease

ASF: asialofetuin

$\beta^{3}$ hArg: $\beta^{3}-(S)$-homoarginine

$\beta^{3}$ hAsp: $\beta^{3}-(R)$-homoaspartate

$\beta^{3}$ hSer: $\beta^{3}-(R)$-homoserine

BIRD: Bilinear Rotation Decoupling

BMB: bis-maleimido-butane

BRC: Biological Research Centre

BS: back-scattered

COSY: Correlation Spectroscopy

CPMG: Carr-Purcell-Meiboom-Gill

CRD: carbohydrate recognition domain

CSA: chemical shift anisotropy

DLS: dynamic light scattering

ELISA: enzyme-linked immunosorbent assay

FACS: fluorescence-activated cell sorting, flow cytometry analysis

G0-PAMAM: generation-zero poly(amidoamine)

Gal-1: Galectin-1

GEM: group epitope mapping

GS-STD: group-selective saturation transfer difference

HMW: high molecular weight

$h \mathrm{NOE}$ : heteronuclear nuclear Overhauser effect

HSQC: Heteronuclear Single Quantum Coherence

$\mathrm{IC}_{50}$ : half maximal inhibitory concentration

INEPT: Insensitive Nuclei Enhanced by Polarization Transfer

ITC: isothermal titration calorimetry

LacNAc: N-acetyllactosamine

LMW: low molecular weight

LTP: long-term potentiation

MC: Monte Carlo

MD: molecular dynamics

MOE: Molecular Operating Environment

MTT: 3-(4,5-dimethylthiazol-2-yl)-2,5-diphenyltetrazolium bromide

MW: molecular weight

NMR: nuclear magnetic resonance

NOE: nuclear Overhauser effect

NOESY: Nuclear Overhauser Effect Spectroscopy

PBS: phosphate buffered saline 
ROESY: Rotating Frame Overhauser Effect Spectroscopy

$S^{2}$ : squared generalized order parameter

SAR: structure-activity relationship

SEC: size-exclusion chromatography

SPR: surface plasmon resonance

STD: saturation transfer difference

TEM: transmission electron microscopy

ThT: Thioflavin $\mathrm{T}$ (4-(3,6-dimethyl-1,3-benzothiazol-3-ium-2-yl)- $N, N$-dimethylaniline chloride)

TMP: tetra-maleimidopropionyl-G0-PAMAM

TOCSY: Total Correlation Spectroscopy

trNOE: transferred nuclear Overhauser effect

TROSY: Transverse Relaxation Optimized Spectroscopy 


\section{List of publications and lectures}

\section{Full papers related to the thesis}

I. A. Hetényi, L. Fülöp, T. A. Martinek, E. Wéber, K. Soós, B. Penke

Ligand-induced flocculation of neurotoxic fibrillar $A \beta(1-42)$ by noncovalent crosslinking.

ChemBioChem 2008, 9, 748-757.

IF: $3.945^{*}$

II. E. Wéber, A. Hetényi, B. Váczi, É. Szolnoki, R. Fajka-Boja, V. Tubak, É. Monostori, T. A. Martinek

Galectin-1-Asialofetuin interaction is inhibited by peptides containing the Tyr-XxxTyr motif acting on the glycoprotein.

ChemBioChem 2010, 11, 228-234.

IF: 3.945

III. K. E. Kövér, E. Wéber, T. A. Martinek, É. Monostori, G. Batta

${ }^{15} \mathrm{~N}$ and ${ }^{13} \mathrm{C}$ group-selective techniques extend the scope of STD NMR detection of weak host-guest interactions and ligand screening.

ChemBioChem 2010, 11, 2182-2187.

IF: 3.945

IV. L. Fülöp, I. M. Mándity, G. Juhász, V. Szegedi, A. Hetényi, E. Wéber, Z. Bozsó, D. Simon, M. Benkö, Z. Király, T. A. Martinek

A foldamer-dendrimer conjugate neutralizes synaptotoxic $\beta$-amyloid oligomers.

PLOS ONE 2012

submitted

\section{Other full papers}

1. E. Háznagy-Radnai, B. Réthy, S. Czigle, I. Zupkó, E. Wéber, T. Martinek, G. Falkay, I. Máthé

Cytotoxic activities of Stachys species.

Fitoterapia 2008, 79, 595-597.

IF: 1.899

2. G. Benedek, M. Palkó, E. Wéber, T. A. Martinek, E. Forró, F. Fülöp Efficient synthesis of hydroxy-substituted cispentacin derivatives.

Eur. J. Org. Chem. 2008, 20, 3724-3730.

IF: 3.206

3. I. M. Mándity, E. Wéber, T. A. Martinek, G. Olajos, G. Tóth, E. Vass, F. Fülöp Design of peptidic foldamer helices: A stereochemical patterning approach. Angew. Chem. Int. Ed. 2009, 48, 2171-2175.

IF: 12.730

4. G. Benedek, M. Palkó, E. Wéber, T. A. Martinek, E. Forró, F. Fülöp Efficient synthesis of 3,4- and 4,5-dihydroxy-2-amino-cyclohexanecarboxylic acid enantiomers.

Tetrahedron: Asymmetry 2009, 20, 2220-2225.

IF: 2.484 
5. M. Palkó, G. Benedek, E. Forró, E. Wéber, M. Hänninen, R. Sillanpää, F. Fülöp Synthesis of mono- and dihydroxy-substituted 2-aminocyclooctanecarboxylic acid enantiomers.

Tetrahedron: Asymmetry 2010, 21, 957-961. IF: 2.484

6. Z. Bozsó, B. Penke, D. Simon, I. Laczkó, G. Juhász, V. Szegedi, Á. Kasza, K. Soós, A. Hetényi, E. Wéber, H. Tóháti, M. Csete, M. Zarándi, L. Fülöp Controlled in situ preparation of A $\beta 1-42$ oligomers from the isopeptide 'iso-A $\beta 1-42$ ', physicochemical and biological characterization.

Peptides 2010, 31, 248-256.

IF: 2.654

7. S. Patil, L. M. Saleena, K. Yong-Wah, E. Wéber, H. von Grafenstein Expression and purification of isotopically enriched MHC binding immunogenic peptides for NMR studies.

Int. J. Pept. Res. Ther. 2011, 17, 137-145.

IF: 1.034

8. A. Lakatos, B. Gyurcsik, N. V. Nagy, Z. Csendes, E. Wéber, L. Fülöp, T. Kiss Histidine-rich branched peptides as $\mathrm{Cu}$ (II) and $\mathrm{Zn}$ (II) chelators with potential therapeutic application in Alzheimer's disease.

Dalton Trans 2012, 41, 1713-1726.

9. Ł. Berlicki, L. Pilsl, E. Wéber, I. M. Mándity, C. Cabrele, T. A. Martinek, F. Fülöp, O. Reiser

Unique $\alpha, \beta$ - and $\alpha, \alpha, \beta, \beta$-Peptide Foldamers Based on cis- $\beta$-Aminocyclopentanecarboxylic Acid.

Angew. Chem. Int. Ed. 2012, doi: 10.1002/anie.201107702 IF: 12.730

*The impact factors for the year 2010 are given.

\section{Scientific lectures related to the thesis}

1. Wéber E.:

Amfifil $\beta$-peptid hélixek térszerkezete és asszociációs tulajdonságai

XXVIII. Országos Tudományos Diákköri Konferencia, Orvostudományi Szekció Budapest, 2007. április 3-5.

2. E. Wéber, A. Hetényi, T. A. Martinek:

How not to lose hits in NMR binding tests: comprehensive optimization includes temperature

The 10th Central European NMR Symposium \& Bruker NMR Users Meeting September 29-30, 2008, Zagreb, Croatia, Abstr.: P11.

3. Wéber E., Hetényi A.:

Oldatfázisú szerkezeti biológiai adatok Galektin-1 tumourdajka fehérjéröl

IX. Clauder Ottó Emlékverseny

Budapest, 2009. április 23-24. 
4. Wéber E., Hetényi A., Váczi B., Monostori É., Tóth G., Martinek A. T.:

Galektin-1 tumourdajka fehérje, ahogy az NMR látja: funkció, dinamika, gátlás:

MTA Peptidkémiai Munkabizottság Ülése

Balatonszemes, 2009. május 26-28.

5. Wéber E., Hetényi A., Váczi B., Monostori É., Tóth G., Martinek A. T.:

Galektin-1 tumourdajka fehérje, ahogy az NMR látja: funkció, dinamika, gátlás

XIV. Congressus Pharmaceuticus Hungaricus

Budapest, 2009. november 13-15., Abstr.: P-13.

6. Wéber E., Hetényi A., Fajka-Boja R., Szolnoki É., Batta Gy., Kövér E. K., Monostori É., Martinek A. T.:

Galektin-1 kölcsönhatása laktózzal és YXY motívumot tartalmazó peptidekkel - NMR spektroszkópiás vizsgálatok

MTA Peptidkémiai Munkabizottság ülése

Balatonszemes, 2010. május 26-28.

7. K. E. Kövér, E. Wéber, T. A. Martinek, É. Monostori, G. Batta:

${ }^{15} \mathrm{~N}$ - and ${ }^{13} \mathrm{C}$ group-selective STD NMR techniques for sensitive binding studies

Joint EUROMAR 2010 and 17th ISMAR Conference

July 4-9, 2010, Florence, Italy.

8. K. E. Kövér, E. Wéber, T. A. Martinek, É. Monostori, G. Batta:

${ }^{15} \mathrm{~N}$ - and ${ }^{13} \mathrm{C}$ group-selective STD NMR techniques for the detection of weak host-guest interactions

The 12th Central European NMR Symposium \& Bruker NMR Users Meeting September 26-28, 2010, Graz, Austria, Abstr.: page 25.

9. E. Wéber, Z. Hegedűs, A. Hetényi, É. Szolnoki, T. A. Martinek:

Towards foldamer inhibitors of the tumour nursing protein Galectin-1

COST, Foldamers: design, synthesis and applications

October 6-8, 2010, Bologna, Italy, Abstr.: PS-21. 


\section{Introduction and aims}

The goal of pharmaceutical research is the specific and effective manipulation of disease-modifying targets, which is ideally achieved by small molecules binding to the macromolecule with high affinity. However, it is still a challenging task to inhibit molecular interactions where large surface areas or solvent-exposed binding sites are involved. Macromolecules which could not be efficiently modulated by drug-like small molecules are designated as undruggable proteins. ${ }^{1,2}$ For the inhibition of these targets, a potential solution might be to exploit designed non-natural folded polymers (foldamers), ${ }^{3-5}$ which have emerged as promising materials for biomolecule recognition. ${ }^{6}$ We have investigated two medicinally relevant targets: the immunosuppressant, angiogenic and tumour-nursing Galectin-1 (Gal-1) homodimer, ${ }^{7}$ whose inhibition might result in antimetastatic and antiangiogenic drugs; and the synaptotoxic Amyloid $\beta 1-42(\mathrm{~A} \beta 1-42)^{8-10}$ fibrils and oligomers, which are among the major causative agents of Alzheimer's disease (AD). The inhibition of Gal-1 and A $\beta 1-42$ aggregates is difficult due to their solvent-exposed binding site and the absence of distinct binding pockets.

For studies of the protein-ligand systems, we have used primarily nuclear magnetic resonance (NMR) spectroscopy, which has become a powerful and versatile technique for the characterization of biomolecules $^{11,12}$ and for the detection of molecular interactions. ${ }^{12}$ NMR can be exploited in the process of preclinical drug discovery by finding initial hits through screening, ${ }^{13,14}$ supporting lead optimization, fragment-based drug design ${ }^{15-17}$ and obtaining structure-activity relationships (SARs). ${ }^{18,}{ }^{19}$ As opposed to its complementary method X-ray crystallography, NMR can be used to investigate protein-ligand systems in a biologically more relevant medium, solution. Thus, molecular motions, which are confined to the solution phase, can also be captured. The atomic level structural and dynamic information gained on biomolecules and their complexes from NMR studies can facilitate an understanding of their functions and mechanisms of action and can be utilized in structure-based drug design for the rational improvement of ligands.

Our primary aim was to gain information about our targets by means of NMR spectroscopic techniques, which can promote the structure-based design of new Gal-1-binding compounds and A $\beta 1-42$ inhibitors. We aimed to optimize, validate and improve binding tests which can be efficiently used in an NMR screening process for new inhibitors. In the case of Gal-1, the NMR signal assignment of the labelled protein was a prerequisite for the experiments, so we set out to assign the backbone resonances of ${ }^{15} \mathrm{~N} /{ }^{13} \mathrm{C}$-labelled Gal-1. As a first step, the investigation of the proteins alone and/or in the presence of their natural or literature peptide ligands was targeted. The goal was to characterize their interactions and to 
obtain relevant information about the mode of action of the ligand. Finally, we planned to utilize the techniques and structural/dynamic information in drug discovery, most favourably, for the design of foldamer type ligands of the proteins. In order to support and explain the NMR results and test new compounds, the measurements were supplemented with other biophysical techniques and with biological experiments, such as isothermal titration calorimetry (ITC), particle size measurements, enzyme-linked immunosorbent assay (ELISA) and flow cytometry. In the present work, I would like to focus on the NMR results and to supplement these with some aspects of ITC. 


\section{Literature background}

\subsection{Macromolecule-ligand interactions}

Biological processes, including physiological and pathological mechanisms, are governed by molecular interactions between enzymes and substrates, receptors and their ligands. The basic principles of molecular interactions were depicted by Emil Fischer's classic 'key-lock' analogy (1894) and Daniel E. Koshland's 'induced fit theory' (1958). ${ }^{20}$ The complementarity of the interacting surfaces ('key-lock model') includes the appropriate shape and volume of the molecules and the non-covalent interactions (hydrogen-bonding, ionic, van der Waals, hydrophobic and $\pi$-interactions) stabilizing the complex. Enthalpic (e.g. formation of non-covalent interactions) and entropic (e.g. loss of conformational freedom and solvophobic interactions) factors contribute to complex formation, and the stability of the complex depends on the Gibbs free energy of binding. In several cases, dynamic rearrangements of the molecules enable the fit of the macromolecule and the ligand ('induced fit theory').

Let us consider the dynamic equilibrium of the partners, e.g. the free ligand $\mathrm{L}$, the free macromolecule $\mathrm{M}$ and their complex ML:

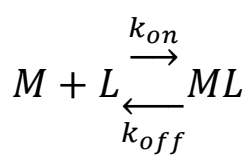

The strength of the binding can be characterized by the dissociation constant $K_{d}$ or by the association constant $K_{a}$ calculated from the equilibrium concentrations of the free macromolecule $[\mathrm{M}]$, the free ligand [L] and the macromolecule-ligand complex [ML]:

$$
K_{d}=\frac{1}{K_{a}}=\frac{k_{o f f}}{k_{o n}}=\frac{[M][L]}{[M L]}
$$

where $k_{\text {off }}$ and $k_{\text {on }}$ are the rate constants for the dissociation and association reactions, respectively. The $K_{d}$ values in biologically relevant processes can range across even twelve orders of magnitude. ${ }^{21,22}$ While enzyme-substrate, receptor-ligand and antibody-antigen interactions usually have high affinity with nanomolar $K_{d}$, weak protein-protein interactions such as reversible cell-cell contacts and the transient assembly/reassembly of signalling complexes are also crucial. $^{21,22}$

In drug discovery, the goal is to develop high-affinity ligands (agonists/antagonists and inhibitors) for disease-modifying targets. As the ligand $K_{d}$ is related to its biological activity, it is essential to characterize the strength of the binding. However, high affinity is required for a lead compound; in the early stages of drug development, weakly-binding molecules are also important. As an example, in the case of fragment-based drug design, weakly-binding fragments are detected and linked together to achieve high-affinity ligands. ${ }^{15}$ Thus, the 
detection of weak interactions is of major importance. The NMR spectroscopic toolbox contains several techniques for the identification of weak binding.

\subsection{Protein-ligand interactions by NMR and ITC}

\subsubsection{Basic concepts of NMR-based ligand-binding tests}

In the past two decades, increasing work has been devoted to the development of NMR methods which can be useful in drug design. The detection and characterization of molecular interactions between a macromolecule and a ligand require different NMR techniques depending on $K_{d}$, the molecular weights (MWs) and types of the partners and the chemical exchange regime between the free and the bound state. Most NMR assays exploit the different properties of the target and the ligand arising from their slow and fast molecular tumbling, respectively (Figure 1).

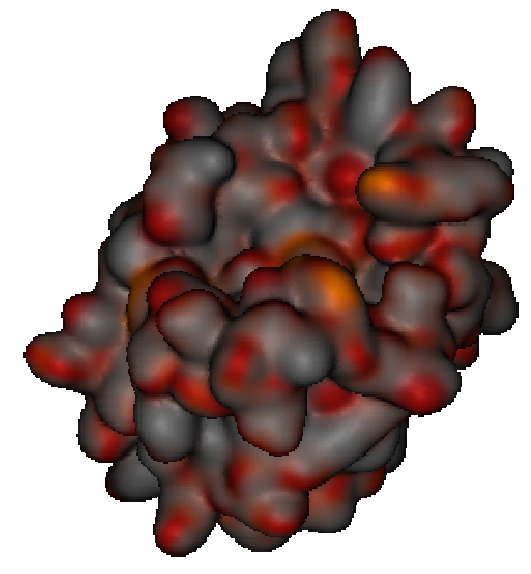

MACROMOLECULE

- Slow diffusion

- Long correlation time, strong negative $\mathrm{NOE}$

- Fast relaxation

- Fast spin-diffusion

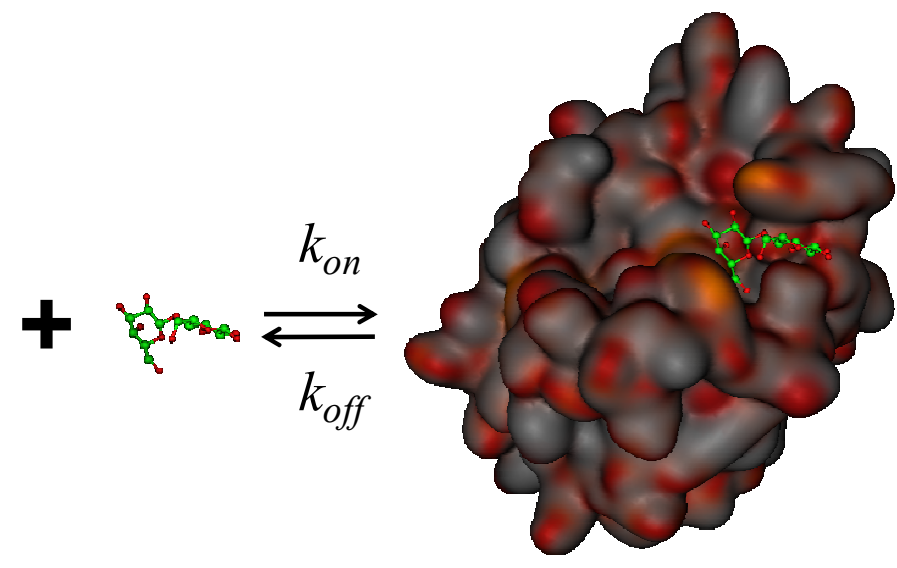

COMPLEX

Similar to the macromolecule
- Fast diffusion

- Short correlation time, weak positive $\mathrm{NOE}$

- Slow relaxation

- Negligible spin-diffusion

Figure 1. Properties of targets, ligands and their complexes. As a small molecule binds to a large macromolecule, it causes changes in both partners, such as changes in size, diffusion properties, chemical environment etc. The interactions between host and guest can be manifested in altered NMR parameters, and thus binding molecules can be identified.

As the ligand and the protein undergo exchange between the free and the complexed states, the binding kinetics and exchange rates affect the properties of the spectra. If the exchange is slow on the NMR time scale, two separate peaks can be observed for the free and the complexed state. In the intermediate exchange regime, a broad 'coalescence point' appears. In the event of fast exchange, the observed resonances or NMR parameters are the population weighted averages of the signals of the free and the bound state and a single sharp signal can be detected. Depending on the partner whose resonances are observed, ligand- or protein-detected experiments can be distuinguished (Table A2). (Techniques for nucleic acids 
are not discussed.) Underlying theory describes interactions between spins, frequencydependent field fluctuations and relaxation mechanisms (Appendix, Theoretical Section A).

In NMR spectroscopy, the interactions between individual spins arise from two types of coupling: through-bond scalar and through-space dipolar coupling. Scalar coupling occurs via bonding electrons, and hence provides information about the connectivity of the atoms and is useful for resonance assignments. Moreover, three-bond scalar couplings can furnish data about dihedral angles. Dipolar coupling between nuclear spins arises when the magnetic field generated by one spin affects the local magnetic field of another spin. The exchange of magnetization between spins perturbs the populations for the different energy levels. This is called nuclear Overhauser effect (NOE). The NOE effect observed depends on the rotational correlation time $\tau_{c}$ of the compound: for small molecules in non-viscous solution, tumbling is fast (short $\tau_{c}$ ) and the NOE is positive (intensity enhancement), while for large molecules or molecules in viscous solutions (long $\tau_{c}$ ), the NOE is negative (intensity reduction). For medium-sized molecules (MW 1000-3000 Da), the NOE is very weak or even zero. The NOE is useful to assess the spatial and motional features of the spins. In the case of protons, the NOE is proportional to $r^{-6}$, which is the basic relationship for structure determination ( $r$ is the interatomic distance between the two protons in question). If the coupled spins are unlike, it is referred to as heteronuclear NOE $(h \mathrm{NOE})$, which is applied to picture the motional properties of the heteronuclear bond vectors, e.g. the amide ${ }^{15} \mathrm{~N}-{ }^{1} \mathrm{H}$.

\subsubsection{Ligand-detected NMR binding tests}

Ligand-observed methods are able to detect the binding event and picture the interaction from the aspect of the ligand, i.e. the binding epitope and the bound conformation of the small molecule. The interaction of a small molecule and a high molecular weight target can be identified via the observation of changes in the ligand NMR parameters (chemical shift, coupling constant, relaxation, etc.) that occur upon binding (Table A2). Accordingly, ligand spectra are recorded and compared in the absence and in the presence of the protein. The advantage of ligand-observed methods is that they usually require only a small amount of the macromolecule (concentrations in the $\mathrm{nM}$ to $\mu \mathrm{M}$ range) and utilize an excess of the ligand, which can be tested in a mixture, too. Their disadvantage is that binding experiments relying on intramolecular and intermolecular magnetization transfer (e.g. transferred nuclear Overhauser effect (trNOE) and saturation transfer difference (STD)) require a considerable exchange between the free and the bound state and are limited to $K_{d}$ in the range of $10^{-2}$ to $10^{-7} \mathrm{M}$. 


\section{Change in ligand ${ }^{1} \mathrm{H}$ relaxation rates (line broadening, signal intensity loss)}

Acquisition of the $1 \mathrm{D}{ }^{1} \mathrm{H}$ spectra of the ligand with and without the protein may indicate binding via the broadening and/or the signal intensity loss of the ligand resonances. In the solution phase, ${ }^{1} \mathrm{H}$ nuclei of large proteins (above $40-100 \mathrm{kDa}$, depending on the shape) exhibit extremely fast transversal relaxation due to the slow rotational tumbling. Hence, these particles have very broad lines (or even do not generate detectable NMR signals). Small molecules that are rapidly tumbling furnish narrow resonances with intensities that are proportional to the concentration of the free ligand. When a small molecule is bound to a large macromolecule, its resonances are broadened or even destroyed by the fast relaxation. The method can also be applied as a quantitative binding test to assess the bound fraction of the ligand.

\section{Transferred NOE (trNOE) experiment}

A small ligand tumbling rapidly in the free state has positive NOEs. Upon binding to the protein tumbling slowly, the ligand will experience slower tumbling, leading to a negative NOE effect. Because of the dynamic equilibrium, spatial and motional information relating to the bound molecules is transferred to the free state, whose signals are observed. ${ }^{23,}{ }^{24}$ The trNOE signal requires fast exchange between the bound and the free state and works best for a $K_{d}$ in the $\mu \mathrm{M}$ to $\mathrm{mM}$ range. In the trNOE experiment, the cross-peaks of the 2D NOESY spectra for the ligand alone and in the presence of the protein are compared. Besides the fact of binding, cross-peaks can furnish information on the bound conformation. ${ }^{25}$

\section{Saturation transfer difference (STD)}

The saturation transfer difference (STD) technique ${ }^{26-28}$ allows the detection of small molecules binding transiently to the target. The method is based on the selective saturation of the macromolecule, following which magnetization is transferred to the bound ligand (Figure 2A), whose signals can be detected in a difference spectrum resulting from an on- and offresonance setup. The advantage of the technique is that compounds can be screened in mixtures, too. The STD can furnish extra information about the interaction: protons in close proximity to the protein are saturated to a higher degree, and thereby atoms/groups in direct contact with the macromolecule can be identified (Figure 2B). The method is referred to as group epitope mapping (GEM). ${ }^{28}$ The STD was presented as a robust screening method, but its efficacy and sensitivity depend on several factors. ${ }^{29,30}$ The values of $k_{\text {on }} / k_{\text {off }}$, temperature, ${ }^{31}$ the saturation of the protein (the irradiation time, the frequency of on-resonance saturation, the size and shape of the protein) and also the intermolecular magnetization transfer from the target to the bound ligand ${ }^{32}$ all influence the STD effect. In general, STD works well for high molecular weight targets, where a steady-state NOE leads to efficient spin-diffusion. 
A)

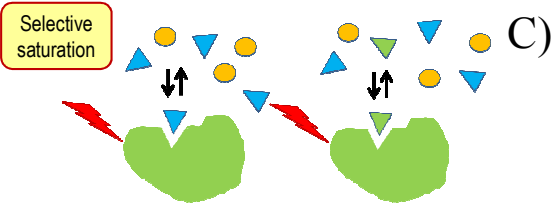

B)

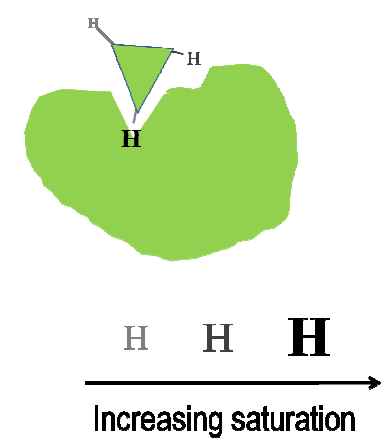

D)
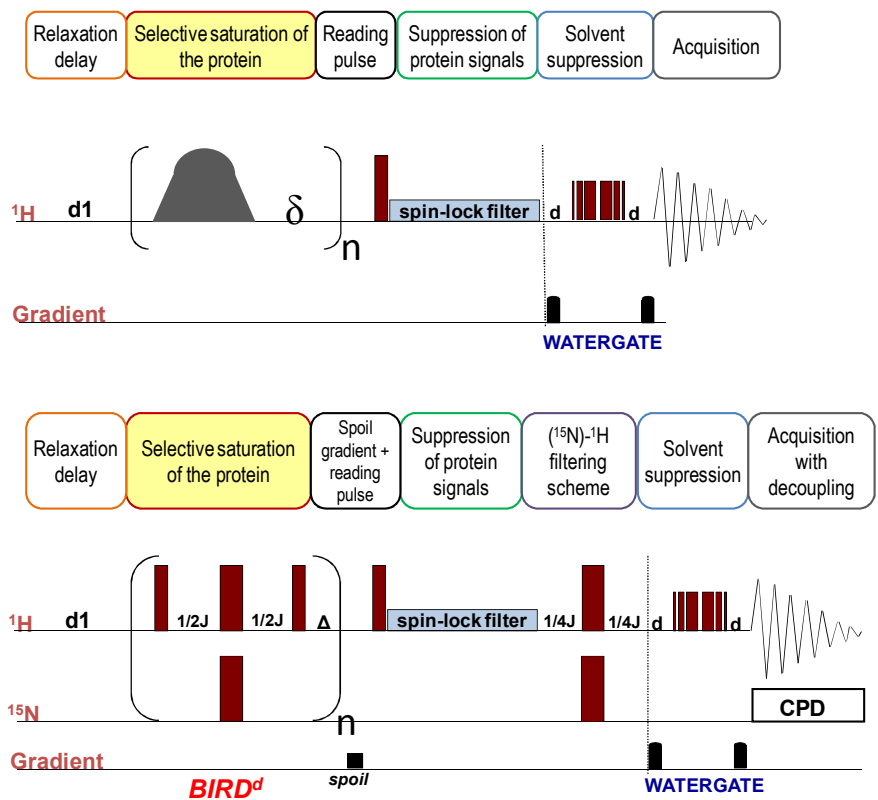

Figure 2. STD experiment. A) Selective saturation of the protein is transferred to the bound ligand. B) Group epitope mapping: protons in direct contact with the receptor will experience higher saturation. C) Conventional ${ }^{1} \mathrm{H}$ STD pulse sequence with the WATERGATE solvent suppression scheme. ${ }^{28}$ D) ${ }^{15} \mathrm{~N}$ group-selective STD pulse sequence of Kövér et al., applying BIRD filter for protein saturation. ${ }^{33}$

The STD pulse sequence consists of the following blocks: relaxation delay (d1), selective saturation of the protein, purging gradient (optional), 90 degree reading pulse, suppression of protein signals (optional), solvent suppression (required for $\mathrm{H}_{2} \mathrm{O}$ samples) and detection (Figure 2C, D). Protein saturation is usually achieved by irradiation of the resonances of the 'methyl hump', which results in almost complete saturation of the target resonances due to intramolecular spin-diffusion. While the conventional STD technique utilizes Gauss-shaped ${ }^{1} \mathrm{H}$ pulses for saturation (Figure 2C), other selective excitation schemes have been also proposed and analysed. ${ }^{34}$ The ${ }^{15} \mathrm{~N}$ group-gelective STD (GS-STD) pulse sequence of Kövér et al. (Figure 2D) ${ }^{33}$ exploits the BIlinear Rotation Decoupling BIRD ${ }^{\mathrm{d}}$ (BIRD) filter, which excites ${ }^{1} \mathrm{H}$ attached to ${ }^{15} \mathrm{~N}$, while ${ }^{1} \mathrm{H}$ attached to ${ }^{14} \mathrm{~N}$ remains aligned to the $+z$ axis.

\subsubsection{Protein-detected NMR methods}

Protein-detected experiments usually require isotope-labelled $\left({ }^{15} \mathrm{~N}\right.$-labelled or ${ }^{15} \mathrm{~N} /{ }^{13} \mathrm{C}$ labelled) macromolecules at higher concentrations (0.1-2 mM), but can afford high-resolution structural and dynamic data about the protein and the complex. Unfortunately, there is an upper size limit for macromolecules $(30-60 \mathrm{kDa}$, depending on the isotope labelling and the spectrometer) whose resonances can be observed and assigned by NMR. 


\section{Resonance assignment}

The resonance assignment of the macromolecule is a prerequisite for protein-detected methods and structural/dynamic studies. Wüthrich has shown that the resonances of peptides and proteins can be assigned by a sequential procedure using ${ }^{1} \mathrm{H}$ methods. ${ }^{35}$ Signals of small $(<10 \mathrm{kDa})$ non-labelled proteins can be assigned by 2D homonuclear methods such as Correlation Spectroscopy (COSY) and Total Correlation Spectroscopy (TOCSY) for the identification of the spin systems, and Nuclear Overhauser Effect Spectroscopy (NOESY) for the detection of sequential NOEs. Proteins of $10-15 \mathrm{kDa}$ require ${ }^{15} \mathrm{~N}$ labelling and ${ }^{15} \mathrm{~N}$-edited methods, which include Heteronuclear Single Quantum Coherence (HSQC) blocks resulting in 3D techniques such as ${ }^{15} \mathrm{~N}$ TOCSY-HSQC and ${ }^{15} \mathrm{~N}$ NOESY-HSQC, which help to resolve overlapping peaks and provide the amide ${ }^{15} \mathrm{~N}$ resonances, too. For proteins with a molecular weight of $15-30 \mathrm{kDa},{ }^{15} \mathrm{~N} /{ }^{13} \mathrm{C}$-labelling is required and $3 \mathrm{D}$ triple resonance techniques involving ${ }^{15} \mathrm{~N},{ }^{13} \mathrm{C}$ and ${ }^{1} \mathrm{H}$ spins are the method of choice. ${ }^{11,12}$ Above $30 \mathrm{kDa},{ }^{2} \mathrm{H}$ labelling can decrease the spin-spin relaxation rates of the protein, allowing the assignment of higher MW proteins.

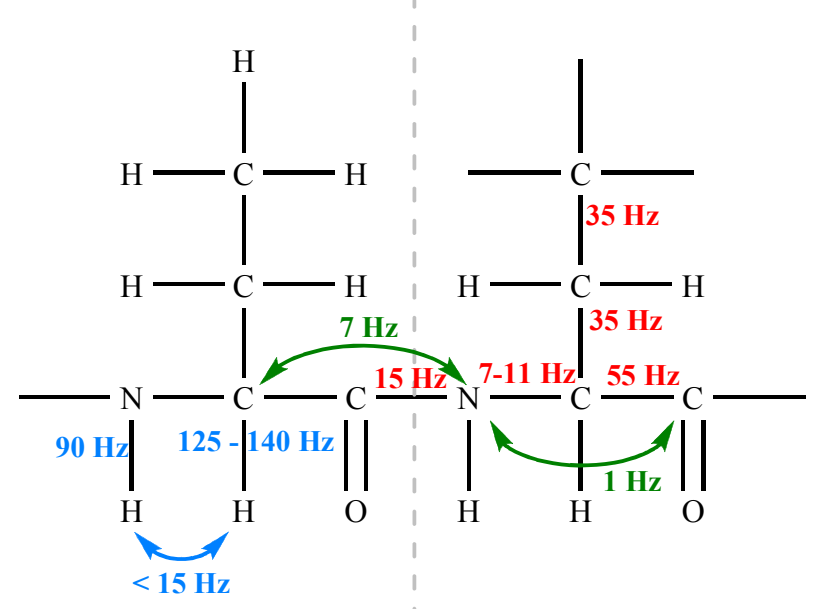

Figure 3. One- and two-bond $J$-coupling constants used in triple resonance protein NMR experiments.

The transfer of magnetization between spins is achieved via INEPT (Insensitive Nuclei Enhanced by Polarization Transfer) transfer steps using delays acquired from one- and two-bond heteronuclear $J$-coupling constants (Figure 3 ). The three dimensions of basic triple resonance experiments ${ }^{36-41}$ usually represent the chemical shifts of the ${ }^{15} \mathrm{~N}$ amide nitrogen ('N'), the ${ }^{1} \mathrm{H}$ amide proton (' $\mathrm{H}$ ') and the ${ }^{13} \mathrm{C}$ carbonyl, alpha and/or beta carbons ('CO', 'CA' and ' $\mathrm{CB}$ ', respectively), but other setups are also available (e.g. $\mathrm{HBHA}(\mathrm{CO}) \mathrm{NH}$ showing the frequencies of the alpha and beta protons, the amide ' $\mathrm{N}$ ' and the amide ' $\mathrm{H}$ '). The pulse sequences are denominated by using the list of atom names involved in the magnetization transfer, bracketing those atoms which are not detected. The assignment of the backbone 
resonances is achieved via complementary pairs of $3 \mathrm{D}$ experiments, which correlate the amides and the respective and/or the preceding carbonyl or alpha carbons (Figure 4). As an example, $\mathrm{HNCO}$ shows the connectivity between $\mathrm{NH}_{(\mathrm{i})}$ and the preceding carbonyl $\mathrm{CO}_{(\mathrm{i}-1)}$ alone, while $\mathrm{HN}(\mathrm{CA}) \mathrm{CO}$ correlates $\mathrm{NH}_{(\mathrm{i})}$ equally with the interresidual $\mathrm{CO}_{(\mathrm{i})}$ and intraresidual $\mathrm{CO}_{(\mathrm{i}-1)}$.
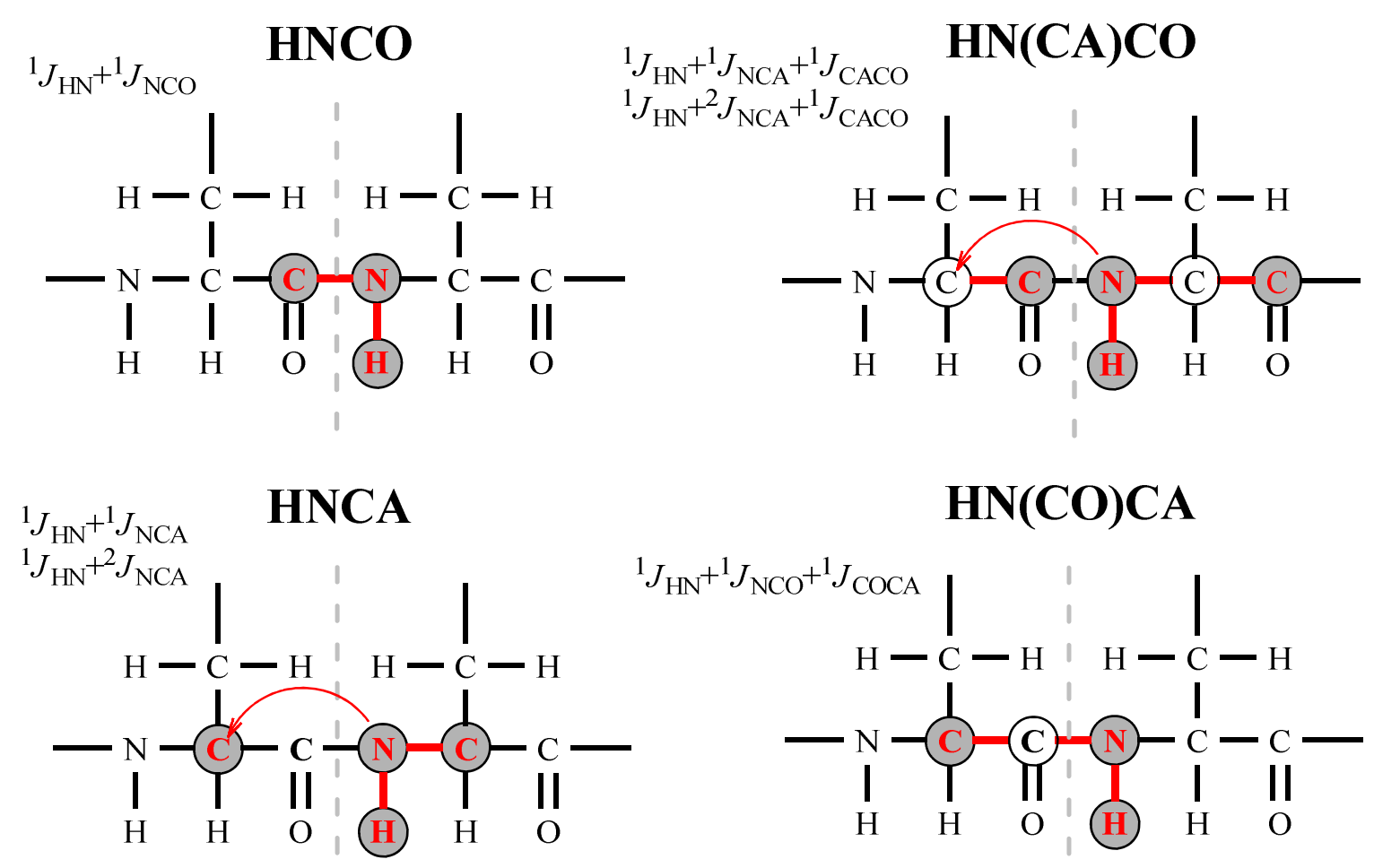

Figure 4. Information content of basic backbone experiments. In the upper left corners, the one- and twobond $J$-coupling constants involved in the INEPT transfer steps of the experiments are shown.

\section{Chemical shift perturbations: ${ }^{15} \mathrm{~N}$ HSQC titration}

The binding of ligands to their targets causes changes in the chemical shifts because of the altered electron densities, which can be a direct effect of the proximity of the ligand or can be attributed to the structural rearrangements upon complexation, too. In principle, ligand and target resonances can be monitored by using different types of spectra $\left(1 \mathrm{D}{ }^{1} \mathrm{H}, 2 \mathrm{D}\right.$ homo- or heteronuclear methods), but most conveniently the ${ }^{15} \mathrm{~N}$ HSQC spectrum of the labelled protein is used for chemical shift mapping. ${ }^{12}$ The ${ }^{15} \mathrm{~N}$ HSQC spectrum demonstrates the peaks of the amide groups and the side-chain $\mathrm{NH} / \mathrm{NH}_{2}$ nitrogens and provides a fingerprint for the protein. A series of ${ }^{15} \mathrm{~N}$ HSQC spectra are acquired for the protein sample at increasing ligand concentrations. Depending on the $K_{d}$, the changes in the position, linewidth or intensity of the signals indicate change in the chemical environment. Through non-linear curve fitting of the observed chemical shift changes vs. ligand concentration, $K_{d}$ can be also estimated. The advantage of ${ }^{15} \mathrm{~N}$ HSQC titration is that it can indicate the binding site, and even very weak interactions can be detected up to a $K_{d}$ of $10^{-2} \mathrm{M}^{21}$ 


\section{Relaxation measurements and model-free approach}

Dynamic properties of targets can be essential for the biological effect. NMR is able to probe the motional properties of proteins in solution. ${ }^{11,12,42}$ The random rotational motion of a molecule and the internal motions within the molecule generate magnetic field fluctuations, which stimulate transitions between excited and ground states that affect relaxation. ${ }^{42,43}$ Relaxation parameters (the longitudinal relaxation rate $R_{l}$, transverse relaxation rate $R_{2}$ and $h \mathrm{NOE}$ ) can be measured experimentally. Via model-free analysis ${ }^{44,45}$ and a multistep fitting procedure, the motional parameters of the protein $\left(\tau_{c}, D, S^{2}, \tau_{e}\right.$ and $\left.R_{e x}\right)$ can be calculated (Appendix, Theoretical Section A). ${ }^{42}$ The squared generalized order parameter $S^{2}$ expresses the amplitude of the internal motion: if no internal motion is present, it approaches its maximum value 1; lower $S^{2}$ values indicate motions with higher amplitude. The internal correlation time for the motions of the bond vector is the effective correlation time $\tau_{e}$, which gives the time scale, while the exchange term $R_{e x}$ describes the exchange contribution to $R_{2}$ and is an indicator of the $\mu$ s to ms time scale dynamics.

\subsubsection{Characterization of protein-ligand interactions by ITC}

ITC can be used to determine the thermodynamic parameters of macromolecule-ligand interactions. ${ }^{46,47}$ Measurement of the heat allows the determination of the equilibrium binding constant $\left(K_{a}\right)$, the standard Gibbs free energy change $(\Delta G)$, the enthalpy change $(\Delta H)$, the entropy change $(\Delta S)$, and the stoichiometry $(n)$ of the association event. The basic equation which relates these parameters is

$$
\Delta G=-R T \ln K_{a}=\Delta H-T \Delta S
$$

where $R$ is the universal gas constant and $T$ is the temperature in degrees Kelvin.

In a typical ITC experiment, the ligand solution in syringe is titrated into a cell containing the macromolecule. Upon molecular interactions, heat is released or absorbed. Each injection of the ligand causes a heat change $\left(q_{i}\right)$ depending on the concentrations, the binding constant and stochiometry, the molar enthalpy, the heat of dilution, the amount of previously added ligand and the reaction volume of the sample cell $\left(V_{0}\right)$. In the case of a single independent binding site, assuming a fractional occupancy of $\Theta$, the binding constant $K_{a}$ is given by

$$
K_{a}=\frac{\Theta}{(1-\Theta)[L]}
$$

After some mathematical manipulation (Appendix, Theoretical Section B), the differential heat of the $i$ th injection can be expressed as

$$
q_{i}=n\left[M_{T}\right] V_{0} \Delta H_{b}\left(\Theta_{i}-\Theta_{i-1}\right)
$$

where $\left[\mathrm{M}_{\mathrm{T}}\right]$ is the total macromolecule concentration. Plotting the heats evolved per titration point against the ligand-macromolecule concentration ratio, a sigmoid saturation curve is 
achieved and a non-linear fitting based on Eq. (4) yields $K_{a}$, the binding enthalpy $\Delta H_{b}$ and $n$. In the case of a two-step binding event, assuming two independent binding sites, two sets of $K_{a}, \Delta H_{b}$ and $n$ are fitted (Appendix, Theoretical Section B).

\subsection{Target proteins and their inhibition}

\subsubsection{Galectin-1: $\beta$-sandwich homodimer involved in immune regulation and tumour metastasis}

Galectins are ubiquitous $\beta$-galactoside-binding proteins with conserved sequences of about 130 amino acids. They are expressed by various tissues under physiological and pathological conditions ${ }^{7}$ and several cell types have receptors for them. ${ }^{48}$ Dimerization enables galectins to form cross-linked complexes, glycoprotein lattices, and is of major importance as concerns their biological function. ${ }^{49-51}$ In the 15-membered family of galectins, Gal-1 is the most thoroughly studied protein. Probably the most important of its various biological functions is its powerful immunosuppressive effect, which has attracted the attention of immunologists and cancer biologists (Figure 5). The anti-inflammatory effects of Gal-1 have been described both in vitro ${ }^{52-54}$ and in vivo, in experimental inflammatory/autoimmune animal models. ${ }^{55-58}$ It causes the apoptosis of activated T-lymphocytes ${ }^{59-62}$ and down-regulates the production of inflammatory cytokines. ${ }^{63-65}$

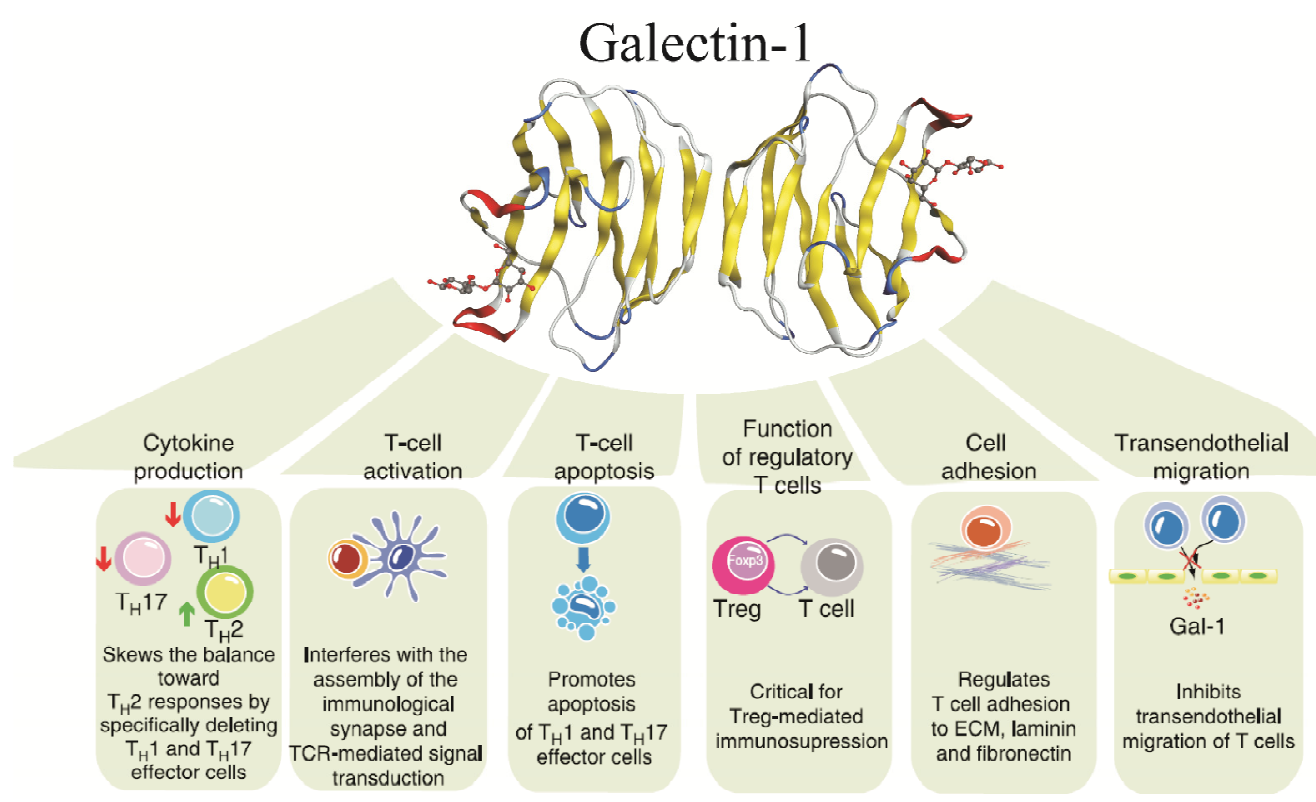

Figure 5. $\beta$-sandwich structure of Gal-1 (top) and its biological effects. Figure adapted from ref. [58].

Gal-1 is abundantly expressed in most solid tumours and promotes cancer progression and metastasis by inhibiting the tumour-specific immune response, thereby supporting cancer cell migration and neovascularization. ${ }^{49,66-69}$ Hence, Gal-1 is considered to be a promising therapeutic target in cancer and immunological disorders. The importance of Gal-1 in 
angiogenesis has also been pointed out, ${ }^{70}$ and it is therefore a potential target for angiostatic cancer therapy.

As Gal-1 has one carbohydrate-recognition domain (CRD) per monomer unit and exists in solution as a homodimer with a total molecular mass of $29 \mathrm{kDa}$, Gal-1 belongs in the subclass of prototype galectins. ${ }^{7}$ The modulation of Gal-1 activity via a monomer-dimer equilibrium has also been proposed, ${ }^{71}$ but with its dimerization constant of $K_{d}=2-7 \mu \mathrm{M},{ }^{71,72}$ Gal-1 exists in solution mainly in the dimer form. The 3D structure of the Gal-1-lactose complex was first determined by X-ray crystallography. ${ }^{73}$ Its overall secondary structure can be described as a $\beta$-sandwich (Figure 5), consisting of two anti-parallel $\beta$-sheets of five and six strands, respectively. The $\mathrm{N}$ and the $\mathrm{C}$ termini of the monomers are positioned at the dimer interface and the highly conserved CRDs are located at the far ends of the same face as a solvent-exposed binding site. Upon ligand binding, conformational changes of Gal-1 have been proposed. ${ }^{74}$

Galectins act by binding to the carbohydrate moieties of cell surface glycoproteins. Their minimal ligands, such as lactose and $N$-acetyllactosamine (LacNAc), bind to the CRD by weak intermolecular interactions with an approximate $K_{d}$ value of $100 \mu \mathrm{M}^{75,76} \mathrm{Gal}-1$ has been extensively investigated with its disaccharide ligands, but the natural glycans which are able to interact with galectins are larger and heterogeneous in composition and size. The interactions of Gal-1 and different complex carbohydrates and glycans were recently studied. ${ }^{77-80}$ For the $\beta$-galactomannan Davanat, a binding site different from the conventional CRD has been reported, ${ }^{79}$ shedding new light upon the Gal-1 structure and function. Furthermore, structurally unrelated proteins have been described to bind to Gal-1 in a carbohydrate-independent manner. ${ }^{7,81}$

As competitive inhibitors of the CRD could be potential drugs against tumour metastasis, extensive research has been focused on the development of effective inhibitors of Gal-1 or related family members. The minimal ligands, such as lactose and LacNAc, can bind to galectins and inhibit their biological activity, but they have low inhibitory potency, are sensitive to hydrolysis, and are generally too polar to serve as drugs. Synthetic carbohydrate analogues might be more potent and feasible Gal-1 inhibitors. Thiosugars, ${ }^{82-84}$ synthetic lactulose amines, ${ }^{85}$ aryl $O$ - and $S$-galactosides, ${ }^{86}$ carbohydrate triazoles and isoxazoles ${ }^{87}$ have been reported to have the ability to inhibit Gal-1. Carbohydrate polymers, such as multivalent glycodendrimers and glycoconjugates, ${ }^{88-91}$ have proved to be more potent inhibitors than lactose. Peptides containing the consensus sequence Tyr-Xxx-Tyr were first reported to bind to the plant lectin, Concanavalin A with an affinity comparable to that of natural ligands. ${ }^{92}$ The screening of peptide libraries with different types of animal and plant lectins, including 
Gal-1, led to the selection of sequences with the Tyr-Xxx-Tyr motif. ${ }^{93,94}$ It has also been postulated that galectins might be inhibited through the use of peptide glycomimetics. ${ }^{95-97}$ It has been revealed experimentally that pentapeptides with the key Tyr-Xxx-Tyr core could function as glycomimetics, since binding to sugar binding sites was observed in plant and animal lectins. An inherent selectivity for galectin family members was suggested. ${ }^{94}$ The efficacy of the peptide-Gal-1 interaction was demonstrated in competition tests (solid-phase assays and surface plasmon resonance (SPR)) in which the Gal-1-binding glycoprotein asialofetuin (ASF), a $48 \mathrm{kDa}$ protein possessing three triantennary $\mathrm{N}$-linked carbohydrates, was used as competitor. ${ }^{98,99}$ Although these studies suggested that the Tyr-Xxx-Tyr motif was an effective glycomimetic, recent work indicated that there might be other sequences that exhibit the lactose-dependent inhibition of Gal-1. ${ }^{100,}{ }^{101}$ Gal-1 has also been shown to be a receptor for the angiogenesis-inhibitor anginex, a designed peptide $33-\mathrm{mer}^{102}$ which folds in an amphipathic, three-stranded antiparallel $\beta$-sheet conformation. ${ }^{103}$

\subsubsection{Amyloid- $\beta$ (A $\beta$ ) peptide aggregates in Alzheimer's disease}

Presenile dementia with symptoms including disorientation and the loss of short-term memory was first observed and described in the early 1900s by a German psychiatrist and neuropathologist, Alois Alzheimer. He also identified cellular abnormalities, e.g. amyloid plaques and neurofibrillary tangles in the brain. Since then, several studies have proved that $\beta$-Amyloid $(\mathrm{A} \beta)$ peptide aggregates play a central role in the progression of the neurodegeneraive disorder $\mathrm{AD}$ and $\mathrm{A} \beta$ species correlate with the severity of the disease. ${ }^{104-107}$ The 38-43 amino acid residue $A \beta$ peptides, which arise from proteolytic cleavage of the amyloid precursor protein ${ }^{108}$ by $\beta$ - and $\gamma$-secretase, ${ }^{109}$ and have a high propensity to aggregate, forming oligomers, protofibils and fibrils. The deposits are mainly composed of the fibrils of the 40- and 42-mer peptides, but the neurotoxicity of the 42-mer A $\beta 1-42$ is much greater due to its higher tendency to aggregate. Besides the full-length peptide, a wide range of $\mathrm{A} \beta$ fragments (e.g. sequences composed of the $\mathrm{A} \beta$ residues 1-28, 12-28, 18-28, 11-25, 16-22 and 14-23) have also been found to aggregate. ${ }^{110}$ The supramolecular structure and morphology of $\mathrm{A} \beta$ fibrils have been studied by several methods, such as atomic force microscopy ${ }^{111,112}$ and transmission electron microscopy (TEM). ${ }^{113}$ Due to their non-crystalline, insoluble and unstable nature, high-resolution structural data on $A \beta$ fibrils (Figure 6) have mainly been deduced from solid-state $\mathrm{NMR}^{113,114}$ or solution NMR studies using non-natural solvents ${ }^{115-}$ 117 and molecular dynamics (MD) simulations. ${ }^{118-120}$ The hydrophilic $\mathrm{N}$ terminus has been found to be unstructured, ${ }^{115,116}$ while the hydrophobic central domain, the hydrophilic linker region and the hydrophobic $C$ terminus form a ' $\beta$-strand - turn - $\beta$-strand' motif, which consists of two parallel, in-register $\beta$-sheets. ${ }^{113,114,121}$ As Thioflavin $\mathrm{T}$ (ThT) can interact 
specifically with the crossed $\beta$-sheet structures, ${ }^{122-125}$ the fluorometric detection of ThT binding is a well-known means of indicating $\beta$-sheets and characterizing $A \beta$ fibrils.

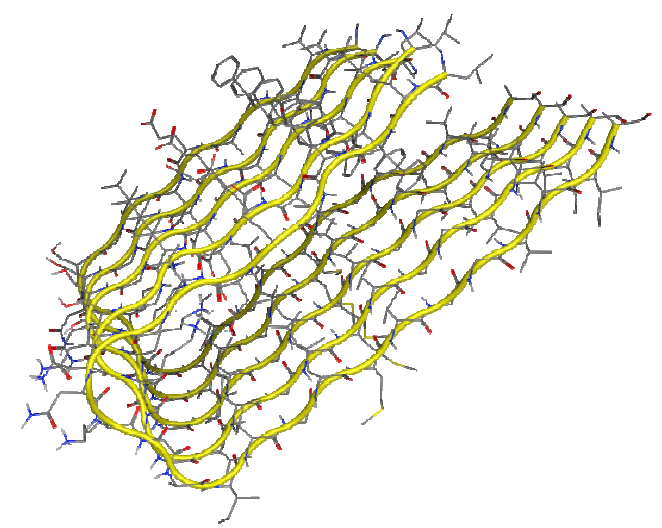

Figure 6. Representative structure for A $\beta 1-42$ fibrils (PDB: 2BEG). ${ }^{115}$

Although senile plaques are composed of fibrils, recent studies highlighted soluble $A \beta$ oligomers $^{8,126,127}$ as the primary pathological species in AD. They were shown to cause neuronal dysfunction ${ }^{10,104}$ and to inhibit long-term potentiation (LTP), ${ }^{106,}{ }^{126}$ which is a correlate of learning and memory. Generally, A $\beta 1-42$ oligomers can be subdivided into low molecular weight (LMW) and high molecular weight (HMW) oligomers, which can be defined as less than 8-mers and species with a MW of $\sim 42 \mathrm{kDa}$ to $>1 \mathrm{mDa}$, respectively. As the soluble oligomeric assemblies exist as transient mixtures of various species, their precise molecular structure is not known, though a wide range of oligomeric species has been described, from trimers to hexamers and globulomer structures (dodecamers), depending on the preparation protocol and the detergents applied. ${ }^{118,128}$

A possible strategy for the treatment of $\mathrm{AD}$ is to target $\mathrm{A} \beta$ and reduce its assembly. Several molecules have been found to bind to $\mathrm{A} \beta$, such as $\mathrm{ThT}^{123,125,129,130}$ and its analogues, ${ }^{131}$ curcumin ${ }^{132}$ and its derivatives ${ }^{133}$ and tramiprosate. ${ }^{134}$ Peptides that are partially homologous to the central hydrophobic $\mathrm{L}^{17} \mathrm{VFFA}^{21}$ region of $\mathrm{A} \beta$, but contain amino acids that prevent the adoption of a $\beta$-sheet structure are able to bind to $A \beta$ and to inhibit amyloid formation in vitro and to disaggregate preformed $A \beta$ fibrils. ${ }^{135-141}$ These short peptides which can influence the structure and aggregation of $A \beta$ are effective neuroprotective agents. ${ }^{142}$ The interactions of small molecules and peptides with $A \beta$ (fragments) have been monitored by $\mathrm{SPR}^{143}$ and NMR spectroscopic techniques. ${ }^{144,}{ }^{145}$ As reported for fibrillar A $\beta 14-23,{ }^{144,} 145$ peptide ligands exhibit decreased signal intensities upon binding to large A $\beta 14-23$ aggregates. Transferred residual dipolar couplings and trNOE measurements indicated weak interactions between short neuroprotective peptides and A $\beta 14-23 .{ }^{145}$ Interestingly, different bound conformations of LPFFD and DPFFL were proposed in the presence of A $\beta 14-23^{142,143}$ or A 1-40 fibrils, indicating different fibril structures. ${ }^{144}$ The peptides exert their full 
protective effects against $A \beta$ within a short time-frame, but the exact mechanism of action is unclear. It might comprise a partial $\beta$-sheet-breaking effect or molecular surface covering that involves weak binding. ${ }^{146-148}$

\subsubsection{Foldamers as drug candidates for difficult targets}

The inhibition of our targets, Gal-1 and A $\beta 1-42$ aggregates, is difficult due to their solvent-exposed binding site and the absence of any distinct binding pockets. The Gal-1 homodimer is able to bind lactose and related saccharides and sugar derivatives only by weak forces $\left(K_{d} \sim 100 \mu \mathrm{M}\right)$. In order to achieve high-affinity ligands, a larger contact surface should be involved in the interaction. As an example, a 33-mer peptide has been shown to exhibit nanomolar $K_{d}$ for Gal-1. ${ }^{70}$ In the case of A $1-42$ aggregates, the exact solution structure of the target is not known. Moreover, the aggregates are transient mixtures of different sizes and/or morphology associates. A distinct hydrophobic pocket is unlikely, but hydrophilic amino acids of $A \beta$ should be exposed to the solvent as the aggregation of $A \beta 1-42$ is driven by hydrophobic forces.

The vast majority of pharmaceuticals are still small organic compounds ( $\mathrm{MW}<1000$ $\mathrm{Da}$ ). Indeed, medically relevant proteins, such as $\mathrm{G}$ protein-coupled receptors, ion channels, protein kinases, metallopeptidases and nuclear hormone receptors can be successfully modulated by small molecules. However, several targets can not be efficiently addressed by low MW compounds. In general, protein binding, antigen binding, DNA, RNA and carbohydrate binding result in lower hit rates when subjected to low MW fragment library screening with 2D HSQC NMR spectroscopy. ${ }^{1}$ These targets usually do not have a distinct binding pocket, that could engulf the small ligands. They are referred to as undruggable, ${ }^{1,2}$ on the basis of their low tendency to bind drug-like molecules. On the other hand, proteins with large solvent-exposed binding sites can be inhibited by protein therapeutics, where thousands of atoms and large surface areas are available to contact the target and form favourable noncovalent interactions. The development of protein therapeutics is expanding, but their application can be inconvenient due to their varying chemical integrity and purity, potential immunogenicity, limited shelf-life and inability to cross cell membranes.

Exploiting unnatural self-organizing polymers (foldamers) ${ }^{3-5}$ might be a potential approach to the inhibition of targets with large solvent-exposed binding sites. Foldamers, as intermediates between macromolecules and small molecules, can involve biomimetic sequences and recognition surfaces like monoclonal antibodies and protein therapeutics, but are easier to handle due to their smaller size and tunable secondary structure. They have the potential to fold into well-defined hierarchical structures, such as various helices, strand-like conformations and turns, and are also capable of forming higher-order self-assemblies (e.g. 
helix bundles and vesicles). Foldamers can be constructed by using various monomers (foldamers with aromatic carbon atoms in the backbone, heterocyclic skeletons; peptidic foldamers composed of $\alpha$-, $\beta$ - and $\gamma$-amino acids, aminoxy acids and azapeptides), applying a wide range of proteinogenic side-chains. Diastereomers of the alicyclic $\beta$-amino acids 2-aminocyclohexanecarboxylic acid (ACHC) and 2-aminocyclopentanecarboxylic acid (ACPC) with constrained side-chains are especially popular building blocks. ${ }^{149}$ The diversity of foldamers is comparable to that of the natural proteins and nucleic acids, which are responsible for complex biological functions.

As proof of principle, foldamers have been reported to recognize pharmaceutically relevant targets and to inhibit protein-protein interactions (Table 1). ${ }^{6}$ Functional foldamers are primarily peptidic foldamers, which are the most thoroughly studied unnatural selforganizing polymers. Their helix type is designated by the number of atoms in the H-bonded pseudoring, e.g. H14 or H10/12. The secondary structure and self-assembly of peptidic foldamers can be controlled via the $\beta$-amino acid sequence and backbone stereochemistry, ${ }^{150}$ and also tuned via the side-chain chemistry. ${ }^{151}$ Moreover, their resistance to enzymatic degradation has been demonstrated, ${ }^{152-154}$ which is a very important feature for a drug scaffold.

Table 1. Pharmaceutical applications of foldamers.

\begin{tabular}{|c|c|c|c|}
\hline Target & Foldamer type & Medicinal relevance & Reference \\
\hline $\begin{array}{l}\text { lipid transport protein } \\
\text { SR-B1 }\end{array}$ & $\beta$-nonapeptide helix & $\begin{array}{l}\text { reduction of fat and cholesterol } \\
\text { absorption }\end{array}$ & Werder et al. ${ }^{155}$ \\
\hline$\gamma$-secretase & H12 $\beta$-peptide & prevention and treatment of $\mathrm{AD}$ & Imamura et al. ${ }^{156}$ \\
\hline $\begin{array}{l}\text { transcriptional activator- } \\
\text { responsive element }\end{array}$ & $\begin{array}{l}\text { undecamer with } \\
\text { positively charged } \\
\text { side-chains }\end{array}$ & $\begin{array}{l}\text { inhibition of transcription of HIV } \\
\text { RNA }\end{array}$ & Gelman et al. ${ }^{157}$ \\
\hline HIV gp41 & H14 $\beta^{3}$-peptide & blockade of HIV fusion & Stephens et al. ${ }^{158}$ \\
\hline HIV gp41 & $\alpha / \beta$-peptides & blockade of HIV fusion & Horne et al. ${ }^{159}$ \\
\hline $\begin{array}{l}\text { human cytomegalovirus } \\
\text { entry }\end{array}$ & $\beta$-peptide & $\begin{array}{l}\text { inhibition of cytomegalovirus } \\
\text { infection }\end{array}$ & English et al. ${ }^{160}$ \\
\hline $\begin{array}{l}\text { herpes simplex virus } \\
\text { type-1 }\end{array}$ & $\begin{array}{l}\text { cationic } \mathrm{H} 14 \beta- \\
\text { peptides }\end{array}$ & $\begin{array}{l}\text { inhibition of herpes simplex virus } \\
\text { type } 1 \text { infection }\end{array}$ & $\begin{array}{l}\text { Akkarawongsa et } \\
\text { al. }{ }^{161}\end{array}$ \\
\hline $\begin{array}{l}\text { human oncogene product } \\
\text { double minute } 2 \text { (hDM2) }\end{array}$ & $\begin{array}{l}\text { de novo designed } \mathrm{H} 14 \\
\beta \text {-peptides }\end{array}$ & $\begin{array}{l}\text { inhibition of the interaction of } \\
\text { tumour suppressor protein } 553 \\
\text { and oncoprotein } \mathrm{hDM} 2\end{array}$ & Kritzer et al. ${ }^{162}$ \\
\hline $\begin{array}{l}\mathrm{BH} 3 \text {-recognition cleft of } \\
\text { the protein } \mathrm{Bcl}-\mathrm{x}_{\mathrm{L}}\end{array}$ & $\alpha / \beta$-peptides & $\begin{array}{l}\text { control of programmed cell death } \\
\text { pathways }\end{array}$ & Horne et al. ${ }^{163}$ \\
\hline
\end{tabular}




\section{Experimental}

\subsection{Synthesis and expression of peptides and proteins}

Non-labelled and ${ }^{15} \mathrm{~N} /{ }^{13} \mathrm{C}$-labelled human recombinant Gal-1 were expressed and purified by the Monostori group in the Biological Research Centre (BRC) of the Hungarian Academy of Sciences. A $\beta 1-42$ and its depsipeptide derivative were synthetized by the Penke group (Zsolt Bozsó), and the preparation of amyloid fibrils and oligomers was implemented after standardized protocol ${ }^{164}$ by Lívia Fülöp (Department of Medicinal Chemistry, University of Szeged). For the investigations of foldamers, the depsipeptide $\operatorname{Ser}^{26}$ iso-A $\beta 1-42^{165}$ was utilized, which was converted to the native sequence by applying physiological $\mathrm{pH}$. At $\mathrm{pH}$ 7.4, an immediate N-O acyl migration takes place and oligomers are spontaneously formed without the application of any detergent or residual organic solvent in the final sample. ASF was purchased from Sigma-Aldrich. Peptides were synthetized by solid-phase peptide synthesis. Disaccharides lactose [ $\beta$-D-galactopyranosyl- $(1 \rightarrow 4)$-D-glucose] and LacNAc [ $\beta$-Dgalactopyranosyl-( $(1 \rightarrow 4)-N$-acetyl-D-glucosamine] were purchased from Sigma-Aldrich. Protein and $\alpha$-peptide sequences are designated by using the standard one-letter amino acid codes.

\subsection{NMR spectroscopy}

The vast majority of the NMR spectra were recorded on a Bruker AV600 spectrometer equipped with a $2.5 \mathrm{~mm}$ triple-resonance capillary probe. Proteins and ligands were dissolved in $20 \mathrm{mM}$, pH 7.4 phosphate buffer $\left(90 \% \mathrm{H}_{2} \mathrm{O}, 10 \% \mathrm{D}_{2} \mathrm{O}\right)$ containing $0.02 \% \mathrm{NaN}_{3}$. Spectra were acquired with the WATERGATE ${ }^{166}$ solvent suppression pulse scheme with a binomial water suppression delay of $150 \mu \mathrm{s}$. All NMR spectra were processed and analysed with Topspin 2.0 (Bruker). When different conditions were used or the experiments were performed with another instrument, the changes are indicated in the text.

\section{Sample preparation and general information for ligand-detected binding tests STD and trNOE (for Gal-1, ASF and Aß1-42)}

Small peptides and disaccharides were investigated with non-labelled proteins (Gal-1, ASF and A $\beta 1-42$ ). The following concentrations were used: (i) $30 \mu \mathrm{M} \mathrm{Gal-1}$ or ASF and 2.0 $\mathrm{mM}$ peptide (TYDYF-NH $\mathrm{N}_{2}$, WYKYW-NH $\mathrm{N}_{2}$, TYDYFR-NH $\mathrm{N}_{2}$ and TYPYFR-NH $\mathrm{N}_{2}$ ) or disaccharide ligand (lactose and LacNAc); (ii) $0.1 \mathrm{mM}$ fibrillar $\mathrm{A} \beta 1-42$ with $0.5 \mathrm{mM}$ pentapeptide (LPFFD, LPYFD-NH 2 , FRHDS-NH 2 and RIIGL-NH ${ }_{2}$ ) and/or ThT; (iii) $0.1 \mathrm{mM}$ A $\beta 1-42$ oligomer with $2 \mathrm{mM}$ foldamer peptide. As a reference, STD and trNOE experiments were also performed without the target, containing the ligand alone. The binding tests were 
carried out at $280 \mathrm{~K}, 303 \mathrm{~K}$ and $298 \mathrm{~K}$ for the Gal-1+peptides/disaccharides, ASF+peptides and $A \beta 1-42+$ peptides systems, respectively.

\section{Saturation transfer difference (STD)}

Prior to binding tests and screening, the parameters were carefully optimized. Spectra were acquired by using a series of 40 equally spaced $50 \mathrm{~ms}$ Gaussian-shaped pulses for saturation of the protein, with a total saturation time of $2 \mathrm{~s}$. The frequency of the on-resonance irradiation was chosen to achieve effective and selective saturation of the protein. For the Gal-1-lactose complex, a series of different on-resonance irradiation frequencies were tested: $0.5,1.0,7.0,8.0,9.0$ and $10.0 \mathrm{ppm}$. In the presence of Tyr-Xxx-Tyr peptide ligands, $0.5 \mathrm{ppm}$ and 0 ppm was used for Gal-1 and ASF, respectively. For A $\beta 1-42$, the protein saturation was applied at - $1 \mathrm{ppm}$. In all cases, the off-resonance saturation frequency was set at $40.0 \mathrm{ppm}$. A total of $2 \mathrm{k}$ or $4 \mathrm{k}$ scans were collected for each pseudo $2 \mathrm{D}$ experiment.

\section{Ligand-detected binding tests with labelled Gal-1: GS-STD}

Experiments were performed at $280 \mathrm{~K}$ on a Bruker Avance II 500 spectrometer equipped with a $5 \mathrm{~mm}$ z-gradient triple resonance $\left({ }^{1} \mathrm{H} /{ }^{13} \mathrm{C} /{ }^{15} \mathrm{~N}\right)$ proton-detected (txi) probe head. Samples contained $4 \mathrm{mM}$ lactose in complex with $60 \mu \mathrm{M}{ }^{15} \mathrm{~N} /{ }^{13} \mathrm{C}$-labelled Gal-1. For attenuation of the protein signals, a $T_{l \rho}$ relaxation filter of $20 \mathrm{~ms}$ duration was applied. A relaxation delay of $2 \mathrm{~s}$ and $2 * 4 \mathrm{k}$ transients were used for the difference spectra. The ${ }^{1} \mathrm{H}$ STD spectrum was obtained by using the standard pulse sequence with a train of $90^{\circ}$ Gaussian pulses applied at $1 \mathrm{ppm}$. A train of $\mathrm{BIRD}^{\mathrm{d}}$ pulses with $\Delta=200 \mathrm{~ms}$ and $N=8$ was applied. For ${ }^{1} \mathrm{H}-{ }^{15} \mathrm{~N}$ saturation of the ${ }^{15} \mathrm{~N}$-labelled Gal-1, the ${ }^{15} \mathrm{~N}$ carrier frequency was set to $117 \mathrm{ppm}$ for on-resonance and to $270 \mathrm{ppm}$ for off-resonance irradiation. For the ${ }^{13} \mathrm{C}$ GS-STD spectra, the band-selective inversion of carbon (+/-50 ppm) was obtained with a Q3 Gaussian cascade ${ }^{167}$, 168 of $256 \mathrm{~ms}$ within the BIRD ${ }^{\mathrm{d}}$ cycle. To saturate the aliphatic region, the Q3 pulse of $+/-50$ ppm bandwidth was set to $15 \mathrm{ppm}$. The aromatic region was irradiated by applying the Q3 pulse at $157 \mathrm{ppm}$.

\section{Transferred NOE experiments (for Gal-1, ASF and Aß1-42)}

The 2D NOESY measurements were performed with 256 increments and with a NOE mixing time of 150-200 ms; the number of scans was 64 .

\section{Signal intensity loss and quantitative NMR binding tests with Aß1-42 fibrils}

For quantitative binding tests with A $\beta 1-42$ fibrils and short peptides, $15 \mu 1$ of ligand stock solution $(5 \mathrm{mM})$ and $120 \mu \mathrm{l}$ of buffer $\left(10 \mathrm{mM}\right.$, pH 7.4 phosphate $\mathrm{D}_{2} \mathrm{O}$ buffer) were mixed and transferred to the NMR tube, and the reference ${ }^{1} \mathrm{H}$ NMR spectrum was recorded. Subsequently, the peptide solution was mixed with $20 \mu \mathrm{l}$ of fibrillar A $\beta 1-42$ stock. In the final 
sample, the ligand:fibrillar $A \beta 1-42$ ratio was 5:1. For the competition measurements, the second ligand was added as a stock solution $(15 \mu 1)$ to the existing sample after co-incubation of the first ligand $+\mathrm{A} \beta 1-42$ for $50 \mathrm{~min}$. The reference spectrum was scaled to the concentration difference due to dilution, the difference spectrum was calculated and integrated, and its ratio was compared with the reference intensities to give the bound fraction of the ligand. All the measurements were repeated at least three times on separate samples, and the reproducibility of the bound fractions was within the relative error of $2 \%$.

\section{Backbone assignment of ${ }^{15} \mathrm{~N} /{ }^{13} \mathrm{C}-\mathrm{Gal}-1$}

NMR samples of $1.5 \mathrm{mM}{ }^{15} \mathrm{~N} /{ }^{13} \mathrm{C}-\mathrm{Gal}-1$ were prepared in phosphate buffer containing $5 \%$ glycerol. The resonance assignments of the backbone and side-chain atoms were obtained from $\mathrm{HNCO},{ }^{39-41} \mathrm{HNCA}^{39-41} \mathrm{HN}(\mathrm{CO}) \mathrm{CA},{ }^{40,} 41 \mathrm{HN}(\mathrm{CA}) \mathrm{CO},{ }^{38,} 41 \mathrm{CBCA}(\mathrm{CO}) \mathrm{NH},{ }^{36,} 37$ $\mathrm{HBHA}(\mathrm{CO}) \mathrm{NH}^{36,37}$ and ${ }^{15} \mathrm{~N}$ NOESY-HSQC ${ }^{169}$ (mixing time: $120 \mathrm{~ms}$ ) experiments recorded at $308 \mathrm{~K}$. Some of the measurements were repeated on a Varian $800 \mathrm{MHz}$ instrument with a cryogenically cooled salt-tolerant, ${ }^{13} \mathrm{C}$-enhanced, triple resonance probe. Processed data were analysed with the program Sparky $3.114 .{ }^{170}$ The chemical shifts were referenced to 2,2dimethyl-2-silapentane-5-sulfonic acid (DSS).

\section{${ }^{15} \mathrm{~N}$ HSQC titrations for ${ }^{15} \mathrm{~N} /{ }^{13} \mathrm{C}$-labelled Gal-1}

In the ${ }^{15} \mathrm{~N}$ HSQC titration experiments, the ${ }^{15} \mathrm{~N}$-labelled Gal-1 concentration was 0.5 $\mathrm{mM}$. Titrations were performed in two different ways, depending on the solubility of the ligands: $(i)$ For ligands which are highly soluble in water (e.g. lactose and LacNAc), in each step $2 \mu 1$ of a $14 \mathrm{mM}$ ligand stock solution was added to the $120 \mu 1$ protein sample, and the ${ }^{15} \mathrm{~N}$ HSQC spectrum of Gal-1 was measured. This was repeated until no significant change was observed in the spectra. In this way, with 8 titration steps, the ligand concentration was varied from 0.2 to $2 \mathrm{mM}$. (ii) Since a sufficiently concentrated stock solution cannot be prepared from the Tyr-Xxx-Tyr peptides, two titration points were acquired, and ligands were added in solid form to the Gal-1 sample. At the first titration point, the peptide concentration was $1 \mathrm{mM}$, while at the second point, the solution was saturated for the compound (with $\sim 2-4$ $\mathrm{mM}$ ligand). ${ }^{15} \mathrm{~N}$ HSQC spectra were acquired with 256 increments; the number of scans was 16.

\section{Relaxation measurements and model-free approach for ${ }^{15} \mathrm{~N} /{ }^{13} \mathrm{C}$-labelled Gal-1}

$T_{1}, T_{2}$ relaxation and heteronuclear NOESY experiments were recorded at $600 \mathrm{MHz}$ at $303 \mathrm{~K}$, with samples of $0.5 \mathrm{mM} \mathrm{Gal-1}$ with and without lactose. For $T_{1}$, variable delays of 0 , 100, 300, 500, 800, 1000, 1200 and $1500 \mathrm{~ms}$ were employed. For $T_{2}$, measurements were recorded with a CPMG (Carr-Purcell-Meiboom-Gill) refocusing delay of $450 \mu \mathrm{s}$ and by 
using relaxation delays of $0,17,34,51,68,85,102$ and 119 ms. A 256 x 2048 real data matrix was acquired for each duration, with 32 scans per increment. The $h$ NOE data sets were recorded with a saturation delay of $6 \mathrm{~s}$ as 512 x 1024 real matrices with 64 scans per increment for the spectra recorded with and without saturation. The model-free analysis was carried out in the program package relax ${ }^{171,172}$ with an iterative fitting of the rotational diffusion tensor $D$ and the parameters of the internal dynamics. First, an isotropic approximation of the overall rotational correlation time was determined from the ratios $R_{1} / R_{2}$, excluding outliers, according to Pawley et al., ${ }^{173}$ and approximate values of the $S^{2}$ were determined. Next, the parameters of the prolate spheroid diffusion model were fitted by using the PDB coordinates of $1 \mathrm{GZW}$ with fixed $S^{2}$. Finally, five different model-free models were optimized with fixed $D: \mathrm{m} 1\left[S^{2}\right], \mathrm{m} 2\left[S^{2}, \tau_{e}\right], \mathrm{m} 3\left[S^{2}, R_{e x}\right], \mathrm{m} 4\left[S^{2}, \tau_{e}, R_{e x}\right]$ and $\mathrm{m} 5\left[S^{2}, S_{f}^{2}, \tau_{e}\right]$, where $\tau_{e}$ and $R_{e x}$, are the effective correlation time and the exchange term. The procedure was iterated until $D$ converged. The accepted models were evaluated against Akaike's information criteria, ${ }^{174}$ and model $\mathrm{m} 4$ was selected as giving the lowest lack of fit and simplest model to avoid overfitting. Errors of the parameters were calculated by Monte Carlo simulation as implemented in relax.

\section{Structure refinement of new compounds}

Signal assignments were performed by using the gradient 2D TOCSY ${ }^{175}$ and Rotating Frame Overhauser Effect Spectroscopy (ROESY) ${ }^{176}$ with WATERGATE ${ }^{169,177}$ spectra of the 1-4 mM samples recorded in aqueous buffer. The temperature was chosen so as to obtain good signal resolution. ROESY measurements were carried out with a mixing time of $225 \mathrm{~ms}$ or $400 \mathrm{~ms}$ and with 64 scans. TOCSY measurements were acquired with homonuclear Hartman-Hahn transfer with the MLEV-17 sequence, with a mixing time of $80 \mathrm{~ms}$; the number of scans was 32. For all the 2D spectra, 2048 time domain points were applied, while the number of increments was 256 or 512. NMR-restrained molecular mechanical simulations were carried out in the Molecular Operating Environment (MOE) of the Chemical Computing Group. The conformational sampling was carried out by using the hybrid Monte Carlo (MC)Molecular Dynamics (MD) simulation as described in ref. [150].

\subsection{Other methods}

\section{Isothermal titration calorimetry for Aß1-42 oligomers and foldamers}

Isothermal titrations were performed with a Microcal VP-ITC microcalorimeter at $288 \mathrm{~K}$. In individual titrations, $10 \mu \mathrm{l}$ of ligand stock $(175$ or $222 \mu \mathrm{M})$ was injected from the computer-controlled $300 \mu \mathrm{l}$ microsyringe at intervals of $300 \mathrm{~s}$ into the $\mathrm{A} \beta$ oligomer solution (36 or $72 \mu \mathrm{M}$ ) dissolved in the same phosphate buffered saline (PBS) $\mathrm{pH} 7.4$ buffer as the 
ligand. The total ligand concentration was set in the syringe so that the titration stopped when the precipitation became excessive. Control experiments were performed by injecting the ligand into a cell containing buffer with no target, and the heats of dilution were subtracted from those measured in the presence of $A \beta$. Titrations were also performed with buffer in the syringe and $A \beta$ oligomer sample in the cell to check for the heat response of $A \beta$ dilution itself. The experimental data were fitted to the two-independent site binding model by using a non-linear least-squares procedure, with $H_{b}, H_{b}$ ' (binding enthalpies), $K_{a}, K_{a}$ ' (association constants), $n$ and $n$ ' (number of binding sites for monomer) as adjustable parameters.

\section{ELISA test for binding of Gal-1 to ASF in the presence of competitors and flow cytometric analysis of Gal-1 binding to cells}

ELISA plates were coated with ASF, and $0.5 \mu \mathrm{M}$ Gal-1 was added alone or in the presence of 2.5-2500 $\mu \mathrm{M}$ ligand (lactose or Tyr-Xxx-Tyr peptides). After incubation and washing, anti-Gal-1 monoclonal antibody was added, followed by horseradish peroxidaseconjugated anti-mouse Ig. The reaction was visualized with ortho-phenylenediamine as chromogen and $\mathrm{H}_{2} \mathrm{O}_{2}$ as substrate, and the absorbance of each sample was measured at 492 nm. For flow cytometric analysis of Gal-1 binding to cells, the leukaemic T-cell line Jurkat cells were incubated with Gal-1 alone $(1.8 \mathrm{mM})$ or with Gal-1 and the peptides or lactose (5 $\mathrm{mM}$ ). After washing, the cell-surface-bound Gal-1 was treated with monoclonal antibody to

Gal-1, followed by Atto488-conjugated antimouse IgG. The fluorescence intensity was analysed with a FACSCalibur cytofluorimeter. ELISA and FACS experiments were performed by Roberta Fajka-Boja (BRC).

\section{Particle size, morphology and electrostatic stability of the Aß1-42 samples}

Time-dependent signal intensity loss and quantitative NMR spectroscopic binding tests for the A $\beta 1-42$ fibril samples were complemented with Dynamic Light Scattering (DLS), TEM and $\zeta$-potential measurements. Samples were prepared with the same protocol as used for the NMR experiments: $100 \mu \mathrm{M} \mathrm{A} \beta 1-42$ fibrils and $0.5 \mathrm{mM}$ ligand (LPFFD and/or ThT). Experiments were performed by Lívia Fülöp. 


\section{Results and discussion}

\subsection{NMR studies of Galectin-1 and its ligands}

\subsubsection{Resonance assignment}

At the beginning of our studies with Gal-1, no signal assignment and NMR solution structure were available for Gal-1. Accordingly, the first goal was to assign the backbone resonances of the protein. For the $3 \mathrm{D}$ experiments, sample conditions were chosen so as to obtain the best sensitivity and sample stability. Following literature conditions, ${ }^{70} \mathrm{pH} 5.2$ solution was tried, but the protein proved less stable due to its isoelectric point near $\mathrm{pH}$ 5.2. As the signal intensity of the ${ }^{15} \mathrm{~N}$ HSQC spectra at $\mathrm{pH} 7.4$ was acceptable, physiological $\mathrm{pH}$ was preferred. Without additives, a maximum protein concentration of $0.5 \mathrm{mM}$ could be achieved. By the addition of $5 \%$ glycerol to the sample, $1.5 \mathrm{mM}$ Gal-1 could be dissolved, allowing the application of less sensitive triple resonance experiments and increasing the stability of the sample. Glycerol did not affect the positions of the Gal-1 peaks.

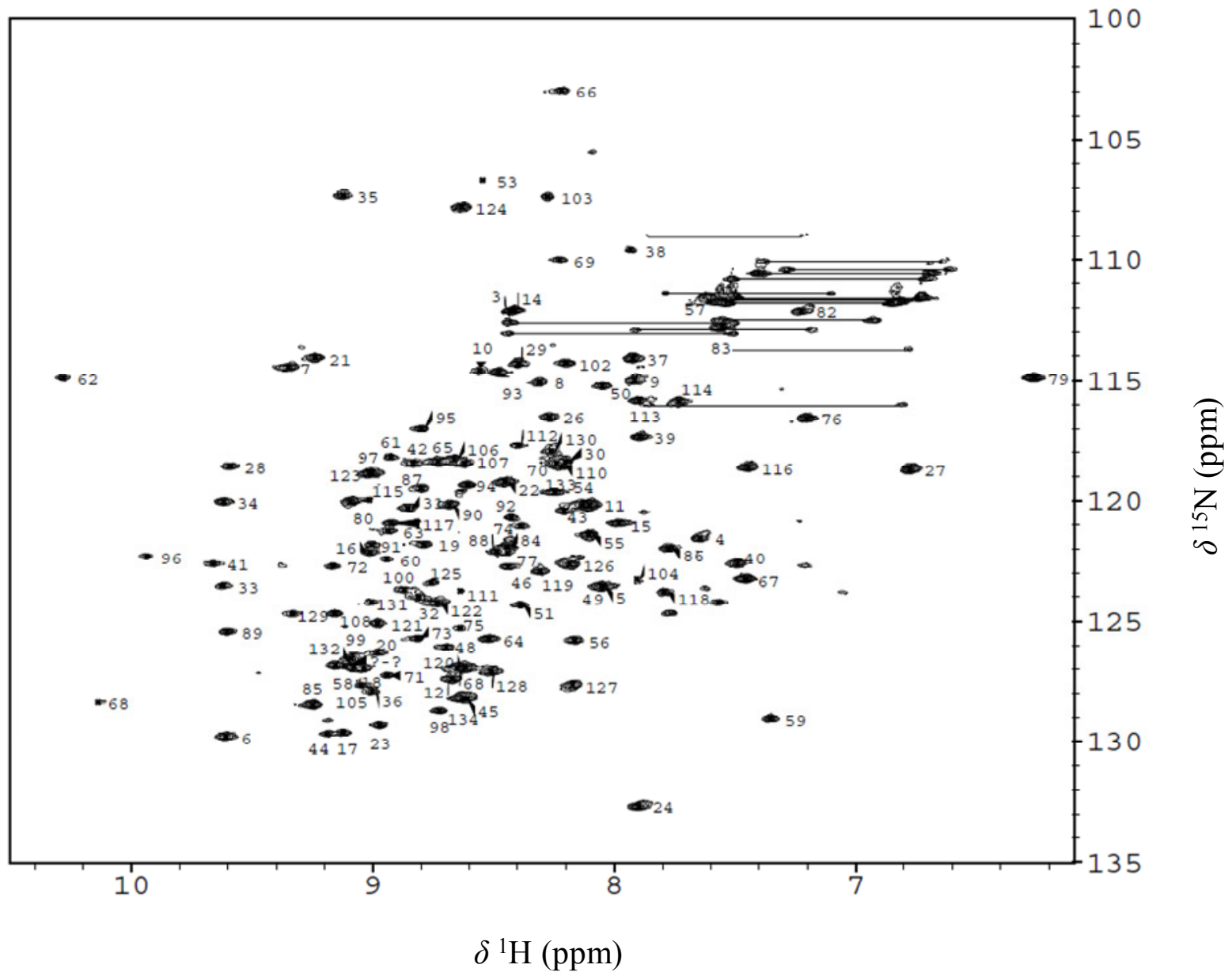

Figure 7. ${ }^{15} \mathrm{~N}$ HSQC spectrum of Gal-1 with the residue number of the assigned amide peaks in $20 \mathrm{mM} \mathrm{pH}$ 7.4 sodium phosphate buffer, without lactose. Signals connected with solid lines show side-chain nitrogens.

The assignment was achieved by the triple resonance approach. The backbone chemical shifts could be successfully assigned at $\mathrm{pH} 7.4$ (Figure 7), and the great majority of the CB 
and $\mathrm{HB}$ resonances were also identified (Table A3). For His52, located near the binding site at the tip of the lactose binding loop, no signal was detected at $\mathrm{pH} 7.4$, whereas the resonance in question was observed at $\mathrm{pH}$ 5.2. The absence of the His52 amide peak at $\mathrm{pH} 7.4$ was probably due to a process involving exchange with the solvent and conformational changes in the flexible loop. The amide peaks of the N-terminal residues $A^{1}-G^{3}$ could not be assigned either, for similar reasons. Our independent resonance assignment for Gal-1 at physiological $\mathrm{pH}$ was found to be in good accordance with that obtained by another research group at $\mathrm{pH}$ 5.3 in the presence of lactose. ${ }^{178}$

\subsubsection{Investigations with the natural ligand lactose}

The experiments with Gal-1 and lactose were designed to $(i)$ improve our understanding of the function of Gal-1 homodimer in the solution phase, (ii) serve as a model system for the GS-STD experiments and (iii) furnish positive controls and validation for the proposed NMR assays. Most of the NMR experiments were performed with the natural ligands lactose and LacNAc and essentially identical results were observed for the two disaccharides. For simplicity, only lactose will be discussed.

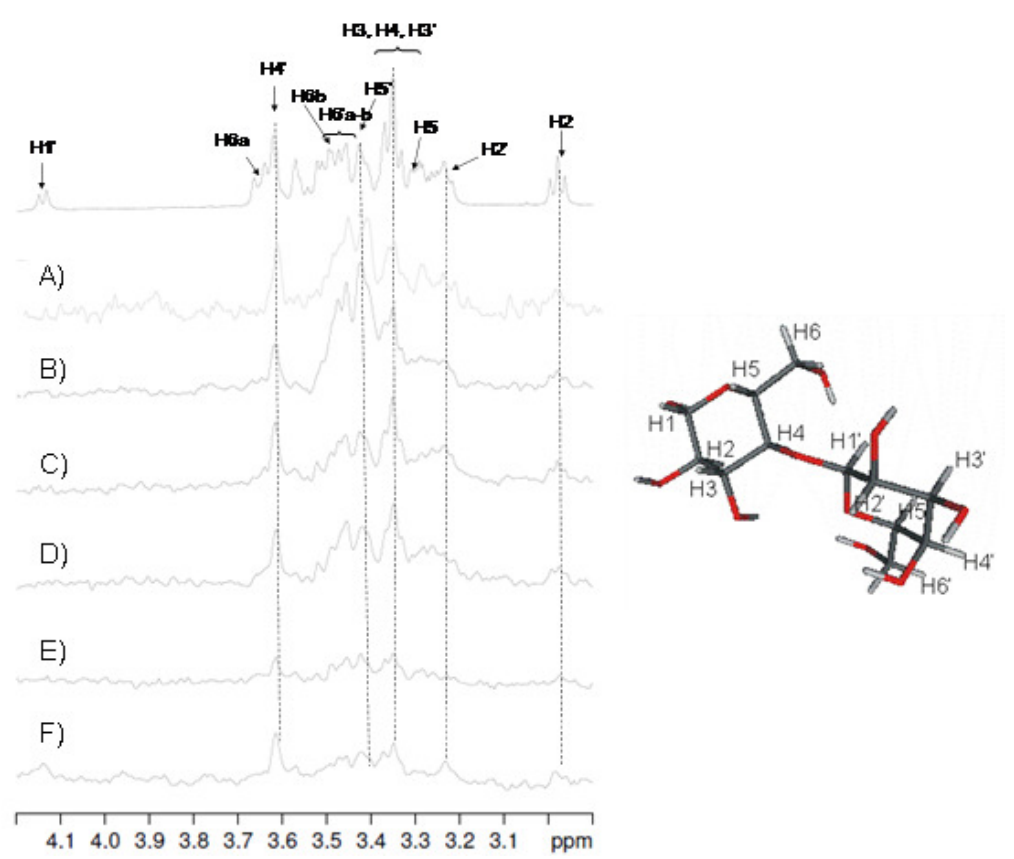

Figure 8. ${ }^{1} \mathrm{H}$ STD spectra of the Gal-1-lactose complex obtained with different on-resonance irradiation frequencies. 0.5, 1.0, 7.0, 8.0, $9.0 \mathrm{ppm}$ and $10.0 \mathrm{ppm}$ for A), B), C), D), E) and F), respectively. The ${ }^{1} \mathrm{H}$ reference spectrum with the assignment is displayed at the top.

In the STD tests with lactose, the observed signals became more intense when the experiments were carried out at low temperature $(280 \mathrm{~K})$. A similar phenomenon was also observed for the related protein Gal-7.31 The enhancement might be explained by the increased protein-ligand contact time and by the more efficient spin-diffusion. The effect of the different on-resonance irradiation frequencies was also tested (Figure 8). The best 
saturation was obtained with an on-resonance irradiation of $1 \mathrm{ppm}$; while $0.5,7$ or $8 \mathrm{ppm}$ were also acceptable.

The trNOE experiment with a mixing time of 150-200 ms worked excellently for Gal-1 and lactose both at 280 and at $303 \mathrm{~K}$. The small molecular weight lactose with a short rotational correlation time has positive cross-relaxation rate (negative NOE cross-peaks if diagonals are phased positive) at $303 \mathrm{~K}$. On addition of Gal-1 to the sample, a small loss in intensity was observed, which can be indicative of binding. At $280 \mathrm{~K}$, the binding of lactose to Gal-1 caused inversion of the sign of the NOE cross-peaks because of the slower molecular tumbling. As concerns the binding conformation of the disaccharide, no extra information was obtained from the trNOE cross-peaks.

Although the structures of Gal-1 complexed with different disaccharide ligands are known, ${ }^{15} \mathrm{~N}$ HSQC titration in solution may provide extra information concerning the structural changes that occur upon binding. ${ }^{15} \mathrm{~N}$ HSQC spectra of Gal-1, recorded with increasing ligand concentrations, revealed the shifting of certain amide peaks (Figure 9). The results were in good agreement with the $K_{d}$ of approximately $100 \mu \mathrm{M}$ found for the Gal-1lactose system. ${ }^{75,76}$ As expected, the peaks corresponding to the CRD were significantly shifted.

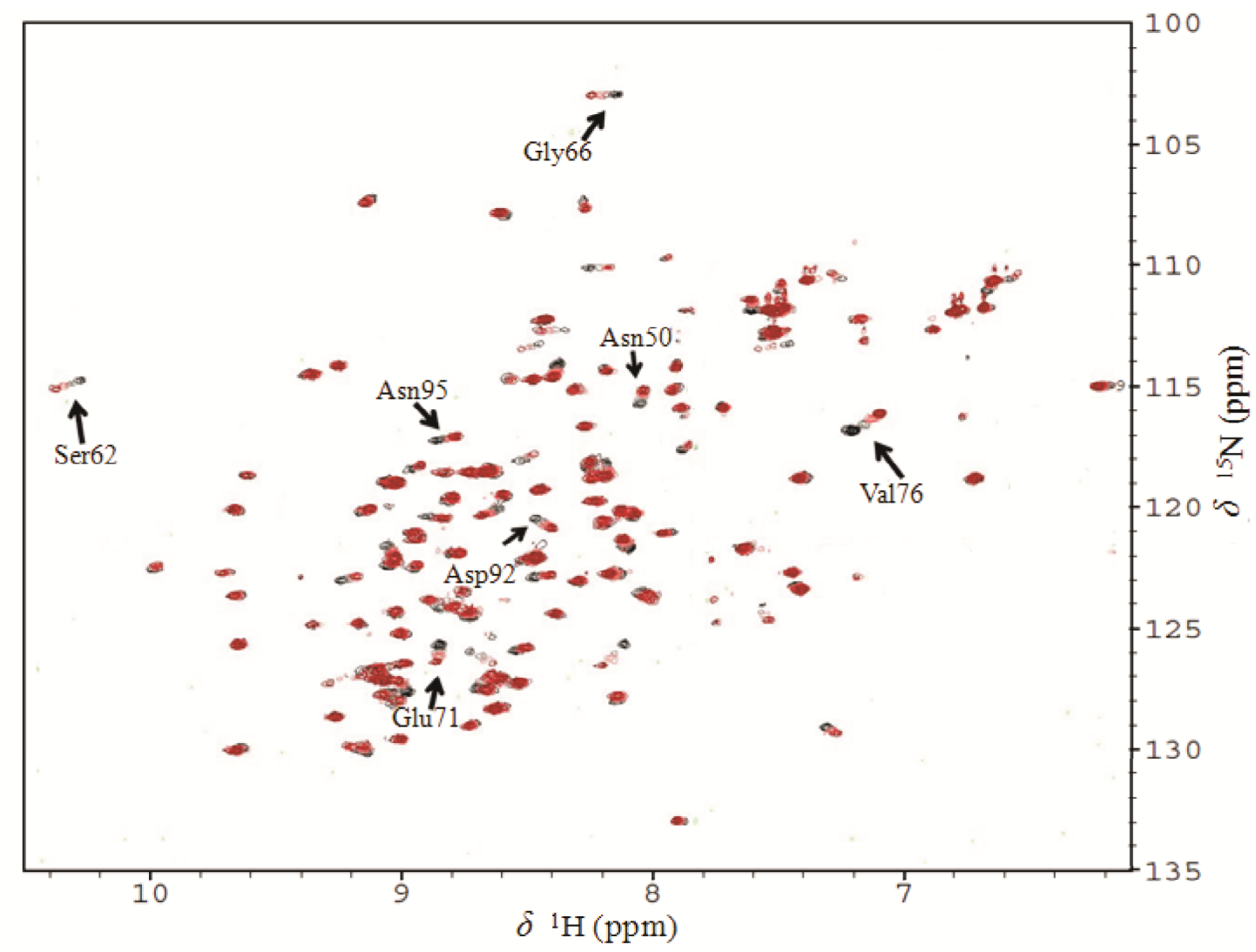

Figure 9. ${ }^{15} \mathrm{~N}$ HSQC titration of Gal-1 with lactose. Overlay of the ${ }^{15} \mathrm{~N}$ HSQC spectra obtained for the 0.5 $\mathrm{mM}$ free Gal-1 sample and with increasing lactose concentrations $(0.2-2 \mathrm{mM})$. Assignments for some shifted peaks are marked with arrows. 
Interestingly, the titration showed alterations for some residues remote from the binding site (Figure 10). Residues Glu105, Thr90, Phe91 and Asp92 (Figure 10A, B), located on the side opposite to the CRD, exhibited considerable chemical shift changes. These findings strongly suggested that the binding of lactose is accompanied by structural/dynamic rearrangements propagating to distant parts of the protein. Similar results have been found for lactose and for complex glycans in recently published studies. ${ }^{76,79,80}$

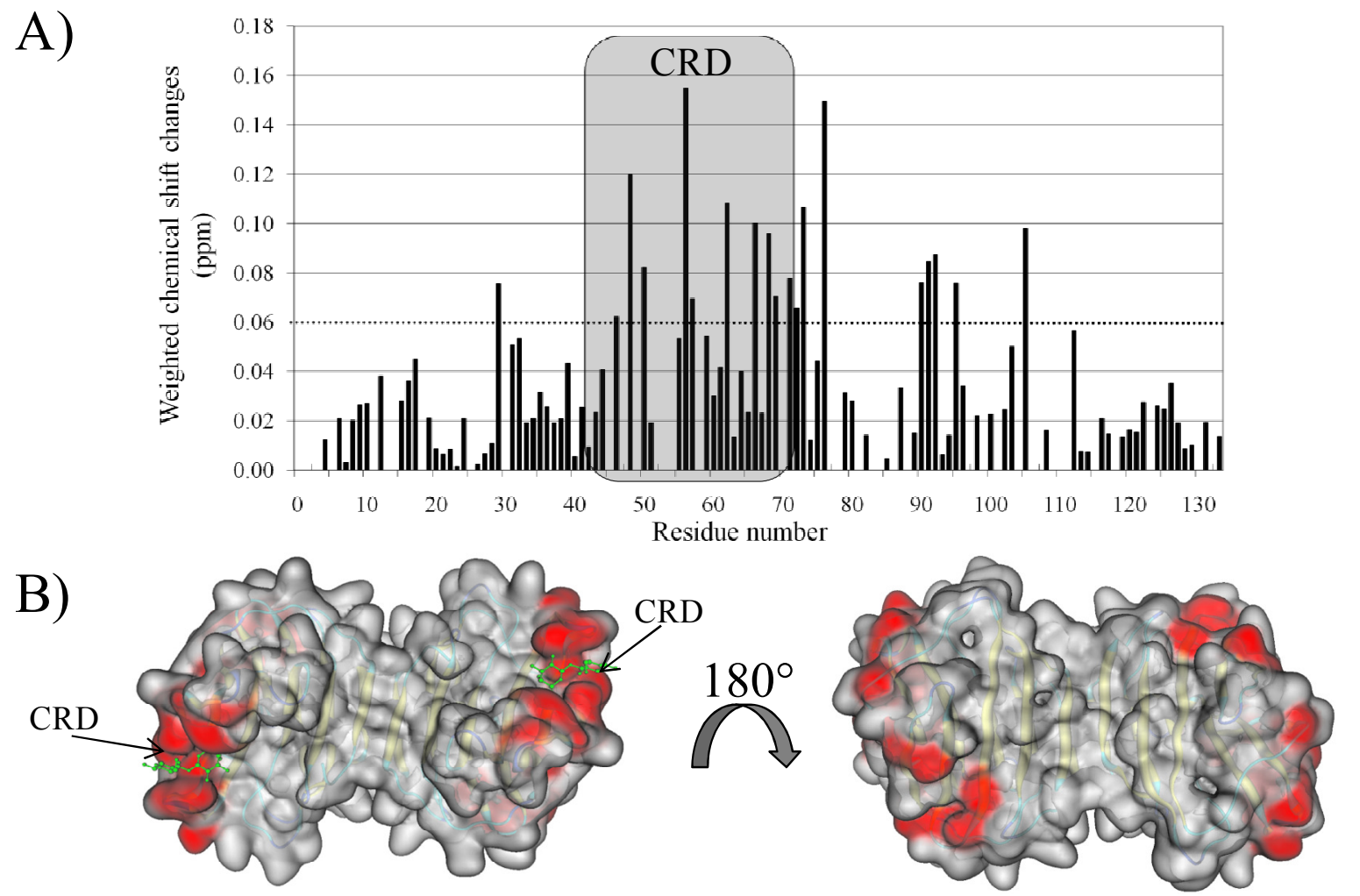

Figure 10. ${ }^{15} \mathrm{~N}$ HSQC titration of Gal-1 with lactose at $\mathrm{pH}$ 7.4. A) Weighted chemical shift changes ${ }^{14}$ $\left[\Delta \delta\left({ }^{1} \mathrm{H}\right)^{2}+\left(\Delta \delta\left({ }^{15} \mathrm{~N}\right) / 6.51\right)^{2}\right]^{1 / 2}$ of Gal-1 upon titration with lactose at $\mathrm{pH}$ 7.4. The dotted line at $0.06 \mathrm{ppm}$ indicates the value for the average shift plus one standard deviation. Highlighted residues (grey background) are located around the binding site. B) Top 15 shifted residues upon lactose titration mapped (red) on the surface of the Gal-1 homodimer: Asn56, Val76, Arg48, Ser62, Arg73, Gly66, Gln105, Trp68, Asp92, Phe91, Asn50, Glu71, Thr90 and Asn95.

The ${ }^{15} \mathrm{~N}$ HSQC titration results indicated that lactose binding affects the dynamic features of the whole protein. In order to characterize the motional properties of Gal-1, $R_{1}, R_{2}$ and heteronuclear steady-state NOE values were measured for the backbone amides of the free and the lactose-bound protein (Figure 11) and model-free analysis was carried out. The resulting global parameters showed that the dimerization of Gal-1 affected its relaxation properties in consequence of the MW doubling to $29 \mathrm{kDa}$ (the correlation time $\tau_{c}$ was found to be $12.1 \mathrm{~ns}$ ); and it also influenced the symmetry of the rotational diffusion tensor $D$. The Gal-1 homodimer appeared as a prolate ellipsoid with strongly anisotropic rotational diffusion properties; the anisotropic component of the Brownian rotational diffusion tensor $D_{a}=D_{\mathrm{z}}-0.5\left(D_{x}+D_{y}\right)$ was found $5.8 \cdot 10^{6} \mathrm{~s}^{-1}$. The anisotropy was also reflected in the large 
variation of the relaxation rates depending on the amide bond orientation relative to the principal axes of $D$. The calculations resulted in the model-free parameters $S^{2}, \tau_{e}$ and $R_{e x}$ calculated separately for both free and lactose-bound Gal-1 (Figure 11).
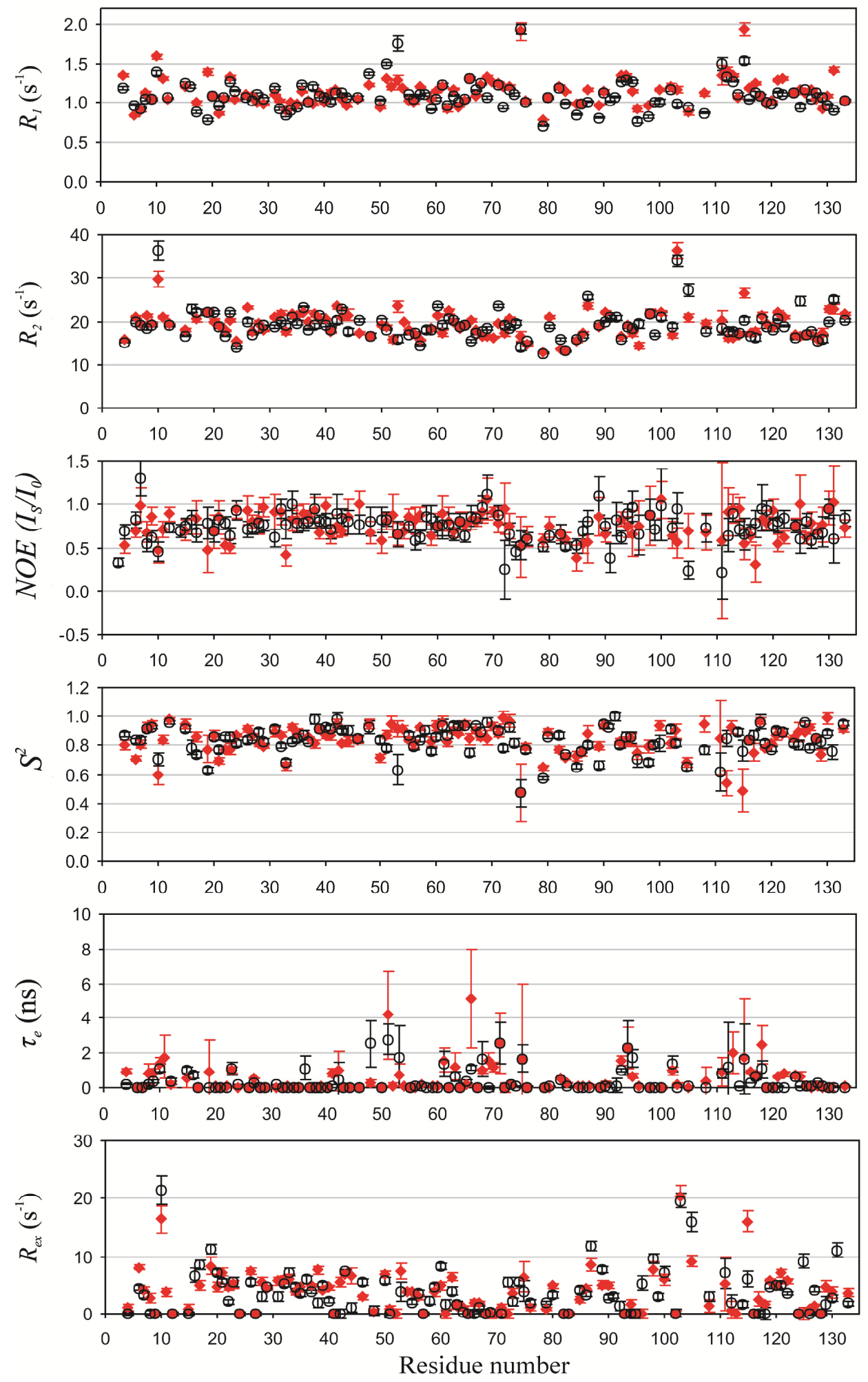

Figure 11. Relaxation data and dynamic parameters obtained via model-free analysis for Gal-1 with and without lactose. Data with error bars are plotted against the residue numbers for free Gal-1 (empty circles) and lactose-complexed Gal-1 (red diamonds). 
For free Gal-1, increased flexibility was observed for the following residues (for annotations, see Figure 12): Asn10 (L1), Leu17-Gly21 (F2), Asn33 (S3), Ala51-Gly53 (L4), Ala75-Ile89 (L6b-F3), Leu96-Va198 (F4), Arg111-Glu115 (L9) and Val131 (F1). The relatively high order at the C-terminal was due to the dimerization. As expected, the loop regions displayed higher mobility on the ns time scale, but the disorder of face $\mathbf{F}$ relative to face $\mathbf{S}$ of the $\beta$-sandwich was surprising (Figure 12). It is noteworthy that high-amplitude ns-scale motions were detected at $\mathbf{L} \mathbf{4}$ and $\mathbf{L 6 b}$, loops contributing to the carbohydrate-binding groove.

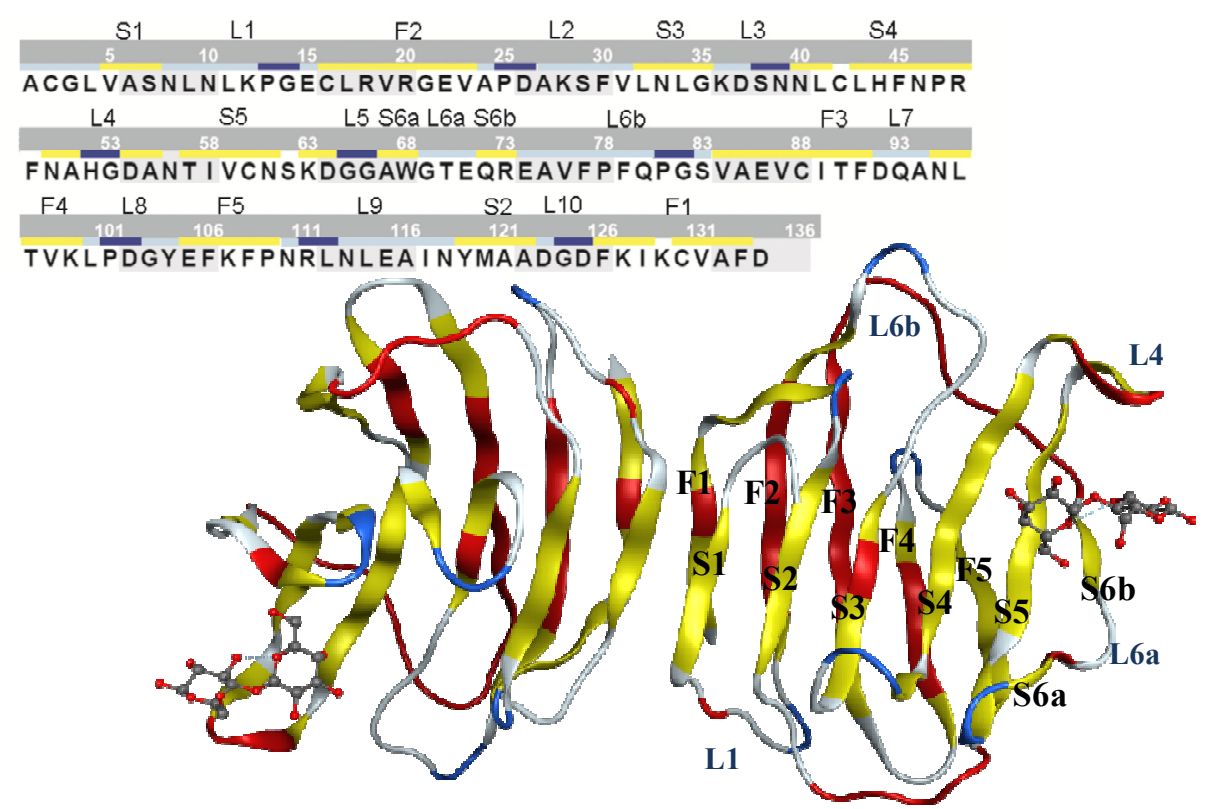

Figure 12. Gal-1 sequence and 3D structure with annotation of the secondary structure elements of five (F1-F5) and six (S1-S6) $\beta$-sheets based on ref. [7]. Flexible regions of the free protein are coloured red.

Upon lactose binding, a significant order increase $\left(\Delta S^{2}>0.1\right)$ was observed for Leu17 and Val19 (F2), Gly53 (L4), Gln72 (S6b), Ile89 (F3), Val98 and Leu100 (F4), Phe108 (F5), Arg111 (L9), and Lys127 and Lys129 (F1). The change for Gly53 and Gln72 was a direct consequence of the rigidifying effect of the ligand binding. This observation was further supported by the pH-dependent appearance of the His52 amide signal, pointing to an exchange phenomenon. Most interestingly, decreased mobility propagated from strands F5 through to $\mathbf{F 1}$ in a contiguous patch of the $\beta$-sandwich core (Figure 13A). This phenomenon pointed to a more compact packing of the hydrophobic interior, which might be due to an overall change in the $\beta$-sandwich curvature, eventually leading to an increased stability of the protein when complexed to lactose. This finding was in good accord with the literature results reporting a higher conformational stability of Gal-1 in the presence of lactose. ${ }^{179-181}$ On the other hand, a significant flexibility increase $\left(\Delta S^{2}<-0.1\right)$ upon lactose binding was also observed for several residues. The disorder increase was found for segments S1 and F1, where the dimerization interface is located. 
A)

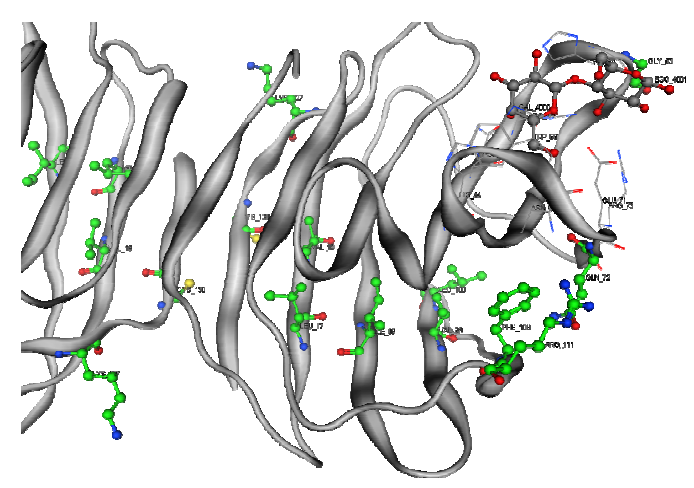

B)

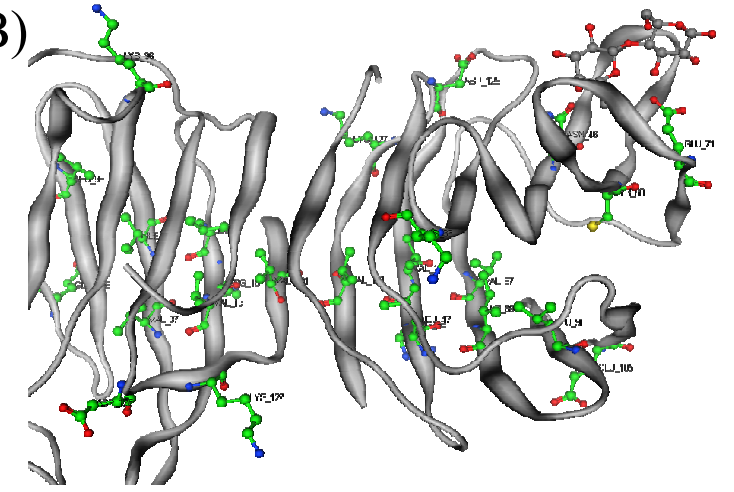

Figure 13. Gal-1 residues with dynamic changes upon lactose binding (green) mapped to the protein structure: increased rigidity (A) and decreased $R_{e x}$ frequency (B).

Our dynamic results for Gal-1 are in accordance with the recent solution NMR studies of Nesmelova et al., ${ }^{76}$ which revealed high flexibility for the lactose-binding loop of the free Gal-1, which is reduced upon ligand binding. They showed that the lactose-binding region is more open in the unbound state, i.e., the lactose-binding loop L4 and Trp68 (S6a) are oriented away from the binding groove. We found the best fitting when $R_{e x}$ was included in the model, which is different from the model in ref. [76]. The appearance of the exchange terms throughout the backbone indicated the tendency of Gal-1 to undergo $\mu$ s and ms-scale conformational rearrangements. Again, relatively high values were observed within the hydrophobic core of face F, which were attenuated by the ligand binding. Residues Ser38, Cys42 and His44 exhibited relative increases in $R_{e x}$ in the presence of lactose, possibly indicating that the involvement of His44 in ligand binding loosened S4 (Figure 13B). On the basis of these results, a conformational communication between the Gal-1 monomers can be speculated, which might explain the negative cooperativity of the two binding sites reported for Gal-1. ${ }^{76}$

\subsubsection{Gal-1-lactose complex as a model system for GS- STD}

In the preliminary STD tests, the saturation of Gal-1 by ${ }^{1} \mathrm{H}$ methods proved imperfect. In STD, the flexibility of the side-chains around the binding pocket could be destructive for the overall saturation transfer. Model-free analysis with Gal-1 and lactose indicated the flexible properties of the lectin and its complex with lactose, especially for the solvent-exposed carbohydrate-binding groove flanked by loops L4 and L6b. Consequently, the Gal-1-lactose complex seemed to be a good model system for testing the different GS-STD approaches for a flexible binding site.

For the ${ }^{15} \mathrm{~N} /{ }^{13} \mathrm{C}$ GS-STD spectra, the original ${ }^{15} \mathrm{~N}$ GS-STD pulse sequence of Kövér $e t$ $a l .{ }^{33}$ was modified. As the amide proton resonances of Gal-1 and the ring proton resonances of lactose do not overlap, the heteronuclear spin-echo-based X-filter was omitted (Figure 14). The ${ }^{15} \mathrm{~N}$ GS-STD sequence exploiting the BIRD ${ }^{\mathrm{d}}$ pulse scheme excites ${ }^{1} \mathrm{H}$ attached to ${ }^{15} \mathrm{~N}$, 
while ${ }^{1} \mathrm{H}$ attached to ${ }^{14} \mathrm{~N}$ remains aligned to the $+z$ axis. Similarly, using ${ }^{13} \mathrm{C}$ pulses, the $\mathrm{BIRD}^{\mathrm{d}}$ pulse train excites ${ }^{1} \mathrm{H}$ attached to ${ }^{13} \mathrm{C}$, while ${ }^{1} \mathrm{H}$ attached to ${ }^{12} \mathrm{C}$ remains aligned to the $+z$ axis.

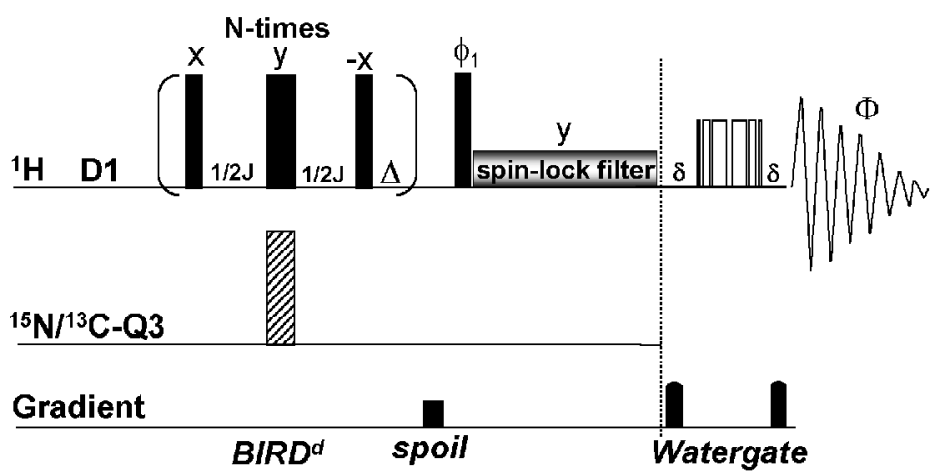

Figure 14. Pulse sequence used for the multinuclear GS-STD experiments. The BIRD ${ }^{\mathrm{d}}$ delay is set to $1 /\left(2 J_{\mathrm{XH}}\right)$. Between on- and off-resonance experiments only the X-carrier frequency was changed. Phase cycling: $\Phi_{I}=\mathrm{x},-\mathrm{x}$ and $\Phi=\mathrm{x},-\mathrm{x}$ for on-resonance and $\Phi=$-x, x for off-resonance, respectively. Sine-bellshaped gradients of $1 \mathrm{~ms}$ duration are used; gradient strengths for purging: 37\%; for WATERGATE: $20 \%$, given as a percentage of the absolute gradient strength of $50 \mathrm{Gcm}^{-1}$. A $T_{l \rho}$ relaxation filter is included to attenuate protein magnetization.

The ${ }^{15} \mathrm{~N}$ BIRD pulse train saturates all the ${ }^{15} \mathrm{~N}$-attached proton magnetizations of the labelled Gal-1, resulting in an almost uniform and direct excitation of the whole protein ${ }^{15} \mathrm{NH} /{ }^{15} \mathrm{NH}_{2}$ region. By using a ${ }^{13} \mathrm{C}$ G-BIRD pulse train, in principle all the ${ }^{13} \mathrm{C}$-attached proton magnetization of a protein could be directly and uniformly saturated. However, the $1.1 \%$ natural abundance of ${ }^{13} \mathrm{C}$ nuclei of the 'unlabelled' ligands makes this approach unreliable due to the saturation of the ${ }^{13} \mathrm{C}$-satellite proton magnetization, which can provide false-positive results. To avoid the undesired excitation of ligand protons, the non-selective ${ }^{13} \mathrm{C}$ pulses in the BIRD sequence are replaced with appropriate band-selective Q3 pulses. ${ }^{167}$, ${ }^{168}$ In our Gal-1-lactose model system, either the aliphatic or the aromatic region of protein resonances could be saturated by using Q3 band-selective carbon pulses while barely affecting the ligand proton magnetization.

The efficacy of different GS and conventional ${ }^{1} \mathrm{H}$ excitation schemes was tested on the ${ }^{15} \mathrm{~N} /{ }^{13} \mathrm{C}$-labelled Gal-1 sample. The signal intensity patterns of the STD spectra obtained in four different experimental setups, i.e. by using conventional ${ }^{1} \mathrm{H}$ STD, ${ }^{15} \mathrm{~N}$ GS-STD, ${ }^{13} \mathrm{C}_{\mathrm{Ar}}$ and ${ }^{13} \mathrm{C}_{\text {aliphatic }}$ GS-STD approaches, were analysed and compared. The anomeric signals above $4.2 \mathrm{ppm}$ could not be observed due to the applied water suppression scheme, and the STD signals could not be integrated because of their severe overlap. However, the impact of the different excitation schemes and their implication concerning the mode and site of binding of the ligand to the Gal-1 surface are apparent from the difference spectra (Figure 15) and the spatial distributions of the excited atoms (Figure 16). 
In the Gal-1-lactose complex, the binding site comprises aliphatic, aromatic, nitrogen and methylgroup-containing side-chains (His44, Asn46, Arg48, His52, Val59, Asn61, Trp68, Glu71 and Arg73). The galactose residue of the ligand is located in the binding pocket, whereas the glucose is solvent-exposed. In agreement with the structure of the complex, spatial selectivity was observed in each of the four experimental setups, i.e. signals of the galactose residue predominated in the STD spectra. Beyond the classical group epitope mapping, ${ }^{28}$ however, the different excitation schemes resulted in additional effects, i.e. 'chemical selectivity' in the saturation spreading, implicating the type of the side-chain in the proximity of the ligand.

By using the conventional ${ }^{1} \mathrm{H}$ STD setup with on-resonance irradiation at $1 \mathrm{ppm}$, the sidechain protons of Val, Leu and Ile of Gal-1 were directly and efficiently saturated without relying on spin-diffusion-based magnetization transfer. The Gal-1 binding site, however, is not rich in these hydrophobic residues; only the Val59 is within $5 \AA$ of H6' (see Figure 16A). This spatial arrangement was supported by the strongest STD effect observed for H6' in the ${ }^{1}$ H STD spectrum (Figure 15A). On the other hand, unlike the other experiments (see below), H4', which is located far from all the methyl protons, exhibited only very weak STD signal.

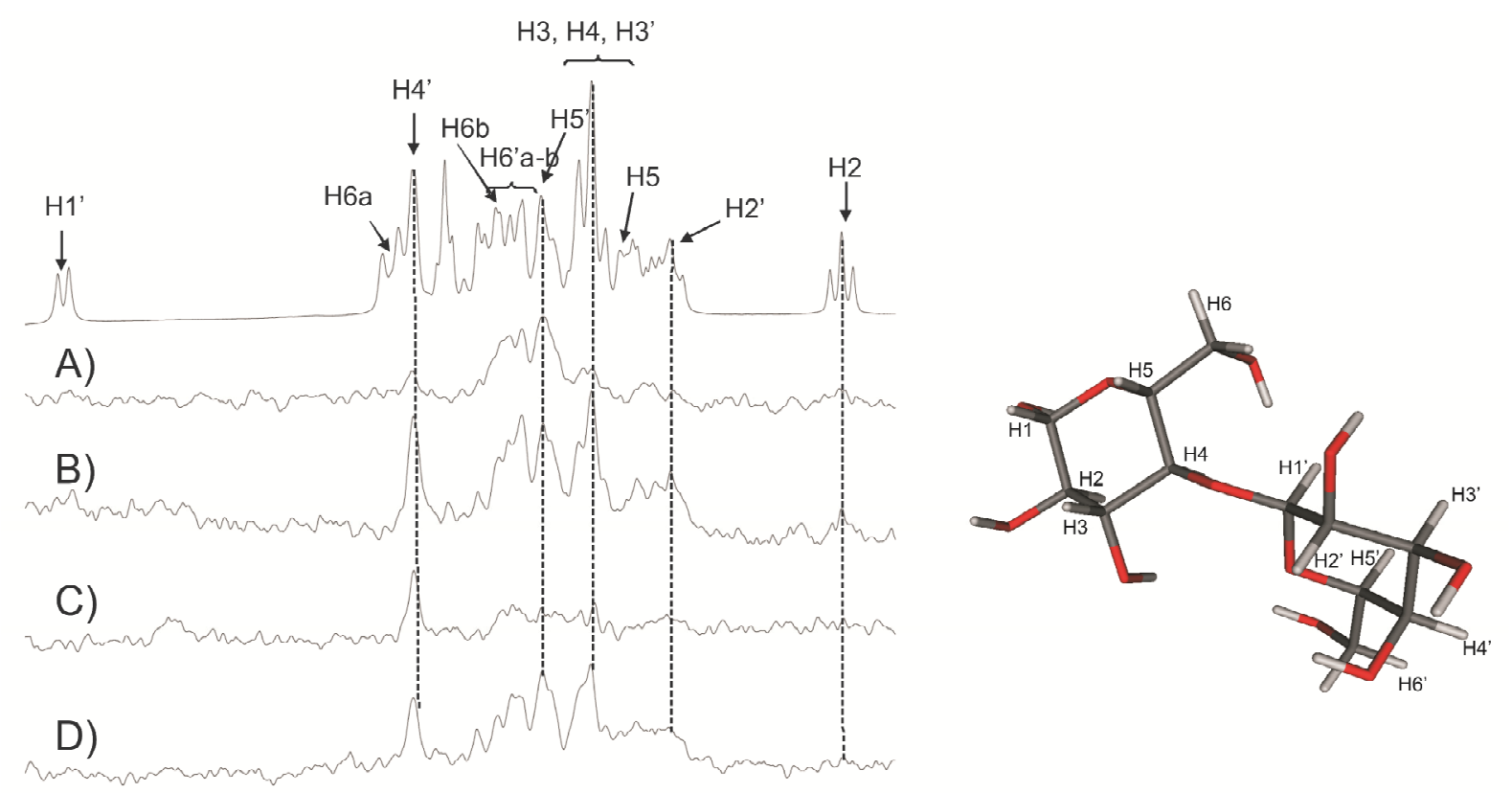

Figure 15. ${ }^{1} \mathrm{H}$ STD and multinuclear GS-STD spectra of the Gal-1-lactose complex. A) ${ }^{1} \mathrm{H}$ STD spectrum obtained with standard pulse sequence with on-resonance irradiation at $1.0 \mathrm{ppm}$. B) ${ }^{15} \mathrm{~N}$ GS-STD spectrum obtained with on-resonance irradiation at $117.0 \mathrm{ppm}$. C) ${ }^{13} \mathrm{C}$ GS-STD spectrum obtained with bandselective saturation in the aromatic region (on-resonance irradiation at $157.0 \mathrm{ppm}$ ). D) ${ }^{13} \mathrm{C}$ GS-STD spectrum obtained with on-resonance irradiation in the aliphatic carbon region (irradiation at $-15.0 \mathrm{ppm}$ ). ${ }^{1} \mathrm{H}$ reference spectrum is on the top with the assignment given for the major isomer $\beta$-lactose (the structure of lactose is on the right). 
The ${ }^{13} \mathrm{C}_{\mathrm{Ar}} \mathrm{GS}$ excitation scheme saturating aromatic protons located in different regions of Gal-1 resulted in fewer and lower-intensity STD peaks, which could be explained by the moderate number of aromatic 'transmitter' protons (Figure 16C) in the proximity of the ligand. The strongest STD effect was observed on H4' (Figure 15C), which is located between His42 and Trp68. All the other STD peaks (H3', H5' and H6') appeared to be weak, in agreement with the structure of the Gal-1-lactose complex. With regard to the interatomic distance, the STD peak of H2' was expected to be more intense, but the high flexibility of His52 could probably decrease the efficiency of saturation transfer. Thus, the ${ }^{13} \mathrm{C}_{\mathrm{Ar}} \mathrm{GS}-\mathrm{STD}$ spectrum provided specific information supporting the close proximity of $\mathrm{H} 4$ ' to the aromatic side-chains.

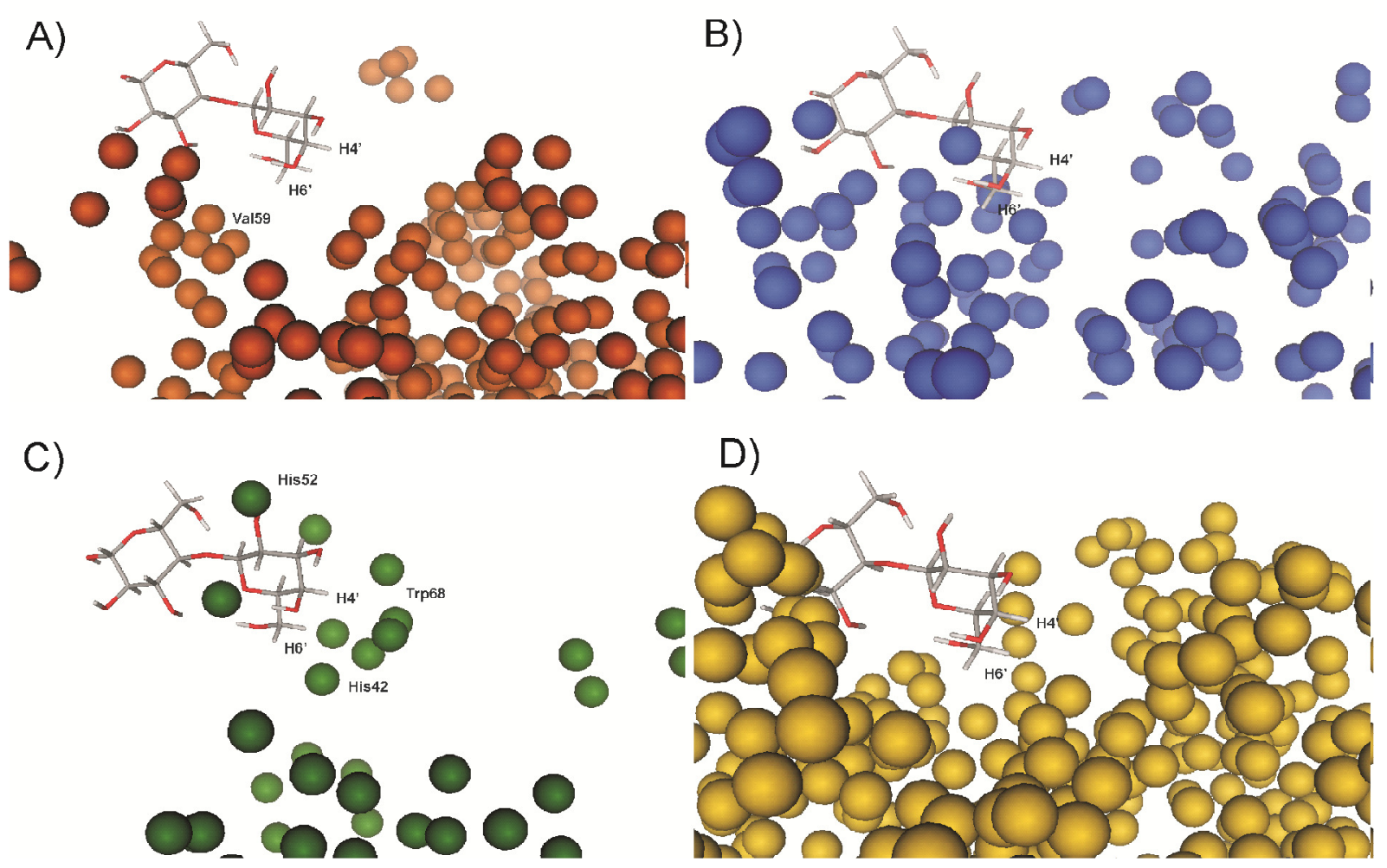

Figure 16. Spatial distribution of the excited atoms in the different STD experimental setups. A) ${ }^{1} \mathrm{H}$ STD (Val, Leu and Ile methyl protons). Only Val59 is within $5 \AA$ of lactose. B) ${ }^{15} \mathrm{~N}$ GS excitation scheme. The high number of 'transmitter' ${ }^{15} \mathrm{~N}$ amides throughout the whole protein results in homogeneous saturation of the protein, giving rise to STD effects on all lactose hydrogen atoms close to the binding site. C) ${ }^{13} \mathrm{C}_{\mathrm{Ar}} \mathrm{GS}$ excitation scheme. A distinct group of aromatic residues are located in the binding site (Trp68, His42 and His52), which was able to transfer magnetization to ligand protons in close proximity. Further, aromatic side-chains are remote from the binding site. D) ${ }^{13} \mathrm{C}_{\text {aliphatic }}$ GS excitation scheme. The high number of aliphatic hydrogen atoms attached to ${ }^{13} \mathrm{C}$ results in homogeneous saturation of the protein; this gives rise to STD effects on all lactose hydrogen atoms close to the binding site.

The ${ }^{15} \mathrm{~N}$ GS saturation of Gal-1 or the irradiation of the protein aliphatic region by using the ${ }^{13} \mathrm{C}_{\text {aliphatic }}$ GS excitation scheme resulted in similar STD spectra (Figure 15B, D) with strong and more uniform signal intensities, with a slight preference for the ${ }^{15} \mathrm{~N}$ experiment. Considering the high number of 'transmitter' ${ }^{15} \mathrm{~N}$ amide or ${ }^{13} \mathrm{C}$ aliphatic hydrogen atoms 
throughout the whole protein and their efficient, direct (not spin diffusion based) irradiation, homogeneous protein saturation could be achieved (Figure 16B, D), which was apparent from the STD spectra obtained. In these scenarios, no 'chemical selectivity' was implicated. It should be noted that in the ${ }^{15} \mathrm{~N}$ GS-STD experiment, the nitrogen-containing side-chains (His44, Arg48, His52 and Trp68) of Gal-1 were also saturated; this can be appreciated by the enhanced STD effects on H2', H3' and H4' ligand protons.

\subsubsection{Binding tests with Tyr-Xxx-Tyr peptides}

The literature on Tyr-Xxx-Tyr peptides suggested that these compounds might be promising drug candidates and models for the design of new Gal-1 inhibitors. In order to test this hypothesis, four compounds were synthetized. The most effective inhibitors, WYKYW- $\mathrm{NH}_{2}{ }^{93}$ and TYDYF- $\mathrm{NH}_{2},{ }^{81}$ were selected as lead sequences. A hexapeptide analogue with an additional polar amino acid, TYDYFR-NH $\mathrm{N}_{2}$, and a conformationally constrained sequence, TYPYFR-NH $\mathrm{N}_{2}$, were also prepared.

\section{ELISA and FACS: competitive tests for binding of Gal-1 to ASF and to cell surface glycoproteins, respectively}

ELISA and FACS were both designed to assess the efficacy of the compounds as concerns the inhibiton of the Gal-1-glycoprotein interaction. The major difference between the two experiments is the type of the glycoprotein: ELISA uses ASF as glycoprotein model, while in FACS, Gal-1 binds to the natural surface glycoproteins of leukaemic Jurkat T-cells. Both competition tests were carried out with the Tyr-Xxx-Tyr peptides and with lactose in order to investigate their inhibitory effects and to compare the peptides with the native ligand.

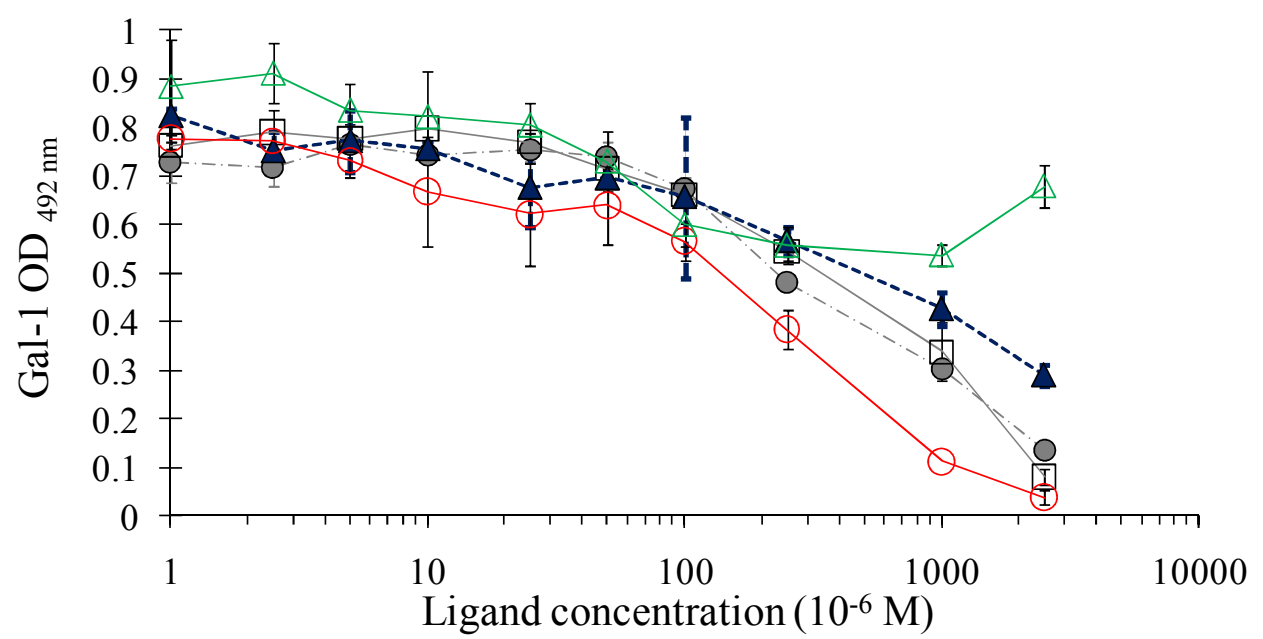

Figure 17. ELISA experiments: inhibition of Gal-1 binding to ASF by various competitors: TYDYF-NH

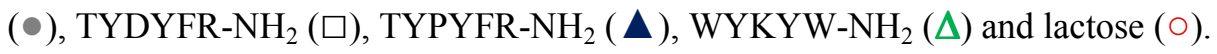


In ELISA, with the exception of WYKYW-NH${ }_{2}$, the peptides exhibited efficacies comparable with that of lactose in the inhibition of the Gal-1-ASF interaction (Figure 17). The conformationally constrained TYPYFR- $\mathrm{NH}_{2}$ did not perform well; displacement occurred in a concentration-dependent manner with a similar decay as for the other compounds, thereby indicating a similar, though weaker inhibition. A U-shaped curve was obtained for WYKYW- $\mathrm{NH}_{2}$, showing its inability to displace Gal-1 fully at higher concentrations. This behaviour could be explained by aggregation of the ligand, which was supported by DLS measurements. The observation might serve as an explanation for the reported anomalous behavior of the peptide in SPR measurements. ${ }^{93}$ FACS revealed inhibition of the Gal-1glycoprotein interaction in the case of lactose, but not for TYDYF- $\mathrm{NH}_{2}$ or TYDYFR-NH (Figure 18). The results demonstrate that these peptides do not inhibit the interactions between Gal-1 and the cell-surface glycoproteins of Jurkat cells. TYPYFR-NH $\mathrm{NH}_{2}$ and WYKYW- $\mathrm{NH}_{2}$ could not be investigated because of aggregation of the compound at high concentrations or because of fluorescence quenching of the applied organic dye Atto488 by tryptophan side-chains, ${ }^{101,182,183}$ respectively.
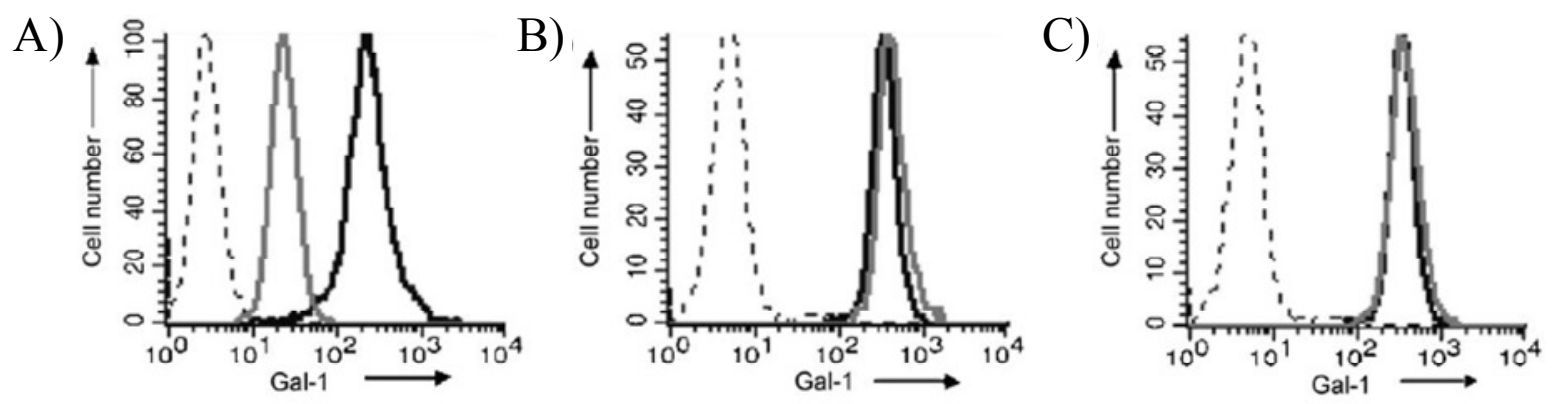

Figure 18. FACS of Gal-1 binding to the leukaemic Jurkat T-cell line. The fluorescence intensity is shown for the control (dashed), Gal-1 (black) and Gal-1 with the ligands (grey). A) lactose, B) TYDYF-NH ${ }_{2}$ and C) TYDYFR- $\mathrm{NH}_{2}$.

There are two possible explanations for the negative results obtained for TYDYF-NH $\mathrm{N}_{2}$ and TYDYFR-NH $\mathrm{N}_{2}$ ( $i$ ) The peptides might act as glycomimetics, but they are not able to compete with the complex glycoconjugates presented on the cell surface over the studied concentration range because their affinity for Gal-1 is lower. (ii) Alternatively, the Tyr-XxxTyr peptides studied do not act on Gal-1 as glycomimetics, and hence they are not able to compete with glycoconjugates for the CRD. In this case, the nature of the interactions between Gal-1, ASF and the peptides must be clarified.

\section{NMR binding tests with Gal-1 and ASF}

STD experiments were performed with TYDYF-NH $\mathrm{NH}_{2}, \mathrm{TYDYFR}^{-\mathrm{NH}_{2}}$ and TYPYFR-NH $\mathrm{N}_{2}$ in the presence of Gal-1. No signal other than noise appeared in the difference spectra (Figure 19B1-D1), rendering a direct peptide-Gal-1 interaction unlikely. Ligand- 
detected measurements with WYKYW- $\mathrm{NH}_{2}$ were not carried out because the magnetization transfer pathway was ambiguous for the heavily aggregating ligand, leading to false-positive results, as was evident from our control experiments. However, the interaction between ASF and WYKYW- $\mathrm{NH}_{2}$ could be shown unequivocally by NMR, as the addition of ASF caused a loss of intensity in the peptide peaks, and line broadening was also observed. Moreover, the STD results suggested that all the peptide ligands studied bound to the glycoprotein (Figure 19B2-D2); the signals of the peptides appeared in the difference spectra. In the corresponding measurements with lactose, no signal was detected in the presence of ASF, which indicated that this interaction was specific for the peptides.

\section{Gal-1}

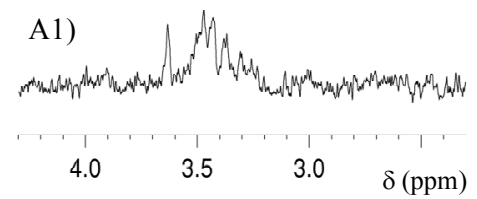

B1)

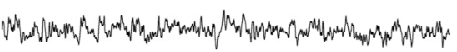

C1)

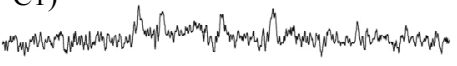

D1)

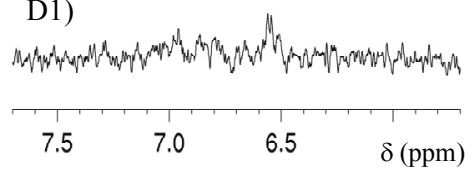

ASF
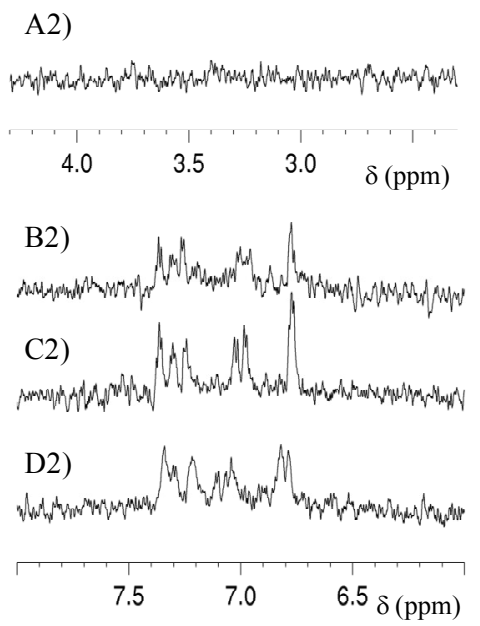

Figure 19. Informative regions of the STD spectra with 1) Gal-1 and 2) ASF for A) lactose reference, B) TYDYF-NH ${ }_{2}$, C) TYDYFR-NH ${ }_{2}$, and D) TYPYFR- $\mathrm{NH}_{2}$.

Relative to lactose $(\mathrm{MW}=342 \mathrm{Da})$, the investigated Tyr-Xxx-Tyr ligands (MW 700-850 Da) demonstrated slower free tumbling than did lactose: at $303 \mathrm{~K}$, lowintensity negative NOESY cross-peaks and at $280 \mathrm{~K}$ positive ones were observed for the free peptides (Figure 20), if diagonal peaks were phased positive. Upon the addition of Gal-1, the cross-peaks remained constant or the intensity changes remained within experimental error, which indicated that interaction between the peptides and Gal-1 was not likely (Figure 20B1-D1). In contrast, upon the addition of ASF to the peptides, the sign and the intensity of the NOE cross-peaks changed, and new peaks appeared in the NOESY spectra (Figure 20B2-D2). The trNOE results with ASF confirmed the ASF-peptide interactions. For TYDYF- $\mathrm{NH}_{2}$, the low-intensity negative cross-peaks disappeared, while strong positive crosspeaks appeared for TYDYFR-NH $\mathrm{N}_{2}$ and TYPYFR-NH $\mathrm{N}_{2}$. These differences in the trNOE patterns for the various peptides indicated a sequence-dependent residence time in the bound state. Only sequential NOE cross-peaks appeared; which might suggest that the peptides bind to ASF in an extended conformation. 

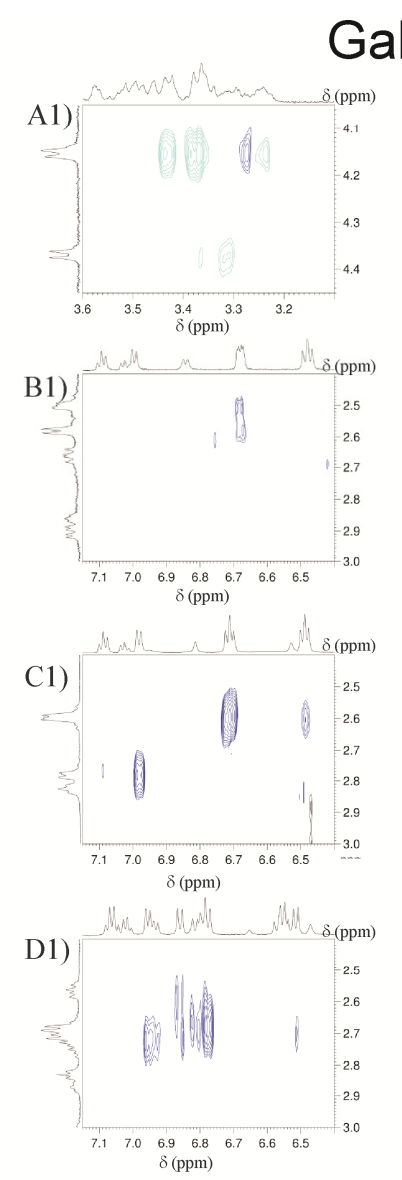

\section{al-1}
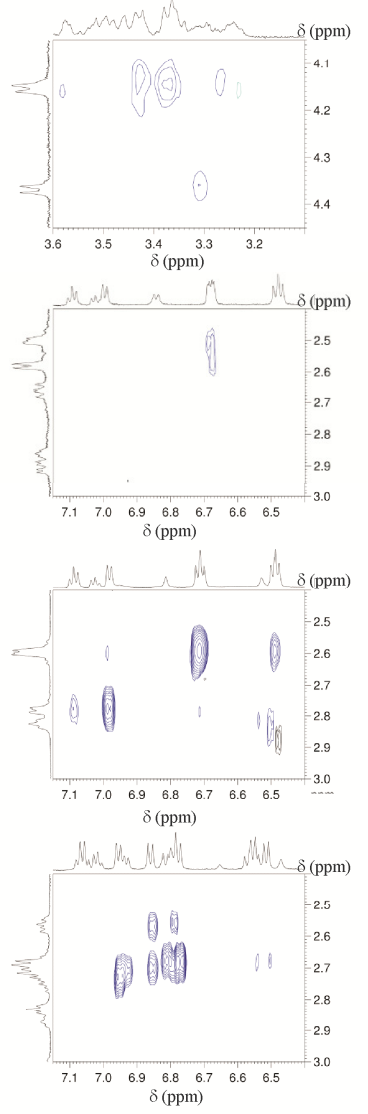

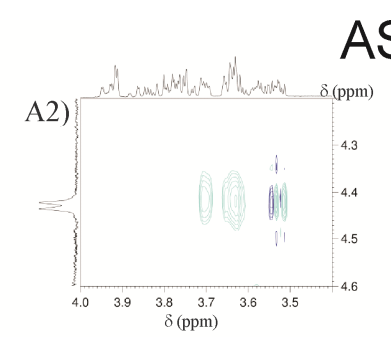

ASF
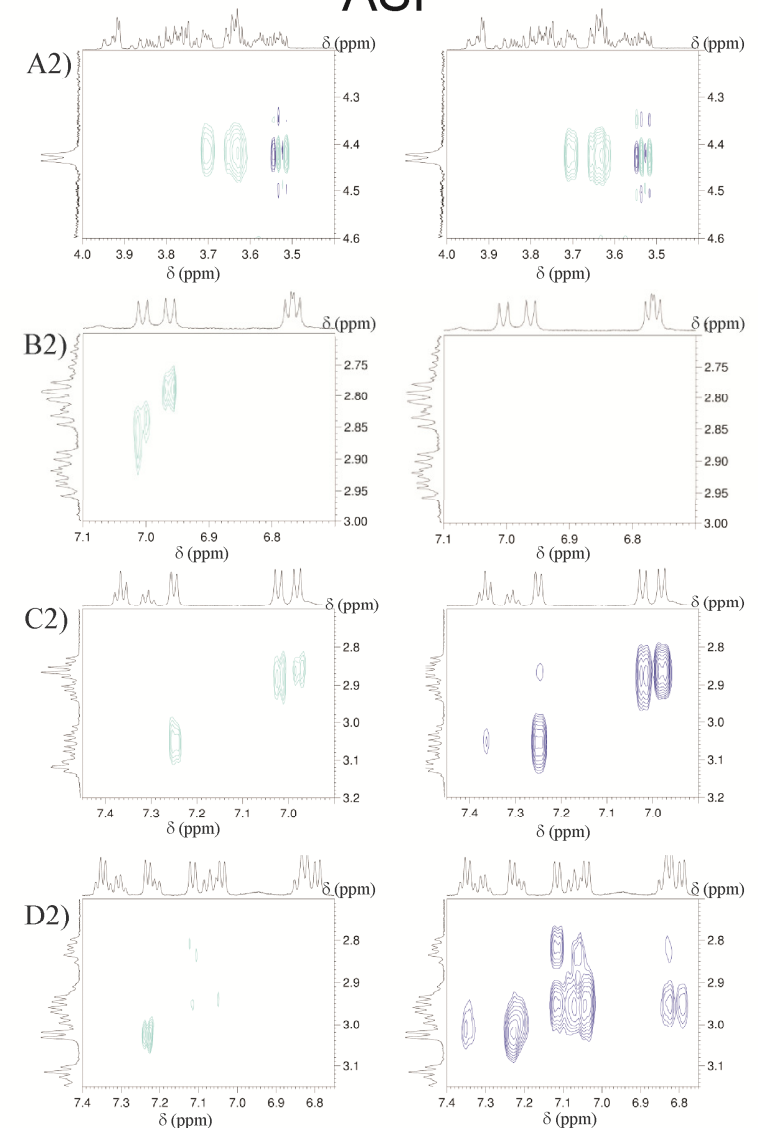

Figure 20. TrNOE results with Gal-1 and ASF. The different columns present the different controls and proteins: 1) control (left) and with Gal-1 (right); 2) control (left) and with ASF (right). The rows present the results for the different ligands: A) lactose reference, B) TYDYF-NH $\mathrm{N}_{2}$, C) TYDYFR- $\mathrm{NH}_{2}$ and D) TYPYFR-NH $\mathrm{N}_{2}$. A change in the sign of the cross-peaks (cyan: negative, blue: positive) relative to the control indicates the binding of the compound to Gal-1 or ASF.

A missing signal in STD or the absence of intensity changes in trNOE does not rule out a binding event. STD and trNOE are suitable for the detection of weak binding $\left(K_{d} \approx 10^{-2}-10^{-7} \mathrm{M}\right)$; a prerequisite of these techniques is a sufficiently high dissociation rate $\left(k_{o f f}\right){ }^{26}$ For a peptide ligand, $k_{\text {off }}$ can be low, even for weak binding, if the dissociation is accompanied by slow conformational rearrangements. For such a scenario, ${ }^{15} \mathrm{~N}$ HSQC titration is the methodology of choice to explore interactions. In order to confirm our hypothesis concerning the binding properties of the Tyr-Xxx-Tyr peptides and to exclude the specific binding of the peptides to Gal-1, ${ }^{15} \mathrm{~N}$ HSQC titrations were performed. Titration experiments demonstrated that none of the peptides TYDYF- $\mathrm{NH}_{2}, \mathrm{TYDYFR} \mathrm{NH}_{2}$, TYPYFR-NH $\mathrm{N}_{2}$ and WYKYW-NH${ }_{2}$ affected either the peak positions or the intensities of the cross-peaks in the ${ }^{15} \mathrm{~N}$ HSQC spectra. Even when the peptide concentrations were increased to saturation $(\sim 2-4 \mathrm{mM})$, no change was detected. If binding between the peptides and Gal-1 had occurred, it could have been measured, as the apparent $K_{d}$ estimated for Tyr-Xxx-Tyr peptides from the ELISA would have facilitated the ${ }^{15} \mathrm{~N}$ HSQC detection. These results 
confirmed the STD and trNOE findings; the peptide ligands do not bind to Gal-1 or $K_{d}$ is significantly higher.

NMR binding tests with Gal-1 and ASF yielded an explanation for the apparently inconsistent results obtained from ELISA and cell-based experiments: while STD, trNOE and ${ }^{15} \mathrm{~N}$ HSQC titrations uniformly demonstrated that the Tyr-Xxx-Tyr sequences do not bind to Gal-1, the ligand-detected binding tests revealed weak binding to ASF. The present Tyr-XxxTyr peptides proved effective in the competitive tests not because they were able to bind to Gal-1 and to replace ASF, but rather because of their interactions with the glycoprotein ASF. Tyr-Xxx-Tyr peptides affected the carbohydrate antennae of ASF in a way that prevents Gal-1 binding. The ASF binding property of the sequences studied might involve the carbohydrate chains and the protein surface of the ASF, thereby modifying the presentation of the carbohydrate antennae, and the molecular mechanism of inhibition is of an allosteric nature (Figure 21). Additional binding tests after the hydrolysis of glycans from ASF would answer the question of whether the compounds interact with the complex carbohydrate chains or with the protein.

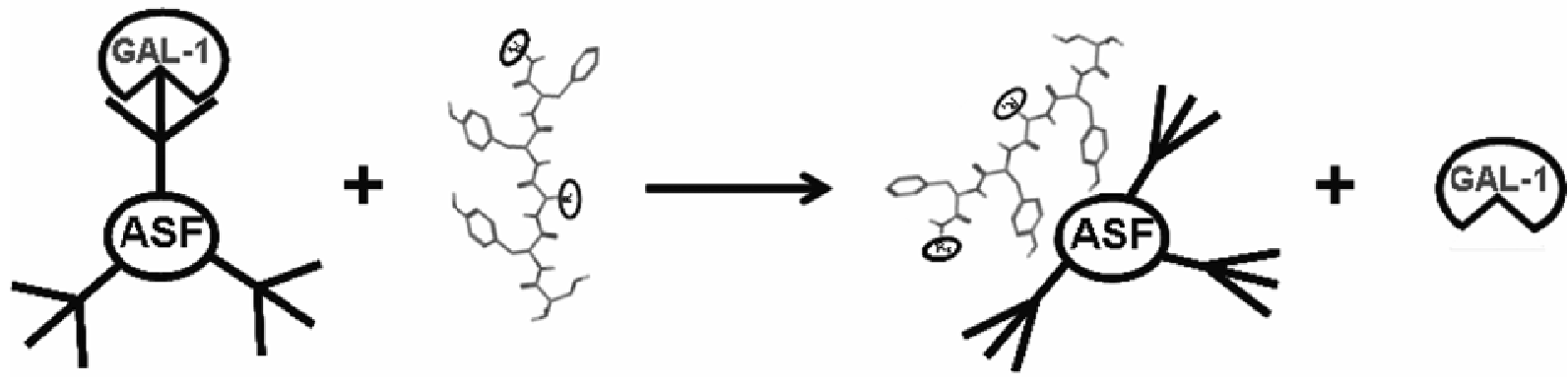

Figure 21. Proposed mechanism for the inhibition of the Gal-1-ASF interaction by Tyr-Xxx-Tyr type peptides.

\subsection{Binding of neuroprotective peptides and foldamers to Aß1-42 aggregates}

\subsubsection{Ligand-induced flocculation of A $\beta 1-42$ fibrils}

Signal quenching of short peptides and ThT in the presence of Aß1-42 aggregates

A $\beta 1-42$ fibrils are invisible to solution NMR spectroscopy, but they can be investigated by ligand-observed methods. The short neuroprotective peptides LPFFD, LPYFD-NH $\mathrm{N}_{2}$ FRHDS-NH $\mathrm{NH}_{2}$ and RIIGL-NH $\mathrm{N}_{2}$, which exhibited neuroprotective effects against fibrillar A $\beta 1-42$ in vitro in 3-(4,5-dimethylthiazol-2-yl)-2,5-diphenyltetrazolium bromide (MTT), and in vivo in electrophysiology tests(Table 2), ${ }^{184-187}$ were tested by using NMR spectroscopy. As a negative control, the inactive GGGGG- $\mathrm{NH}_{2}$ was utilized. NMR spectroscopic binding tests were carried out by using preformed mature fibrils of $A \beta 1-42$ as a target in an A $\beta 1-42$ :ligand ratio of 1:5. The signal intensity of the pure ligand in the ${ }^{1} \mathrm{H}$ NMR spectra was taken as $100 \%$ 
and the bound fraction of the ligands was calculated. The bound fraction of the neuroprotective peptides varied in the range 9-26\% (Table 2).

Table 2. Neuroprotective effects and bound fractions of the ligands. MTT test data are referenced to a cell viability of $52 \%$ for fibrillar $A \beta 1-42$.

\begin{tabular}{|c|c|c|}
\hline Ligand & $\begin{array}{l}\text { MTT cell viability } \\
\text { test }[\%]^{184,186,187} \\
\end{array}$ & $\begin{array}{l}\text { Fraction bound to } \\
\text { fibrillar A } \beta 1-42[\%]\end{array}$ \\
\hline $\begin{array}{l}\text { LPFFD } \\
\end{array}$ & 84 & 17 \\
\hline LPYFD-NH ${ }_{2}$ & 92 & 19 \\
\hline FRHDS-NH ${ }_{2}$ & 89 & 26 \\
\hline RIIGL-NH 2 & 86 & 9 \\
\hline GGGGG-NH $_{2}$ & 64 & 0 \\
\hline ThT & - & 60 \\
\hline
\end{tabular}

Assuming that one ligand is bound per A $\beta 1-42$ monomer, weak millimolar dissociation constants can be computed by using the Hill-Langmuir equation. It should be noted that no significant line broadening was detected for the ligand resonances, which would otherwise be expected for the fast exchange of a weakly bound ligand. For FRHDS- $\mathrm{NH}_{2}$, the bound fraction exceeded the 1:1 limit. For the negative control GGGGG-NH$H_{2}$, no binding-related signal quenching was observed. The binding tests based on the signal quenching of the ligand were also performed for ThT. As expected, ThT bound to fibrillar A $\beta 1-42$ with a ligand binding ratio of $60 \%$, which indicates that 3 ThT molecules were bound to each A $\beta 1-42$ monomer. To elucidate the effect of LPFFD on ThT binding and vice versa, two samples were prepared: for Sample A, LPFFD was mixed with fibrillar A $\beta 1-42$, and after 50 min ThT was added, while for Sample B, ThT was mixed with fibrillar A $\beta 1-42$, and after 50 min LPFFD was added. ThT has a relatively high affinity for $\mathrm{A} \beta$ fibrils $\left(K_{d}\right.$ ranging from high $\mathrm{nM}$ to low $\mu \mathrm{M}^{124,125}$ ); therefore, if their binding sites overlap, the immediate replacement of LPFFD by ThT is to be expected. In the presence of LPFFD, the ThT binding ratio increased significantly for both samples (Table 3), which suggests that LPFFD does not decrease the $\beta$ sheet content of $A \beta 1-42$. Moreover, lower bound fractions were observed for LPFFD at the first measurement points, which indicates partial replacement.

Table 3. Fractions of LPFFD and ThT bound to A $\beta 1-42$ fibrils in the different samples at the first measurement point $(\mathrm{t}=0 \mathrm{~h})$.

\begin{tabular}{lccc}
\hline \multirow{2}{*}{ Ligand } & \multicolumn{3}{c}{ Fraction bound in NMR tests [\%] } \\
\cline { 2 - 4 } & Single ligand & $\begin{array}{c}\text { Sample } A \\
\text { (LPFFD added first) }\end{array}$ & $\begin{array}{c}\text { Sample } B \\
\text { (ThT added first) }\end{array}$ \\
\hline \hline LPFFD & 17 & 13 & 13 \\
ThT & 60 & 74 & 66
\end{tabular}




\section{Time-dependence of LPFFD and ThT binding}

The time-dependent features of LPFFD and/or ThT binding to A $\beta 1-42$ were monitored for $24 \mathrm{~h}$ (Figures 22 and 23). It should be emphasized that the most significant changes in the bound fraction took place in the first $4 \mathrm{~h}$ of the observation period.

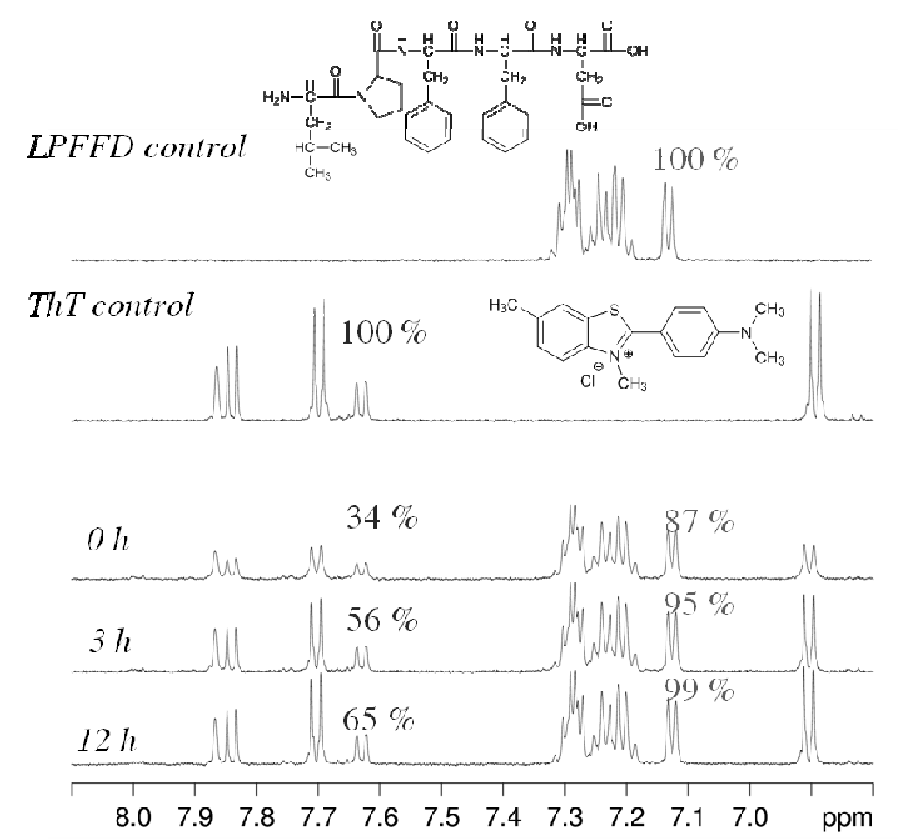

Figure 22. Signal quenching of ThT and LPFFD binding to A $\beta 1-42$.

Within $12 \mathrm{~h}$, the ligand binding ratio of LPFFD alone was found to converge from the initial $17 \%$ to a final value of $6 \%$. For Sample $A$ (LPFFD added first), the rate of decrease was lower than that for the ThT $+\mathrm{A} \beta 1-42$ sample, but a steeper domain was still present during the first $3 \mathrm{~h}$. After $17 \mathrm{~h}$, the bound fraction of LPFFD was zero, while the ThT binding ratio had dropped from the initial $74 \%$ to $47 \%$; both values are significantly higher than the binding ratios observed for the ThT+A $\beta 1-42$ system. For Sample $B$ (ThT added first), the decreased rate pattern was very similar to that for the ThT $+A \beta 1-42$ mixture. Soon after $3 \mathrm{~h}$, the LPFFD binding ratio attained a negligibly low value, but the ThT bound fraction dropped from the initial $66 \%$ to $35 \%$, values which are slightly higher than those for the $\mathrm{ThT}+\mathrm{A} \beta 1-42$ system. The decay in the first $4 \mathrm{~h}$ can be best fitted with a linear equation (slopes are given in the caption of Figure 23), but a curvature can be detected; this indicates slightly increasing slopes. This finding can be explained by sedimentation processes.

As precipitates were observed at the bottom of the test tubes, and floccules were attached to the tube wall, the samples were resuspended and the behaviour of the mixtures was tested for another $24 \mathrm{~h}$ (Figure 23). After resuspension of the sample, LPFFD exhibited a constant binding ratio of $6 \%$, which is identical to the value measured before shake-up. In the resuspended ThT $+\mathrm{A} \beta 1-42$ mixture, the bound fraction of ThT was initially higher at $69 \%$, which had declined to $45 \%$ after an additional 24 h of observation. Resuspended Sample A 
and Sample $B$ exhibited practically the same behaviour: $(i)$ initial ThT-bound fractions of around $70 \%$, which slowly decreased to $\sim 60 \%$; and (ii) initial binding ratios of $10 \%$ for LPFFD, which fell to zero at the same relative rate as for ThT. STD spectra recorded on the resuspended samples confirmed the existence of the binding between the fibrillar A $\beta 1-42$ and the ligands. In the absence of A $\beta 1-42$, no signal quenching of the ligands was observed.

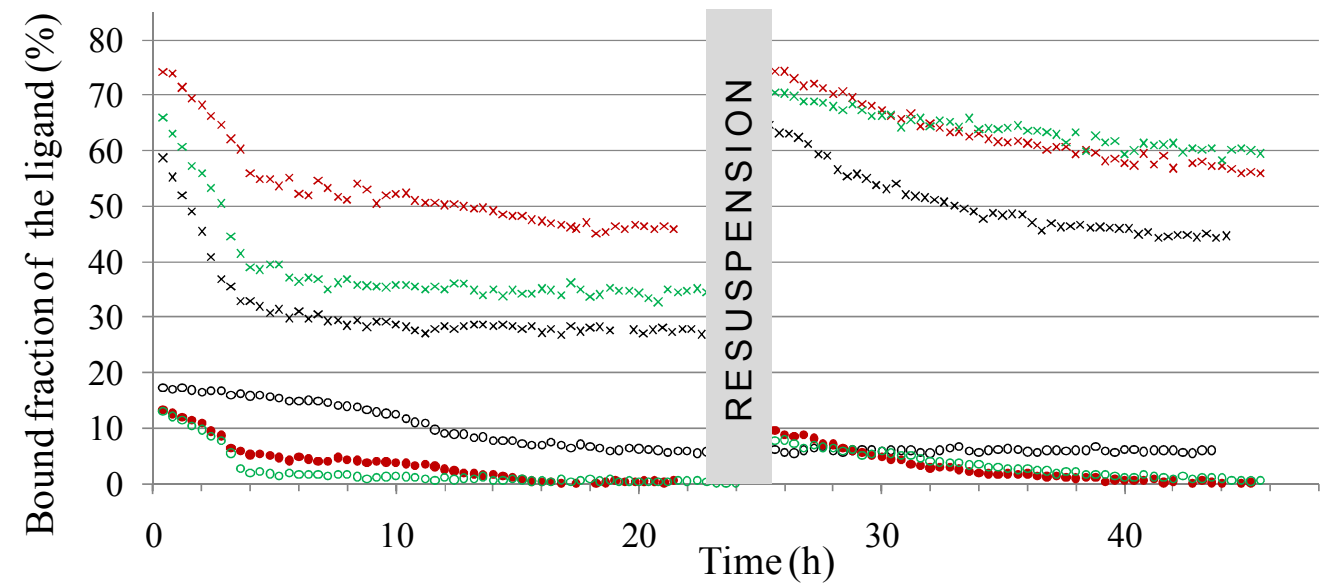

Figure 23. Time dependence of the bound fraction of LPFFD and ThT after sample preparation. $\odot$ : LPFFD alone, x: ThT alone, $\bullet$ : LPFFD in Sample A (LPFFD added first), x: ThT in Sample A, $\circ$ LPFFD in Sample $B$ (ThT added first), $\mathrm{x}$ : ThT in Sample B. For ThT, the slopes fitted for the first $4 \mathrm{~h}$ are $-7.75,-7.56$ and $4.89 \% / \mathrm{h}$ for ThT alone, and in Sample $A$ and $B$, respectively; while the slopes for LPFFD in the first $4 \mathrm{~h}$ are $-0.38,-3.10$ and $-2.40 \% / \mathrm{h}$ for the peptide alone, and in Sample $A$ and $B$, respectively.

As a conclusion, time-dependent NMR measurements demonstrated that the binding phenomena are transient in the first $3 \mathrm{~h}$ and $12 \mathrm{~h}$ for ThT and LPFFD, respectively. It is very likely that the ligands induce particle size changes, thereby causing faster sedimentation and removal of the weak ligand-fibril interactions from the NMR detection volume, i.e. decay of the bound fraction. It should be noted that, under the measurement conditions applied, no resonance of oligomer or monomer-sized A $\beta 1-42$ (MW $<60-100 \mathrm{kDa}$ ) which would have resulted from possible disaggregation of the fibrils, was detected by NMR spectroscopy. DLS, TEM and $\zeta$-potential measurements proved the sedimentation and flocculation hypothesis, too (Appendix, Figure A1). On the basis of the results, ligand-induced flocculation of A $\beta$ fibrils was proposed (Figure 24.).

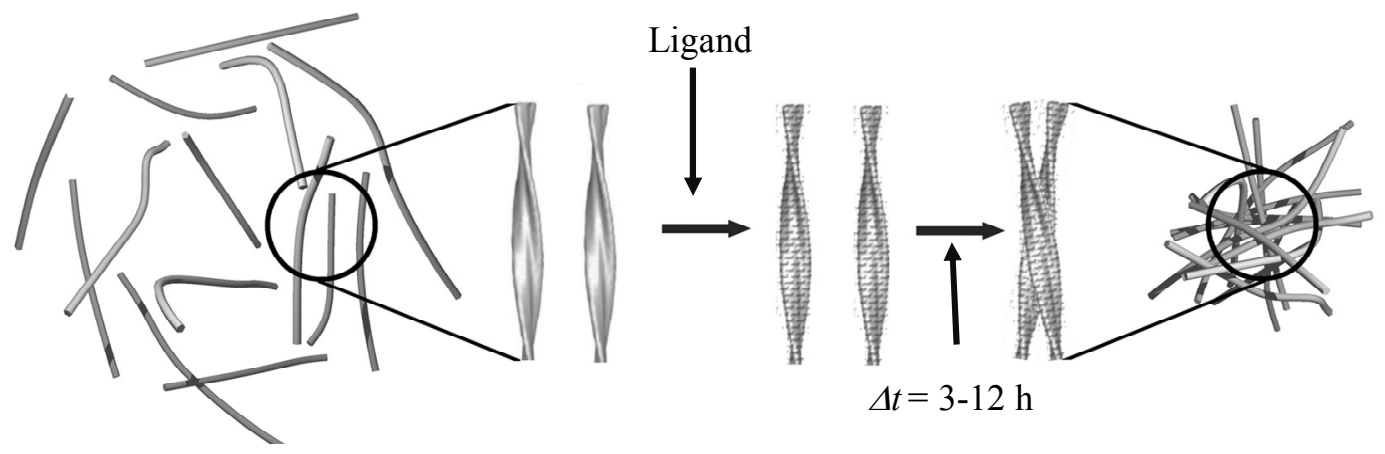

Figure 24. Schematic representation of the ligand-induced flocculation of fibrillar A $\beta 1-42$ by non-covalent cross-linking. The fibril model is taken from ref. [188]. 


\subsubsection{Foldamers binding to A $\beta 1-42$ oligomers}

\section{Foldamer library screening with Aß1-42 oligomers}

Since several studies pointed to the neurotoxic nature of soluble $A \beta$ aggregates, ${ }^{9}, 10,126$ we switched to the investigation of $A \beta$ oligomers. Our goal was to target $A \beta 1-42$ oligomers with foldamers, which, thanks to their diversity, ${ }^{189}$ tunable secondary structure and resistance to enzymatic degradation, ${ }^{152-154}$ have emerged as a novel class of drug scaffolds. With appropriate backbone stereochemistry ${ }^{150}$ and by incorporating 2-3 hydrophilic amino acids into the sequence, short water-stable peptidic foldamers can be constructed, which can direct 3-4 side-chains towards a flat protein surface. In general, they can exhibit only weak $\left(K_{d}>10 \mu \mathrm{M}\right)$ binding, which can be detected by NMR methods.

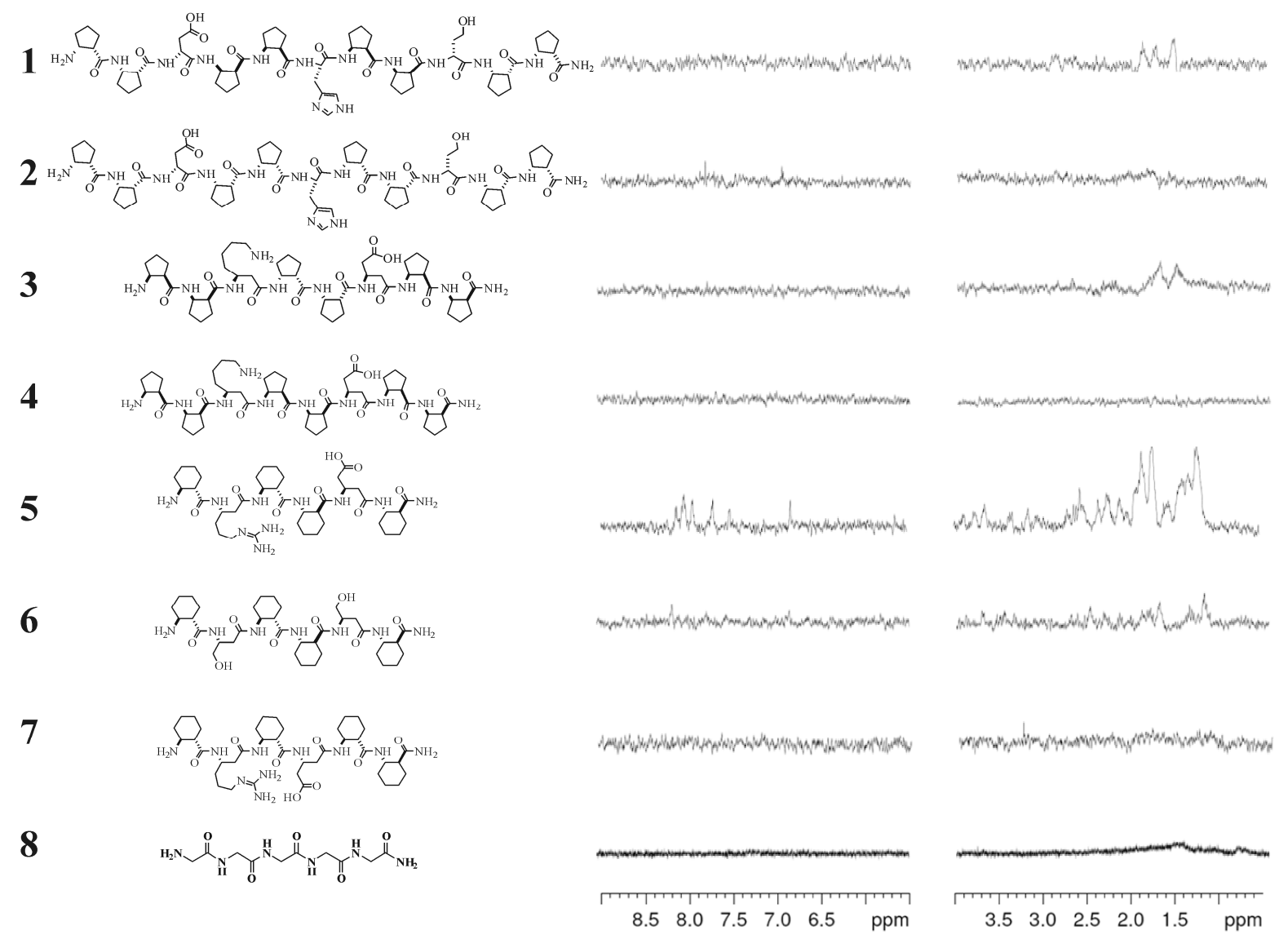

Figure 25. Foldamer structures investigated with A $\beta 1-42$ oligomers (left) and the corresponding STD spectra (right). The peptides exhibited various secondary structures: well-defined H9-12 (2), H14/16 (4), H14 (5-8), turn-like (3), unstructured with helical fragments (1) and the random coil negative control (8).

A small foldamer library was screened, which contained peptides constructed from $\beta^{3}$-amino acids with proteinogenic side-chains, various diastereomers of the alicyclic $\beta$-amino acids $\mathrm{ACHC}$ and $\mathrm{ACPC}^{149}$ and natural $\alpha$-amino acids. Diverse secondary structures and sidechain chemistry patterns were applied as potential recognition segments (Figure 25). STD and trNOE were employed to screen the weak foldamer-A $\beta$ interactions. Serendipitously, compound $\mathbf{5}$ exhibited well-detectable signals in the difference spectrum (Figure 25) and the 
binding was also confirmed via trNOE spectroscopy. The structurally related amphiphilic helices 2, 4 and 6 displayed only weak or no saturation transfer effect at all. No signal was observed for $\mathbf{1}$ and 3, supporting the importance of the helical conformation and the zwitterionic pharmacophore in the binding. To examine the necessity of the proximity of the ion pair for binding, 7 was tested, but no interaction was found in STD. This suggests that the discovered pharmacophore is specific: changing the arrangement/nature of the hydrophobic side-chains and the distance between the charged side-chains abolishes the binding.

The structure refinement indicated that 5 adopts an H14 helix in aqueous buffer. Thus, the $\beta^{3}$-homoarginine $\left(\beta^{3}\right.$ hArg) and $\beta^{3}$-homoaspartate $\left(\beta^{3}\right.$ hAsp) side-chains are in $i-i+3$ juxtaposition (Figure 26A). The long-range NOE interactions characteristic of the H14 helix were also observed in the trNOE spectrum recorded for 5 in the presence of $A \beta 1-42$ oligomers (Figure 26B, C), which strongly suggests that the binding conformation of 5 is H14 helix.

A)
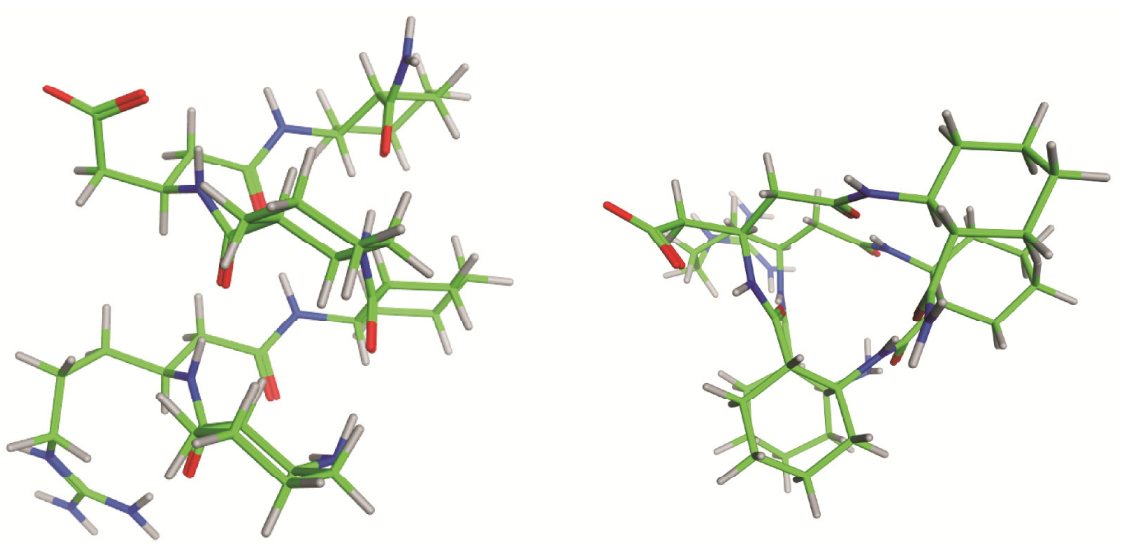

B)

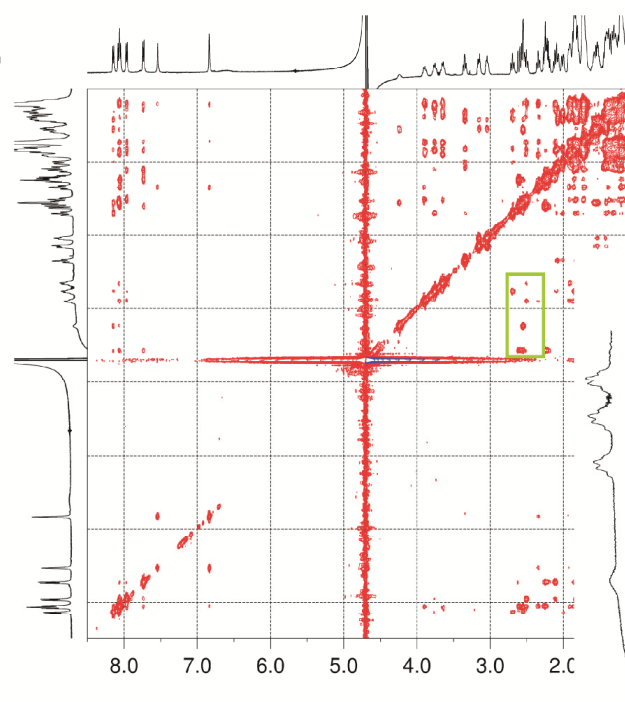

C)

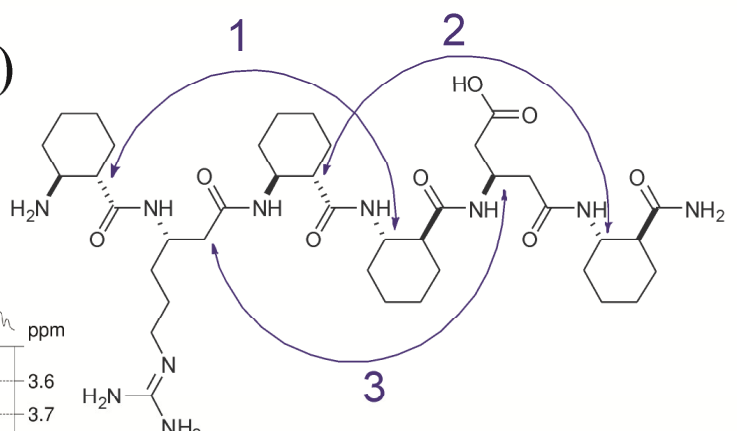

Figure 26. NMR-derived H14 helix conformation of 5. The H14 helix structure (A) was also supported by the trNOE spectra recorded on the mixture of 5 and the A $\beta 1-42$ oligomers (B). Cross-peaks proving the $\mathrm{H} 14$ are indicated by the numbers in the inset of B) and by the corresponding arrows in C). 


\section{Design of multivalent foldamers}

It is very likely that $A \beta$ oligomers have a periodic structure with multiple binding patches for 5. For targets with multiple binding sites, multivalent ligands may enhance the selectivity and affinity of the interactions. ${ }^{190-194}$ Dendrimers were also reported to bind to A $\beta .{ }^{195,196}$ The effects of multivalency on the binding properties were studied with the help of a divalent $\mathbf{9}$ and a tetravalent conjugate $\mathbf{1 0}$ by functionalizing the $\mathrm{C}$ terminus of $\mathbf{5}$ with a GlyGly-Cys linker and ligating it to a bis-maleimido-butane (BMB) or a four-armed tetramaleimidopropionyl poly-amidoamine generation-zero (G0-PAMAM) dendrimer (TMP), respectively. To gain initial insight into the SAR features of the tetravalent ligands, $\mathbf{6}, 7$ and $\mathbf{8}$ were also coupled to the G0-PAMAM template, leading to compounds 11, 12 and 13, respectively (Figure 27A).

A)

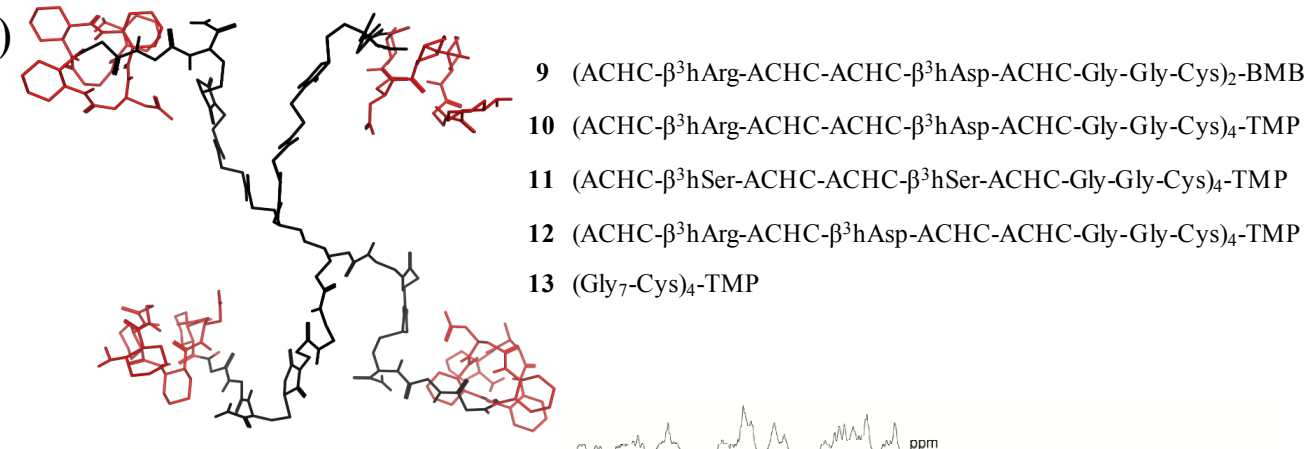

B)
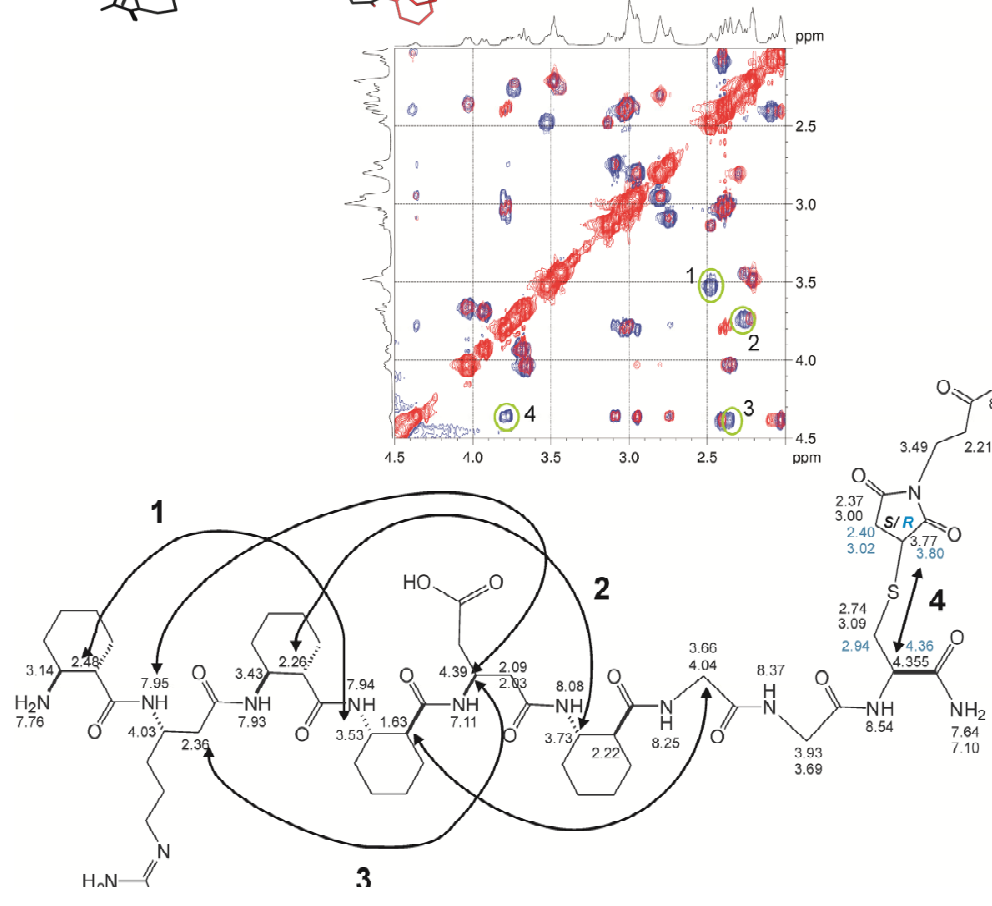

Figure 27. A) Foldamer-TMP and $-\mathrm{BMB}$ conjugates studied and the representative $3 \mathrm{D}$ structure of $\mathbf{1 0}$ (left). The H14 helical conformation adopted by the foldamer segments in water is indicated (red), whereas the flexible linker is in an arbitrary conformation (black). The $(1 S, 2 S)$-2-ACHC was used for all the conjugates, and $\beta^{3}$ hSer is $\beta^{3}$-(R)-homoserine. B) NMR assignments and long-range NOE interactions of the foldamer segment and the maleimide diastereomers of 10. $S$ and $R$ maleimide diastereomers are indicated in black and blue, respectively. The cross-peaks in the overlaid TOCSY (red) and ROESY (blue) spectra prove the $\mathrm{H} 14$ structure of the foldamers. 
The foldamer segments of conjugates 9-12 exhibited long-range NOE interactions characteristic of the H14 helix (Figure 27B), whereas the dendrimer moiety remained unstructured. Since the addition of the thiol group to the maleimido moiety generates an additional stereogenic centre, the NMR resonances of the Cys-maleimide linker region were split. According to the integrals of the corresponding peaks, $R$ and $S$ configurations can be found in equimolar ratio. Since this moiety is in the flexible part of the molecule, the effect of the chiral centre does not propagate further towards either the foldamer part or the PAMAM template.

Due to their considerably greater size $(\mathrm{MW} \sim 5 \mathrm{kDa})$, the binding of multivalent foldamers 9-12 could not be studied by STD or trNOE. The addition of $\mathbf{1 0}$ to the A $\beta 1-42$ oligomer sample caused a loss in intensity of the A $\beta$ NMR signals and precipitates were observed in the NMR tube. In the inverse experiment, where $A \beta$ oligomers were added to the conjugates, similar effects were noticed. These findings-suggested tight binding between A $\beta$ oligomer species and $\mathbf{1 0}$ and a potential cross-linking mechanism.

\section{ITC experiments with multivalent foldamers and Aß1-42 oligomers}

In order to characterize the binding of $\mathbf{1 0}$ to $A \beta 1-42$ oligomers, the interaction was monitored by means of ITC. The titrations were run at $288 \mathrm{~K}$ in order to improve the signalto-noise ratio, and just above the precipitation limit as the ITC method is sensitive to the thermal noise caused by the stirring of large particles. The dilution heat of the $A \beta$ oligomer samples was constant and negligible. The heat of ligand dilution was subtracted from the enthalpogram.

The sample containing $72 \mu \mathrm{M} \mathrm{A} \beta 1-42$ in the titration cell exhibited a two-stage enthalpogram (Figure 28A). As the target is inherently inhomogeneous, and an a priori model of the binding events is not available, the apparent dissociation constants $\left(K_{d}\right)$, the number of sites per A $\beta 1-42$ peptide $(n)$ and the binding enthalpies $\left(\Delta H_{b}\right)$ were estimated by non-linear fitting to the two-independent-site model. The first binding step had $K_{d}=6.9 \pm 1.4 \mathrm{nM}, \Delta H_{b}=$ $7.24 \pm 0.05 \mathrm{kcal} \mathrm{mol}^{-1}$ and $n=0.041 \pm 0.00089$, whereas the lower affinity interaction was characterized by $K_{d}{ }^{\prime}=281.1 \pm 38.7 \mathrm{nM}, \Delta H_{b}{ }^{\prime}=2.58 \pm 0.02 \mathrm{kcal} \mathrm{mol}^{-1}$ and $n^{\prime}=0.18 \pm 0.002$. ITC titrations conducted with a $36 \mu \mathrm{M}$ sample (the lowest possible that still maintains an acceptable signal-to-noise ratio) resulted in similar findings (Figure 28B): $K_{d}=2.2 \pm 2 \mathrm{nM}$, $\Delta H_{b}=6.4 \pm 0.03 \mathrm{kcal} \mathrm{mol}^{-1}$ and $n=0.045 \pm 0.002, K_{d}{ }^{\prime}=743.4 \pm 107.5 \mathrm{nM}, \Delta H_{b}{ }^{\prime}=2.52 \pm$ $0.02 \mathrm{kcal} \mathrm{mol}^{-1}$ and $n^{\prime}=0.54 \pm 0.007$. There was no significant change in the parameters for the first stage, but the dilution led to a higher apparent $K_{d}$ ' in the second stage. The binding stoichiometry also changed from an $A \beta: 10$ ratio of 5.6:1 to one of $\sim 1.9: 1$, indicating that the 
ligand successfully competes for the binding sites which are not shielded by the early onset of the precipitation.
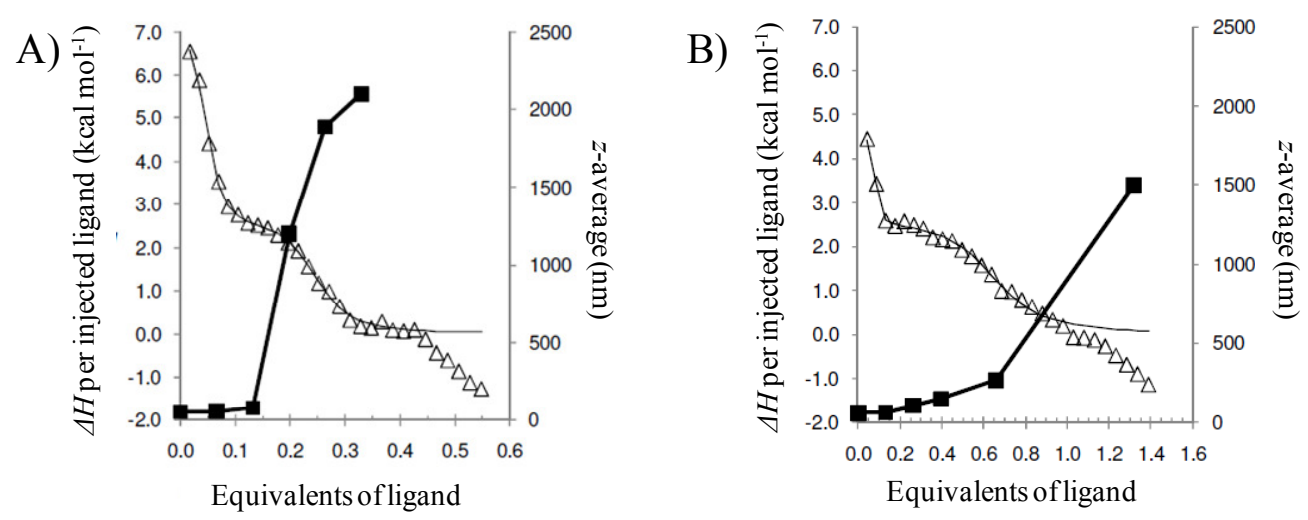

Figure 28. Titration of the $A \beta$ oligomers with 10. ITC enthalpogram (triangles, left scale) and the corresponding $\mathrm{z}$-average diameters (squares, right scales). The $\mathrm{A} \beta$ concentration was $72 \mu \mathrm{M}$ and $36 \mu \mathrm{M}$ in A) and B), respectively.

According to parallel DLS measurements, the precipitation started just before the equivalence point of the second stage, but the first binding event did not affect the average particle size. TEM images confirmed the affinity precipitation for the oligomers, because $\mathbf{1 0}$ caused association of the spherical oligomers a few $\mathrm{nm}$ in size into bundles of aggregates in the $\mu \mathrm{m}$ range.

A)

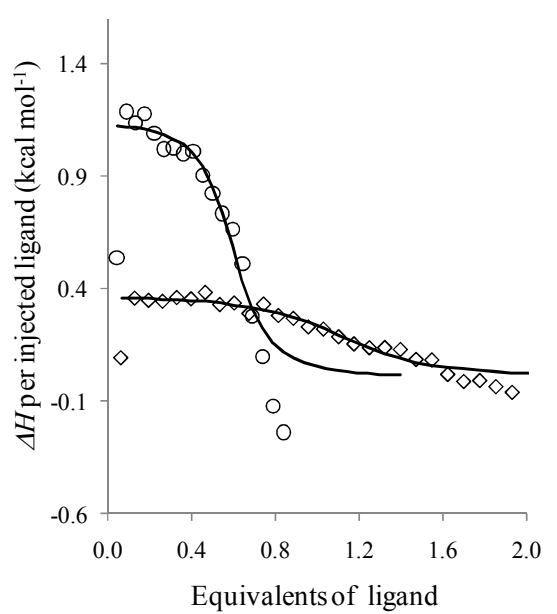

B)

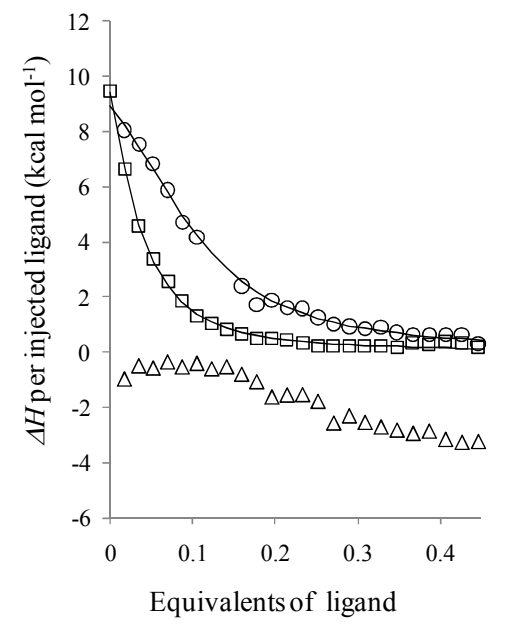

Figure 29. ITC enthalpograms for the titration of the $72 \mu \mathrm{M} \mathrm{A} \beta$ oligomer with peptide conjugates. A) the divalent 9 (circles) and $\mathbf{5}$ (diamonds). Fitted curves are given as solid lines. B) 11 (square), 12 (circles) and 13 (triangles).

The ITC titration with the divalent 9 resulted in a single-stage enthalpogram (Figure 29A) $\left(K_{d}=721.4 \pm 120.1 \mathrm{nM}, \Delta H_{b}=1.1 \pm 0.12 \mathrm{kcal} \mathrm{mol}^{-1}\right.$ and $\left.n=0.53 \pm 0.003\right)$ and the parameters correlated well with those measured for $\mathbf{1 0}$ in the second stage. The rather low endothermic $\Delta H_{b}$ for 5 made fitting difficult, but the stoichiometry clearly increased to $\sim 1: 1$ $(n=0.97 \pm 0.05)$ and $K_{d}$ increased to above $2 \mu \mathrm{M}$. Neither the divalent 9 nor the monovalent 5 led to concentration-dependent precipitation. ITC measurements with 11, 12 and $\mathbf{1 3}$ did not 
reveal any tight binding to the A $\beta$ species (Figure 29B). Fitting of the titration curves revealed weak $\left(K_{d}>2 \mu \mathrm{M}\right)$ and substoichiometric interactions for both 11 and 12. This indicated that these changes in the recognition segments lead to the loss of tight and specific binding. For 13, the curve fitting did not converge, because the exothermic heat response (negative $\Delta H$ values) with negative slope cannot be associated with a binding equilibrium.

My colleagues supplemented the results with several experiments. The nanomolar affinity of $\mathbf{1 0}$ was also confirmed by a capture ELISA (Figure A2A), where biotin-labelled 10 was attached to streptavidin-functionalized microplates. For the foldamer-dendrimer conjugates with modified recognition segments (biotinyl-11 and -12), the $\mathrm{IC}_{50}$ values shifted to above $4 \mu \mathrm{M}$, indicating only weak interactions; and the $\mathrm{IC}_{50}$ values for biotinyl-5, $\mathbf{- 9}$ and -10 exhibited the same increasing trend as observed for the apparent $K_{d}$-s in the ITC titrations. Dot blot experiments performed with $\mathrm{A} \beta$ fractions resulting from the size-exclusion chromatography (SEC) separation of A $\beta 1-42$ oligomers revealed that $\mathbf{1 0}$ preferentially binds to the LMW (4-22 kDa) components at low nanomolar concentration and is also able to bind to the HMW components at a submicromolar level (Figure A2B, C). As the titrations and binding assays indicated that the tetravalent foldamer conjugate $\mathbf{1 0}$ has nanomolar affinity for A $\beta$ oligomers, its efficacy was tested in an ex vivo hippocampus slice LTP model. While the negative control $\mathbf{1 3}$ and the divalent $\mathbf{9}$ had no effect on the synaptotoxicity of the applied $\mathrm{A} \beta 1-42,10$ was able to protect against the synaptic plasticity damage caused by A $\beta 1-42$ oligomers (data not shown).

\subsection{Conclusions}

Ligand-detected binding tests were optimized for lactose-complexed Gal-1, and the backbone resonances of Gal-1 necessary for the protein-detected experiments were successfully assigned. Ligand- and protein-observed NMR binding tests performed with Gal-1 pointed to the dynamic nature of the lectin: ${ }^{15} \mathrm{~N}$ HSQC titration revealed structural changes even distant from the $\mathrm{CRD}$, and ${ }^{15} \mathrm{~N}$ relaxation measurements with model-free analysis revealed high flexibility for the lactose binding loop L4. As the CRD is highly affected by internal motions, the dynamic features of Gal-1 should be considered when new ligands are designed. The phenomenon implies that the structure-based design of new Gal-1 inhibitors should take into account the flexibility and the dynamic features of the lectin.

STD is a valuable tool for study of the binding of small molecules to large biomolecules and to obtain detailed information on the binding epitopes. However, its sensitivity depends on the efficiency of the saturation of protein signals, and also on the intermolecular magnetization transfer from the protein to the bound ligand. The binding site with flexible loops of Gal-1 complexed with lactose served as a model system for GS-STD experiments. 
The ${ }^{15} \mathrm{~N}$ and ${ }^{13} \mathrm{C}$ GS-STD experiments with the Gal-1-lactose model system demonstrated that ligand epitopes in direct contact with flexible atoms can be successfully identified. The proposed GS excitation schemes ensure the direct and efficient saturation of protein resonances. These experimental variants therefore broaden the scope of STD studies to include smaller and/or more dynamic targets. The experiments revealed that GS-STD can be a powerful approach to mapping the binding epitope of a ligand even in the presence of enhanced dynamics (e.g., in the case of small hosts, unstructured proteins) and internal motions of the target protein and its complex. The different GS excitation schemes indicated that the signal-intensity pattern of the STD spectra is affected by both the type and the spatial distribution of the excited 'transmitter' nuclei and by the magnetization transfer (spin diffusion). In particular, 'chemical' and spatial selectivity was observed for the ${ }^{1} \mathrm{H}$ STD (selective for Val, Leu and Ile side-chain protons) and for the ${ }^{13} \mathrm{C}_{\mathrm{Ar}} \mathrm{GS}$ excitation scheme (Phe, Tyr, His and Trp residues), whereas the ${ }^{13} \mathrm{C}_{\text {aliphatic }}$ GS and ${ }^{15} \mathrm{~N}$ GS saturation resulted in a uniform saturation, yielding STD spectra with more and higher-intensity peaks. In conclusion, considering the different spatial and chemical selectivity of the excitation schemes, the observation of local effects might be feasible. The technical advantage of the GS-STD experiments over the standard ${ }^{1} \mathrm{H}$ STD is that it avoids the spectral overlap problem (and consequently it is more robust), it can be applied to protein targets of small to medium size, and it is more sensitive due to direct saturation at multiple sites. However, the combined band and group-selective approach for ${ }^{13} \mathrm{C}$ could have limitations in the case of spectral overlap.

The Tyr-Xxx-Tyr peptide motif has been reported to be a putative glycomimetic sequence, mainly on the basis of its inhibitory effect on the interactions between Gal-1 and ASF. However, the results regarding the efficacy of the Tyr-Xxx-Tyr motif as a glycomimetic inhibitor are still controversial. NMR binding tests with ASF yielded an explanation for the apparently inconsistent results obtained from ELISA and cell-based experiments: while STD, trNOE and ${ }^{15} \mathrm{~N}$ HSQC titrations uniformly revealed that the Tyr-Xxx-Tyr sequences do not bind to Gal-1, the ligand-detected binding tests showed weak binding to ASF. The conception of the putative glycomimetic sequences containing the Tyr-Xxx-Tyr motif has been revised: our NMR studies showed that Tyr-Xxx-Tyr peptides proved effective in the competitive tests not because they were able to bind to Gal-1 and to replace ASF, but rather because of their interactions with the glycoprotein ASF. In view of this molecular-level information, the concept of the Tyr-Xxx-Tyr motif as a glycomimetic should be revised. The results throw light on the misleading information obtained from the competitive tests such as SPR with ASF-functionalized chips or solid-phase assays with a glycoprotein matrix containing ASF. Our findings are also in line with the observation that no significant inhibition was seen with the mannose-specific Concanavalin A when yeast mannan was used instead of ASF. ${ }^{94}$ Apart 
from the lectin-inhibitory activity of the peptides, their interactions with ASF deserve attention. Although the nature of peptide-ASF binding remained unrevealed in our work, the construction of artificial receptor structures for the recognition of carbohydrates is also a hot topic. ${ }^{197,198}$

Ligand-detected binding experiments with A $\beta 1-42$ assemblies included the investigation of fibrils with short neuroprotective peptides and ThT and a foldamer library screening with $A \beta$ oligomers. The high molecular weight $A \beta 1-42$ assemblies could be investigated indirectly, by ligand-detected techniques. The binding of short neuroprotective peptides to A $\beta 1-42$ fibrils could be successfully quantified with ${ }^{1} \mathrm{H}$ NMR. The observed signal quenching revealed the binding of the peptides to the fibrillar $A \beta 1-42$, which indicated that the immediate binding to the $A \beta 1-42$ fibrils can play an important role in their short-time-frame protective effect. The timescale of the particle size changes corresponded to the binding ratio decrease observed in the NMR spectroscopy experiments, i.e. the highest decay in the binding fraction of the ligands was observed in the first 3-4 h. The decay rate is always higher when ThT is present, which correlates well with the results of the particle size measurements: ThT induces faster flocculation with particle sizes larger than those of LPFFD.

A 1-42 oligomers are difficult targets not only because their binding site is solventexposed and their exact structure is not known, but they also exist in solution as transient mixtures of various species. A $\beta$-peptide foldamer exhibiting weak binding to A $\beta 1-42$ oligomers was identified by STD and trNOE. The structure-affinity relationship suggested that the discovered pharmacophore with H14 helix structure and zwitterionic side-chains in juxtaposition is important for the interaction. Following the principles of multivalent ligand design, the four-armed foldamer-dendrimer conjugate $\mathbf{1 0}$ was prepared and tested by various methods. Conjugate 10 captured A $\beta 1-42$ oligomers with high affinity and the selective low nanomolar interaction with the toxic LMW oligomer species provided rescue from their LTPinhibiting effect. The protecting mechanism is not yet understood, but may involve the recognition and the cross-linking of the toxic $A \beta 1-42$ assemblies, or the binding might affect the equilibrium between different $A \beta 1-42$ species. The results demonstrated that the weak binding of a foldamer with biomolecule recognition segments can be enhanced by multivalency and this might extend the scope of the foldamer approach in drug design. More interestingly, a high-affinity foldamer-dendrimer conjugate was constructed and enhanced without any prior knowledge of the binding site. The promising results showed that the foldamer approach can be beneficial in the event of an extremely difficult target, and the principle of multivalent foldamers is also profitable. Moreover, the A $\beta 1-42$ binding compound deserves attention not only as a drug candidate, but also as a substance for the early diagnosis of $\mathrm{AD}$. 


\section{Summary}

1. Solution-phase behaviour of the tumour-nursing protein Gal-1 was characterized by means of NMR spectroscopy in the absence and in the presence of its natural ligand lactose.

1.1. The backbone chemical shifts of ${ }^{15} \mathrm{~N} /{ }^{13} \mathrm{C}$-labelled Gal-1 could be successfully assigned at physiological $\mathrm{pH} 7.4$ and the great majority of the $\mathrm{CB}$ and $\mathrm{HB}$ resonances were also identified.

1.2. ${ }^{15} \mathrm{~N}$ HSQC titrations showed that lactose binding affects the structure of Gal-1 even remote from the CRD, on the opposite side of the protein.

1.3. Backbone relaxation experiments and model-free analyses revealed that lactose binding not only affects the dynamic behaviour of the CRD, but these changes propagate throughout the whole protein.

1.4. Lactose-complexed Gal-1 was used as a model system to study the performance of GS-STD experiments. The ${ }^{15} \mathrm{~N} /{ }^{13} \mathrm{C}$ variants of GS-STD experiments provided a powerful approach for binding epitope mapping of lactose. The STD spectra obtained in four different experimental setups (selective ${ }^{1} \mathrm{H}$ STD, ${ }^{15} \mathrm{~N}$ GS-STD, ${ }^{13} \mathrm{C}_{\mathrm{Ar}}$ and ${ }^{13} \mathrm{C}_{\text {aliphatic }}$ GS-STD approaches) revealed that the signal-intensity pattern of the difference spectra is affected by both the type and the spatial distribution of the excited 'transmitter' atoms, and also by the efficiency of the spin-diffusion-mediated magnetization transfer.

2. The Tyr-Xxx-Tyr peptide motif has been reported to be glycomimetic sequences, mainly on the basis of their inhibitory effect on the Gal-1-ASF interaction. Our STD and trNOE NMR experiments revealed the following findings:

2.1. The Tyr-Xxx-Tyr peptides studied did not bind to Gal-1. ${ }^{15} \mathrm{~N}$ HSQC titrations with ${ }^{15} \mathrm{~N}$-labelled Gal-1 confirmed the absence of any peptide-Gal-1 interaction.

2.2. The binding of Tyr-Xxx-Tyr peptides to ASF was clearly detected.

2.3. The results showed that Tyr-Xxx-Tyr peptides proved effective in the competitive tests not because they were able to bind to Gal-1 and to replace ASF, but rather because of their interactions with the glycoprotein ASF. These data indicated that the Tyr-Xxx-Tyr peptides tested in this work are not glycomimetics as they interact with ASF via an unrevealed molecular linkage.

3. The time-dependent NMR signal quenching of the neuroprotective pentapeptide LPFFD and the fluorescent dye ThT was studied in the presence of A $\beta 1-42$ fibrils. The experiments yielded highly intriguing results: 
3.1. ThT could not fully and immediately replace LPFFD from $A \beta$ and could not prevent the weak binding of LPFFD.

3.2. LPFFD did not decrease the extent of the NMR spectroscopy-detected ThT binding, but rather increased it.

3.3. The quantity of bound ThT was always higher when LPFFD was present.

3.4. No solution NMR spectroscopically visible monomeric or oligomeric A $\beta 1-42$ signal accompanied the resonances of the studied ligands in the spectra.

3.5. In the light of the results, the disaggregation mechanism of neuroprotective peptides is unlikely and ligand-induced flocculation and sedimentation processes could be proposed, which were confirmed by DLS and TEM experiments.

4. A foldamer library was screened with STD and trNOE techniques, testing their binding to soluble A $\beta 1-42$ oligomers.

4.1. A hexapeptide foldamer was found which exhibited weak binding to $A \beta$.

4.2. The weak interaction could be enhanced by following the principles of multivalent ligands: the tetravalent G0-PAMAM conjugate of the peptide exhibited nanomolar binding to oligomers.

4.3. The binding of the tetravalent ligand was characterized by ITC, which showed a twostep binding enthalpogram with a low nanomolar and a submicromolar apparent dissociation constant.

4.4. Initial structure-activity relationship studies revealed that compounds with different recognition elements or with divalent construction exhibited only weak interactions, which suggests that the pharmacophore is specific. 


\section{Acknowledgements}

My special thanks go to my supervisor, Dr. Tamás Martinek, for his guidance of my work, his inspiring ideas, his useful advice and his valuable suggestions.

I would like to express my deep gratitude to Prof. Dr. Ferenc Fülöp, Head of the Institute of Pharmaceutical Chemistry, for providing me with the possibility to work in this department and complete my work under his guidance. I am grateful to Prof. Dr. György Dombi, Head of the Institute of Pharmaceutical Analysis, for his efforts in maintaining the NMR facilities.

I owe my thanks to Dr. Katalin Kövér at the Department of Inorganic and Analytical Chemistry, University of Debrecen, for her kind cooperation in the Gal-1 experiments.

I thank Dr. Anasztázia Hetényi for valuable discussions, for her practical advice in the daily work and for readily helping me when any difficulties arose.

I am grateful to Dr. István Mándity for his helpful advice, especially in the field of foldamers.

As our work required close co-operation in both the Gal-1 and the A $\beta 1-42$ topics, I owe my thanks to our collaborating partners. I express my kindest thanks to Dr. Lívia Fülöp and her group at the Department of Medical Chemistry, Faculty of Medicine, for sharing her knowledge and suggestions about $A \beta 1-42$ samples and for performing numerous experiments (DLS, TEM, ELISA and SEC). I am also grateful to the Monostori group at the Laboratory of Lymphocyte and Signal Transduction, Biological Research Centre, especially to Dr. Éva Monostori and Dr. Roberta Fajka-Boja for the biological support of the Gal-1 topic and for performing ELISA and FACS experiments.

I express sincere thanks to Éva Szolnoki, Zsófia Hegedűs, Dr. István Mándity and Dr. Zsolt Bozsó for their synthetic work and to Balázs Váczi for Gal-1 expression. I am grateful to Mária Benkő for performing ITC experiments and to Dr. Róbert Kiss (Gedeon Richter Plc.) for acquiring 3D NMR experiments at $800 \mathrm{MHz}$.

I express my gratitude for Sanofi-Aventis scholarship in financial support of my Ph.D. studies.

I thank all of my colleagues at the Institute of Pharmaceutical Chemistry and our cooperating partners for their help and advice, and also all my co-authors for contributing to my work.

I would like to thank my family and my friends, for their love, understanding and support in attaining my goal. Finally, I thank all those who have directly or indirectly helped me in the successful completion of this work. 


\section{References}

1. Hajduk, P. J.; Huth, J. R.; Tse, C., Drug Discov Today 2005, 10, 1675-82.

2. Fuller, J. C.; Burgoyne, N. J.; Jackson, R. M., Drug Discov Today 2009, 14, 155-61.

3. Seebach, D.; L. Matthews, J., Chem Commun 1997, 2015-22.

4. Gellman, S. H., Accounts Chem Res 1998, 31, 173-80.

5. Hecht, S. H., I., Foldamers: Structure, properties and applications. Wiley-VCH, Weinheim: 2007.

6. Kritzer, J. A.; Stephens, O. M.; Guarracino, D. A.; Reznik, S. K.; Schepartz, A., Bioorg Med Chem 2005, 13, 11-6.

7. Camby, I.; Le Mercier, M.; Lefranc, F.; Kiss, R., Glycobiology 2006, 16, 137R-57R.

8. Lesne, S.; Koh, M. T.; Kotilinek, L.; Kayed, R.; Glabe, C. G., et al., Nature 2006, 440, 352-7.

9. Haass, C.; Selkoe, D. J., Nat Rev Mol Cell Biol 2007, 8, 101-12.

10. Lue, L. F.; Kuo, Y. M.; Roher, A. E.; Brachova, L.; Shen, Y., et al., Am J Pathol 1999, 155, 853-62.

11. John Cavanagh, W. J. F., Arthur G. Palmer III, Nicholas J. Skelton, Mark Rance Protein NMR Spectroscopy: Principles and Practice. Elsevier Academic Press: 2007.

12. Zerbe, O., BioNMR in Drug Research. Wiley-VCH: Weinheim, 2003.

13. Hajduk, P. J.; Meadows, R. P.; Fesik, S. W., Q Rev Biophys 1999, 32, 211-40.

14. Meyer, B.; Peters, T., Angew Chem Int Ed 2003, 42, 864-90.

15. Huth, J. R.; Sun, C., Comb Chem High T Scr 2002, 5, 631-43.

16. Lepre, C. A., Methods Enzymol 2011, 493, 219-39.

17. Hajduk, P. J., Nat Chem Biol 2006, 2, 658-9.

18. Shuker, S. B.; Hajduk, P. J.; Meadows, R. P.; Fesik, S. W., Science 1996, 274, 1531-4.

19. Hajduk, P. J., Mol Interv 2006, 6, 266-72.

20. Koshland, D. E., Proc Natl Acad Sci USA 1958, 44, 98-104.

21. Vaynberg, J.; Qin, J., Trends Biotechnol 2006, 24, $22-7$.

22. Nooren, I. M.; Thornton, J. M., Embo J 2003, 22, 3486-92.

23. Clore, G. M.; Gronenborn, A. M., J Magn Reson 1982, 48, 402-17.

24. Clore, G. M.; Gronenborn, A. M., J Magn Reson 1983, 53, 423-42.

25. Post, C. B., Curr Opin Struct Biol 2003, 13, 581-8.

26. Mayer, M.; Meyer, B., Angew Chem Int Ed 1999, 38, 1784-8.

27. Meyer, B.; Peters, T., Angew Chem Int Edit 2003, 42, 864-90.

28. Mayer, M.; Meyer, B., J Am Chem Soc 2001, 123, 6108-17.

29. Krishnan, V. V., Curr Anal Chem 2005, 1, 307-20.

30. Krishna, N. R.; Jayalakshmi, V., Prog Nucl Mag Res Sp 2006, 49, 1-25.

31. Groves, P.; Kover, K. E.; Andre, S.; Bandorowicz-Pikula, J.; Batta, G., et al., Magn Reson Chem 2007, 45, 745-8.

32. Gomez-Paloma, L.; Di Micco, S.; Bassarello, C.; Bifulco, G.; Riccio, R., Angew Chem Int Ed 2006, 45, 224-8.

33. Kover, K. E.; Groves, P.; Jimenez-Barbero, J.; Batta, G., J Am Chem Soc 2007, 129, 11579-82.

34. Cutting, B.; Shelke, S. V.; Dragic, Z.; Wagner, B.; Gathje, H., et al., Magn Reson Chem 2007, 45, 720-4.

35. Wuthrich, K., Biopolymers 1983, 22, 131-8.

36. Grzesiek, S.; Bax, A., J Biomol NMR 1993, 3, 185-204.

37. Muhandiram, D. R.; Kay, L. E., J Magn Reson Ser B 1994, 103, 203-16.

38. Clubb, R. T.; Thanabal, V.; Wagner, G., J Magn Reson 1992, 97, 213-7.

39. Schleucher, J.; Sattler, M.; Griesinger, C., Angew Chem Int Ed 1993, 32, 1489-91.

40. Grzesiek, S.; Bax, A., J Magn Reson 1992, 96, $432-40$.

41. Kay, L. E.; Xu, G. Y.; Yamazaki, T., J Magn Reson Ser A 1994, 109, 129-33. 
42. Teng, Q., Protein dynamics. In Structural Biology: Practical NMR Applications, Springer: 2005.

43. Nuclear spin relaxation and molecular dynamics. In Fundamentals of Protein NMR Spectroscopy, G. S. Rule; T. K. Hitchens, Eds. Springer: 2006.

44. Lipari, G.; Szabo, A., J Am Chem Soc 1982, 104, 4546-59.

45. Lipari, G.; Szabo, A., J Am Chem Soc 1982, 104, 4559-70.

46. Perozzo, R.; Folkers, G.; Scapozza, L., J Recept Signal Transduct Res 2004, 24, 1-52.

47. Liang, Y., Acta Biochim Biophys Sin (Shanghai) 2008, 40, 565-76.

48. Elola, M. T.; Chiesa, M. E.; Alberti, A. F.; Mordoh, J.; Fink, N. E., J Biomed Sci 2005, 12, 13-29.

49. Nangia-Makker, P.; Conklin, J.; Hogan, V.; Raz, A., Trends Mol Med 2002, 8, 187-92.

50. Rabinovich, G. A.; Toscano, M. A.; Jackson, S. S.; Vasta, G. R., Curr Opin Struct Biol 2007, 17, 513-20.

51. Brewer, C. F., Biochim Biophys Acta 2002, 1572, 255-62.

52. Kiss, J.; Kunstar, A.; Fajka-Boja, R.; Dudics, V.; Tovari, J., et al., Exp Hematol 2007, 35, 305-13.

53. Norling, L. V.; Sampaio, A. L.; Cooper, D.; Perretti, M., FASEB J 2008, 22, 682-90.

54. Rabinovich, G. A.; Sotomayor, C. E.; Riera, C. M.; Bianco, I.; Correa, S. G., Eur J Immunol 2000, 30, $1331-9$.

55. Offner, H.; Celnik, B.; Bringman, T. S.; Casentini-Borocz, D.; Nedwin, G. E., et al., J Neuroimmunol 1990, $28,177-84$.

56. Rabinovich, G.; Daly, G.; Dreja, H.; Tailor, H.; Riera, C. M., et al., J Exp Med 1999, 190, 385-97.

57. Perone, M. J.; Bertera, S.; Tawadrous, Z. S.; Shufesky, W. J.; Piganelli, J. D., et al., J Immunol 2006, 177, 5278-89.

58. Salatino, M.; Croci, D. O.; Bianco, G. A.; Ilarregui, J. M.; Toscano, M. A., et al., Expert Opin Biol Ther 2008, 8, 45-57.

59. Perillo, N. L.; Pace, K. E.; Seilhamer, J. J.; Baum, L. G., Nature 1995, 378, 736-9.

60. Fajka-Boja, R.; Szemes, M.; Ion, G.; Legradi, A.; Caron, M., et al., Immunol Lett 2002, 82, 149-54.

61. Ion, G.; Fajka-Boja, R.; Toth, G. K.; Caron, M.; Monostori, E., Cell Death Differ 2005, 12, 1145-7.

62. Ion, G.; Fajka-Boja, R.; Kovacs, F.; Szebeni, G.; Gombos, I., et al., Cell Signal 2006, 18, 1887-96.

63. Rabinovich, G. A.; Ariel, A.; Hershkoviz, R.; Hirabayashi, J.; Kasai, K. I., et al., Immunology 1999, 97, 100-6.

64. van der Leij, J.; van den Berg, A.; Harms, G.; Eschbach, H.; Vos, H., et al., Mol Immunol 2007, 44, 50613.

65. Stowell, S. R.; Qian, Y.; Karmakar, S.; Koyama, N. S.; Dias-Baruffi, M., et al., J Immunol 2008, 180, 3091-102.

66. Lahm, H.; Andre, S.; Hoeflich, A.; Kaltner, H.; Siebert, H. C., et al., Glycoconj J 2004, 20, $227-38$.

67. Rabinovich, G. A., Br J Cancer 2005, 92, 1188-92.

68. Liu, F. T.; Rabinovich, G. A., Nat Rev Cancer 2005, 5, 29-41.

69. Danguy, A.; Camby, I.; Kiss, R., Biochim Biophys Acta 2002, 1572, $285-93$.

70. Thijssen, V. L.; Postel, R.; Brandwijk, R. J.; Dings, R. P.; Nesmelova, I., et al., Proc Natl Acad Sci USA 2006, 103, 15975-80.

71. Giudicelli, V.; Lutomski, D.; LeviStrauss, M.; Bladier, D.; JoubertCaron, R., et al., Glycobiology 1997, 7, R8-R10.

72. Cho, M.; Cummings, R. D., J Biol Chem 1995, 270, 5207-12.

73. Lopez-Lucendo, M. F.; Solis, D.; Andre, S.; Hirabayashi, J.; Kasai, K., et al., J Mol Biol 2004, 343, 95770.

74. He, L.; Andre, S.; Siebert, H. C.; Helmholz, H.; Niemeyer, B., et al., Biophys J 2003, 85, 511-24.

75. Gupta, D.; Cho, M.; Cummings, R. D.; Brewer, C. F., Biochemistry 1996, 35, 15236-43.

76. Nesmelova, I. V.; Ermakova, E.; Daragan, V. A.; Pang, M.; Menendez, M., et al., J Mol Biol 2010, 397, 1209-30. 
77. Siebert, H. C.; Andre, S.; Lu, S. Y.; Frank, M.; Kaltner, H., et al., Biochemistry 2003, 42, $14762-73$.

78. Di Virgilio, S.; Glushka, J.; Moremen, K.; Pierce, M., Glycobiology 1999, 9, 353-64.

79. Miller, M. C.; Klyosov, A.; Mayo, K. H., Glycobiology 2009, 19, 1034-45.

80. Miller, M. C.; Nesmelova, I. V.; Platt, D.; Klyosov, A.; Mayo, K. H., Biochem J 2009, 421, 211-21.

81. Gabius, H. J., Int J Biochem 1994, 26, 469-77.

82. Bianchet, M. A.; Ahmed, H.; Vasta, G. R.; Amzel, L. M., Proteins 2000, 40, 378-88.

83. Ingrassia, L.; Camby, I.; Lefranc, F.; Mathieu, V.; Nshimyumukiza, P., et al., Curr Med Chem 2006, 13, 3513-27.

84. Maeda, N.; Kawada, N.; Seki, S.; Arakawa, T.; Ikeda, K., et al., J Biol Chem 2003, 278, 18938-44.

85. Rabinovich, G. A.; Cumashi, A.; Bianco, G. A.; Ciavardelli, D.; Iurisci, I., et al., Glycobiology 2006, 16, 210-20.

86. Giguere, D.; Sato, S.; St-Pierre, C.; Sirois, S.; Roy, R., Bioorg Med Chem Lett 2006, 16, 1668-72.

87. Giguere, D.; Patnam, R.; Bellefleur, M. A.; St-Pierre, C.; Sato, S., et al., Chem Commun 2006, 2379-81.

88. Andre, S.; Ortega, P. J.; Perez, M. A.; Roy, R.; Gabius, H. J., Glycobiology 1999, 9, 1253-61.

89. Andre, S.; Pieters, R. J.; Vrasidas, I.; Kaltner, H.; Kuwabara, I., et al., Chembiochem 2001, 2, 822-30.

90. Vrasidas, I.; Andre, S.; Valentini, P.; Bock, C.; Lensch, M., et al., Org Biomol Chem 2003, 1, 803-10.

91. Belitsky, J. M.; Nelson, A.; Hernandez, J. D.; Baum, L. G.; Stoddart, J. F., Chem Biol 2007, 14, 1140-51.

92. Oldenburg, K. R.; Loganathan, D.; Goldstein, I. J.; Schultz, P. G.; Gallop, M. A., Proc Natl Acad Sci USA 1992, 89, 5393-7.

93. Andre, S.; Arnusch, C. J.; Kuwabara, I.; Russwurm, R.; Kaltner, H., et al., Bioorg Med Chem 2005, 13, 563-73.

94. Arnusch, C. J.; Andre, S.; Valentini, P.; Lensch, M.; Russwurm, R., et al., Bioorg Med Chem Lett 2004, 14, 1437-40.

95. Bachle, D.; Loers, G.; Guthohrlein, E. W.; Schachner, M.; Sewald, N., Angew Chem Int Ed 2006, 45, $6582-5$.

96. Yu, L.; Yu, P. S.; Yee Yen Mui, E.; McKelvie, J. C.; Pham, T. P., et al., Bioorg Med Chem 2009, 17, 4825-32.

97. Kaur, K. J.; Khurana, S.; Salunke, D. M., J Biol Chem 1997, 272, 5539-43.

98. Spiro, R. G., J Biol Chem 1960, 235, 2860-9.

99. Dam, T. K.; Gabius, H. J.; Andre, S.; Kaltner, H.; Lensch, M., et al., Biochemistry 2005, 44, 12564-71.

100. Maljaars, C. E.; Andre, S.; Halkes, K. M.; Gabius, H. J.; Kamerling, J. P., Anal Biochem 2008, 378, 1906.

101. Andre, S.; Maljaars, C. E.; Halkes, K. M.; Gabius, H. J.; Kamerling, J. P., Bioorg Med Chem Lett 2007, $17,793-8$.

102. Mayo, K. H.; Haseman, J.; Ilyina, E.; Gray, B., Biochim Biophys Acta 1998, 1425, 81-92.

103. Dings, R. P.; Arroyo, M. M.; Lockwood, N. A.; van Eijk, L. I.; Haseman, J. R., et al., Biochem J 2003, 373, $281-8$.

104. McLean, C. A.; Cherny, R. A.; Fraser, F. W.; Fuller, S. J.; Smith, M. J., et al., Ann Neurol 1999, 46, 8606.

105. Naslund, J.; Haroutunian, V.; Mohs, R.; Davis, K. L.; Davies, P., et al., JAMA 2000, 283, 1571-7.

106. Walsh, D. M.; Klyubin, I.; Fadeeva, J. V.; Cullen, W. K.; Anwyl, R., et al., Nature 2002, 416, 535-9.

107. Cleary, J. P.; Walsh, D. M.; Hofmeister, J. J.; Shankar, G. M.; Kuskowski, M. A., et al., Nat Neurosci 2005, 8, 79-84.

108. Thinakaran, G.; Koo, E. H., J Biol Chem 2008, 283, 29615-9.

109. Vassar, R.; Bennett, B. D.; Babu-Khan, S.; Kahn, S.; Mendiaz, E. A., et al., Science 1999, 286, 735-41.

110. Miller, Y.; Ma, B.; Nussinov, R., Chem Rev 2010, 110, 4820-38.

111. Legleiter, J., Methods Mol Biol 2011, 670, 57-70. 
112. Canale, C.; Relini, A.; Gliozzi, A., Methods Mol Biol 2011, 736, 81-95.

113. Antzutkin, O. N.; Leapman, R. D.; Balbach, J. J.; Tycko, R., Biochemistry 2002, 41, 15436-50.

114. Balbach, J. J.; Petkova, A. T.; Oyler, N. A.; Antzutkin, O. N.; Gordon, D. J., et al., Biophys $J$ 2002, 83, 1205-16.

115. Luhrs, T.; Ritter, C.; Adrian, M.; Riek-Loher, D.; Bohrmann, B., et al., Proc Natl Acad Sci USA 2005, $102,17342-7$.

116. Olofsson, A.; Sauer-Eriksson, A. E.; Ohman, A., J Biol Chem 2006, 281, 477-83.

117. Crescenzi, O.; Tomaselli, S.; Guerrini, R.; Salvadori, S.; D'Ursi, A. M., et al., Eur J Biochem 2002, 269, $5642-8$.

118. Tomaselli, S.; Esposito, V.; Vangone, P.; van Nuland, N. A. J.; Bonvin, A. M. J. J., et al., Chembiochem 2006, 7, 257-67.

119. Buchete, N. V.; Tycko, R.; Hummer, G., J Mol Biol 2005, 353, 804-21.

120. Urbanc, B.; Cruz, L.; Ding, F.; Sammond, D.; Khare, S., et al., Biophys J 2004, 87, 2310-21.

121. Torok, M.; Milton, S.; Kayed, R.; Wu, P.; McIntire, T., et al., J Biol Chem 2002, 277, 40810-5.

122. LeVine, H., 3rd, Protein Sci 1993, 2, 404-10.

123. Naiki, H.; Higuchi, K.; Hosokawa, M.; Takeda, T., Anal Biochem 1989, 177, $244-9$.

124. Levine, H., Amyloid 1995, 2, 1-6.

125. Lockhart, A.; Ye, L.; Judd, D. B.; Merritt, A. T.; Lowe, P. N., et al., J Biol Chem 2005, 280, 7677-84.

126. Shankar, G. M.; Li, S.; Mehta, T. H.; Garcia-Munoz, A.; Shepardson, N. E., et al., Nat Med 2008, 14 , $837-42$.

127. Fukumoto, H.; Tokuda, T.; Kasai, T.; Ishigami, N.; Hidaka, H., et al., FASEB J 2010, 24, 2716-26.

128. Ahmed, M.; Davis, J.; Aucoin, D.; Sato, T.; Ahuja, S., et al., Nat Struct Mol Biol 2010, 17, 561-7.

129. Naiki, H.; Higuchi, K.; Matsushima, K.; Shimada, A.; Chen, W. H., et al., Lab Invest 1990, 62, 768-73.

130. Naiki, H.; Higuchi, K.; Nakakuki, K.; Takeda, T., Lab Invest 1991, 65, 104-10.

131. Maezawa, I.; Hong, H. S.; Liu, R.; Wu, C. Y.; Cheng, R. H., et al., J Neurochem 2008, 104, 457-68.

132. Yang, F.; Lim, G. P.; Begum, A. N.; Ubeda, O. J.; Simmons, M. R., et al., J Biol Chem 2005, 280, 5892901.

133. Airoldi, C.; Zona, C.; Sironi, E.; Colombo, L.; Messa, M., et al., J Biotechnol 2011.

134. Gervais, F.; Paquette, J.; Morissette, C.; Krzywkowski, P.; Yu, M., et al., Neurobiol Aging 2007, 28, 537-47.

135. Sato, T.; Kienlen-Campard, P.; Ahmed, M.; Liu, W.; Li, H., et al., Biochemistry 2006, 45, 5503-16.

136. Soto, C.; Kindy, M. S.; Baumann, M.; Frangione, B., Biochem Biophys Res Commun 1996, 226, 672-80.

137. Adessi, C.; Soto, C., Drug Develop Res 2002, 56, 184-93.

138. Hilbich, C.; Kisters-Woike, B.; Reed, J.; Masters, C. L.; Beyreuther, K., J Mol Biol 1992, 228, 460-73.

139. Soto, C.; Castano, E. M.; Kumar, R. A.; Beavis, R. C.; Frangione, B., Neurosci Lett 1995, 200, 105-8.

140. Tjernberg, L. O.; Naslund, J.; Lindqvist, F.; Johansson, J.; Karlstrom, A. R., et al., J Biol Chem 1996, $271,8545-8$.

141. Narayanan, S.; Reif, B., Biochemistry 2005, 44, 1444-52.

142. Bieler, S.; Soto, C., Curr Drug Targets 2004, 5, 553-8.

143. Cairo, C. W.; Strzelec, A.; Murphy, R. M.; Kiessling, L. L., Biochemistry 2002, 41, 8620-9.

144. Chen, Z.; Krause, G.; Reif, B., J Mol Biol 2005, 354, 760-76.

145. Chen, Z.; Reif, B., J Biomol NMR 2004, 29, 525-30.

146. Inbar, P.; Yang, J., Bioorg Med Chem Lett 2006, 16, 1076-9.

147. LeVine, H., 3rd, Arch Biochem Biophys 1997, 342, 306-16.

148. LeVine, H., 3rd, Amyloid 2005, 12, 5-14.

149. Fulop, F.; Martinek, T. A.; Toth, G. K., Chem Soc Rev 2006, 35, 323-34. 
150. Mandity, I. M.; Weber, E.; Martinek, T. A.; Olajos, G.; Toth, G. K., et al., Angew Chem Int Ed 2009, 48, 2171-5.

151. Mandity, I. M.; Fulop, L.; Vass, E.; Toth, G. K.; Martinek, T. A., et al., Org Lett 2010, 12, 5584-7.

152. Hintermann, T.; Seebach, D., Chimia 1997, 51, 244-7.

153. Seebach, D.; Abele, S.; Schreiber, J. V.; Martinoni, B.; Nussbaum, A. K., et al., Chimia 1998, 52, 734-9.

154. Frackenpohl, J.; Arvidsson, P. I.; Schreiber, J. V.; Seebach, D., Chembiochem 2001, 2, 445-55.

155. Werder, M.; Hauser, H.; Abele, S.; Seebach, D., Helv Chim Acta 1999, 82, 1774-83.

156. Imamura, Y.; Watanabe, N.; Umezawa, N.; Iwatsubo, T.; Kato, N., et al., J Am Chem Soc 2009, 131, 7353-9.

157. Gelman, M. A.; Richter, S.; Cao, H.; Umezawa, N.; Gellman, S. H., et al., Org Lett 2003, 5, 3563-5.

158. Stephens, O. M.; Kim, S.; Welch, B. D.; Hodsdon, M. E.; Kay, M. S., et al., J Am Chem Soc 2005, 127, 13126-7.

159. Horne, W. S.; Johnson, L. M.; Ketas, T. J.; Klasse, P. J.; Lu, M., et al., Proc Natl Acad Sci USA 2009, 106, 14751-6.

160. English, E. P.; Chumanov, R. S.; Gellman, S. H.; Compton, T., J Biol Chem 2006, 281, 2661-7.

161. Akkarawongsa, R.; Potocky, T. B.; English, E. P.; Gellman, S. H.; Brandt, C. R., Antimicrob Agents Chemother 2008, 52, 2120-9.

162. Kritzer, J. A.; Lear, J. D.; Hodsdon, M. E.; Schepartz, A., J Am Chem Soc 2004, 126, $9468-9$.

163. Horne, W. S.; Boersma, M. D.; Windsor, M. A.; Gellman, S. H., Angew Chem Int Ed 2008, 47, 2853-6.

164. Zarandi, M.; Soos, K.; Fulop, L.; Bozso, Z.; Datki, Z., et al., J Pept Sci 2007, 13, 94-9.

165. Bozso, Z.; Penke, B.; Simon, D.; Laczko, I.; Juhasz, G., et al., Peptides 2010, 31, 248-56.

166. Piotto, M.; Saudek, V.; Sklenar, V., J Biomol NMR 1992, 2, 661-5.

167. Emsley, L.; Bodenhausen, G., Chem Phys Lett 1990, 165, 469-76.

168. Emsley, L.; Bodenhausen, G., J Magn Reson 1992, 97, 135-48.

169. Sklenar, V.; Piotto, M.; Leppik, R.; Saudek, V., J Magn Reson Ser A 1993, 102, 241-5.

170. Kneller, D. G.; Kuntz, I. D., J Cell Biochem 1993, 254-.

171. d'Auvergne, E. J.; Gooley, P. R., J Biomol NMR 2008, 40, 121-33.

172. d'Auvergne, E. J.; Gooley, P. R., J Biomol NMR 2008, 40, 107-19.

173. Pawley, N. H.; Wang, C.; Koide, S.; Nicholson, L. K., J Biomol NMR 2001, 20, 149-65.

174. d'Auvergne, E. J.; Gooley, P. R., J Biomol NMR 2003, 25, 25-39.

175. Bax, A.; Davis, D. G., J Magn Reson 1985, 65, 355-60.

176. Bax, A.; Davis, D. G., J Magn Reson 1985, 63, 207-13.

177. Piotto, M.; Saudek, V.; Sklenar, V., J Biomol NMR 1992, 2, 661-5.

178. Nesmelova, I. V.; Pang, M.; Baum, L. G.; Mayo, K. H., Biomol NMR Assign 2008, 2, 203-5.

179. Cho, M.; Cummings, R. D., J Biol Chem 1995, 270, 5198-206.

180. Schwarz, F. P.; Ahmed, H.; Bianchet, M. A.; Amzel, L. M.; Vasta, G. R., Biochemistry 1998, 37, 586777.

181. Leppanen, A.; Stowell, S.; Blixt, O.; Cummings, R. D., J Biol Chem 2005, 280, 5549-62.

182. Marme, N.; Knemeyer, J. P.; Sauer, M.; Wolfrum, J., Bioconjug Chem 2003, 14, 1133-9.

183. Doose, S.; Neuweiler, H.; Sauer, M., Chemphyschem 2005, 6, 2277-85.

184. Datki, Z.; Papp, R.; Zadori, D.; Soos, K.; Fulop, L., et al., Neurobiol Dis 2004, 17, 507-15.

185. Datki, Z.; Juhasz, A.; Galfi, M.; Soos, K.; Papp, R., et al., Brain Res Bull 2003, 62, 223-9.

186. Szegedi, V.; Fulop, L.; Farkas, T.; Rozsa, E.; Robotka, H., et al., Neurobiol Dis 2005, 18, 499-508.

187. Fulop, L.; Zarandi, M.; Datki, Z.; Soos, K.; Penke, B., Biochem Biophys Res Commun 2004, 324, 64-9.

188. Sachse, C.; Xu, C.; Wieligmann, K.; Diekmann, S.; Grigorieff, N., et al., J Mol Biol 2006, 362, 347-54.

189. Martinek, T. A.; Fulop, F., Chem Soc Rev 2011, 41, 687-702.

190. Kostiainen, M. A.; Hardy, J. G.; Smith, D. K., Angew Chem Int Ed 2005, 44, $2556-9$. 
191. Fournel, S.; Wieckowski, S.; Sun, W.; Trouche, N.; Dumortier, H., et al., Nat Chem Biol 2005, 1, 37782.

192. Sattin, S.; Daghetti, A.; Thepaut, M.; Berzi, A.; Sanchez-Navarro, M., et al., Acs Chem Biol 2010, 5, 301-12.

193. Griffin, J. H.; Linsell, M. S.; Nodwell, M. B.; Chen, Q.; Pace, J. L., et al., J Am Chem Soc 2003, 125, 6517-31.

194. Shukla, R.; Thomas, T. P.; Peters, J.; Kotlyar, A.; Myc, A., et al., Chem Commun 2005, 5739-41.

195. Chafekar, S. M.; Malda, H.; Merkx, M.; Meijer, E. W.; Viertl, D., et al., Chembiochem 2007, 8, 1857-64.

196. Shi, W.; Dolai, S.; Rizk, S.; Hussain, A.; Tariq, H., et al., Org Lett 2007, 9, 5461-4.

197. Kubik, S., Angew Chem Int Ed 2009, 48, 1722-5.

198. Ferrand, Y.; Klein, E.; Barwell, N. P.; Crump, M. P.; Jimenez-Barbero, J., et al., Angew Chem Int Ed 2009, 48, 1775-9. 
Appendix 


\section{Theoretical Section A: Equations and explanations for NMR theory}

The spectral density function $J(\omega)$ describes the intensity of the magnetic field fluctuations. In the absence of internal motion, the spectral density can be expressed as:

$$
J(\omega)=\frac{\tau_{c}}{\left(1+\omega^{2} \tau_{c}^{2}\right)}
$$

where $\omega$ is the Larmor frequency, $\tau_{c}$ is the rotational correlation time and isotropic tumbling is assumed. The rotational correlation time is the time it takes for a molecule to rotate through one radian and is given by the Stokes-Einstein equation:

$$
\tau_{c}=\frac{4 \pi \eta r^{3}}{3 k T}
$$

where $\eta$ is the viscosity and $r$ is the radius of the protein, $k$ is the Boltzmann constant and $T$ is the temperature.

Dipolar coupling, together with chemical shift anisotropy (CSA), generate oscillating electromagnetic fields, which stimulate zero-quantum, single-quantum and double-quantum transitions (described by Solomon ${ }^{\mathrm{a} 1}$ ), thereby affecting relaxation. The phenomenon can be measured via the changes in population levels of dipolar coupled spins: the exchange of magnetization between spins perturbs the populations for the different energy levels. This is called the nuclear Overhauser effect $(\mathrm{NOE}){ }^{\mathrm{a} 2}$ and is caused by cross-relaxation. The cross-relaxation and the observed NOE effect depend on $\tau_{c}$ : for small molecules in nonviscous solution tumbling fast (short $\tau_{c}$ ), cross-relaxation and the NOE is positive (intensity enhancement), while for large molecules or molecules in viscous solutions (long $\tau_{c}$ ), crossrelaxation and the NOE is negative (intensity reduction). For medium-sized molecules (MW 1000-3000 Da), the NOE is very weak or even zero.

The relaxation of proteins, ${ }^{\mathrm{a} 2, \mathrm{a} 3}$ which is usually characterized by amide $\mathrm{N}-\mathrm{H}$ relaxation, is primarily caused by dipolar coupling and CSA. The rate constants for longitudinal and transversal relaxation and for cross-relaxation $\left(R_{1}, R_{2}\right.$ and $\sigma_{N H}$, respectively) for the amide $\mathrm{N}$ $\mathrm{H}$ bond vectors can be expressed as ${ }^{\mathrm{a} 5}$, a6

$$
\begin{gathered}
R_{1}=R_{1}^{D}+R_{1}^{C S A}=\frac{d^{2}}{4}\left[6 J\left(\omega_{H}+\omega_{N}\right)+J\left(\omega_{H}-\omega_{N}\right)+3 J\left(\omega_{N}\right)\right]+c^{2} J\left(\omega_{N}\right) \\
R_{2}=R_{2}^{D}+R_{2}^{C S A}=\frac{d^{2}}{8}\left[6 J\left(\omega_{H}+\omega_{N}\right)+6 J\left(\omega_{H}\right)+J\left(\omega_{H}-\omega_{N}\right)+4 J(0)+3 J\left(\omega_{N}\right)\right]+ \\
\frac{c^{2}}{6}\left[4 J(0)+3 J\left(\omega_{N}\right)\right]+R_{e x} \\
\sigma_{N H}=\frac{d^{2}}{4}\left[6 J\left(\omega_{H}+\omega_{N}\right)-J\left(\omega_{H}-\omega_{N}\right)\right]
\end{gathered}
$$

where $d=\mu_{0} \gamma_{H} \gamma_{N} h\left\langle r_{N H}^{-3}\right\rangle / 8 \pi^{2}$ and $\mu_{0}$ is the permeability of vacuum, $r_{N H}$ is the N-H bond length, $h$ is Planck's constant, $\gamma_{\mathrm{H}}$ and $\gamma_{\mathrm{N}}$ are the gyromagnetic ratios and $c=\Delta \sigma \omega_{N} / \sqrt{3}$ is the CSA for the peptide bond ${ }^{15} \mathrm{~N}$. $R_{e x}$ is the relaxation due to chemical exchange. While $R_{l}$ and 
$R_{2}$ are directly determined experimentally, $\sigma_{N H}$ is determined from a steady-state ${ }^{15} \mathrm{~N}-{ }^{1} \mathrm{H}$ $h \mathrm{NOE}$ experiment via the relationship

$$
\sigma_{N H}=\frac{\gamma_{N}}{\gamma_{H}} R_{1}(N O E-1)
$$

i.e.

$$
N O E=1+\frac{\sigma_{N H}}{R_{1}} \frac{\gamma_{H}}{\gamma_{N}}=1+\frac{d^{2}}{4 R_{1}} \frac{\gamma_{H}}{\gamma_{N}}\left[6 J\left(\omega_{H}+\omega_{N}\right)-J\left(\omega_{H}-\omega_{N}\right)\right]
$$

where the NOE is given by the ratios of the peak intensities in the NOE and NONOE spectra ( $I_{S}$ and $I_{0}$, respectively):

$$
N O E=\frac{I_{S}}{I_{0}}
$$

Magnetic field fluctuations can be generated by internal motions, too. In order to map the spectral density function with the consideration of internal motion, the model-free approach $^{\mathrm{a} 7, \mathrm{a} 8}$ can be applied. The different mathematical models use different combinations of parameters to express the spectral density function and to describe the amplitude and the rate of internal dynamics of the chemical bond vectors (Table A1):

Table A1. Examples of model-free models using different motional parameters.

\begin{tabular}{cll}
\hline Model & \multicolumn{1}{c}{$\begin{array}{c}\text { Optimized } \\
\text { parameters }\end{array}$} & \multicolumn{1}{c}{ Equation for spectral density function } \\
\hline $\mathrm{m} 1$ & $S^{2}$ & $J(\omega)=\frac{2}{5}\left[\frac{S^{2} \tau_{c}}{1+\omega^{2} \tau_{c}^{2}}\right]$ \\
$\mathrm{m} 2$ & $S^{2}, \tau_{e}$ & $J(\omega)=\frac{2}{5}\left[\frac{S^{2} \tau_{c}}{1+\omega^{2} \tau_{c}^{2}}+\frac{\left(1-S^{2}\right) \tau}{1+\omega^{2} \tau_{c}^{2}}\right]$ \\
$\mathrm{m} 3$ & $S^{2}, R_{e x}$ & $J(\omega)=\frac{2}{5}\left[\frac{S^{2} \tau_{c}}{1+\omega^{2} \tau_{c}^{2}}\right] ; R_{2(o b s)}=R_{2}+R_{e x}$ \\
$\mathrm{~m} 4$ & $S^{2}, \tau_{e}, R_{e x}$ & $J(\omega)=\frac{2}{5}\left[\frac{S^{2} \tau_{c}}{1+\omega^{2} \tau_{c}^{2}}+\frac{\left(1-S^{2}\right) \tau}{1+\omega^{2} \tau_{c}^{2}}\right] ; R_{2(o b s)}=R_{2}+R_{e x}$ \\
$\mathrm{~m} 5$ & $S^{2}, S_{f}^{2}, \tau_{e}$ & $J(\omega)=\frac{2}{5}\left[\frac{S^{2} \tau_{c}}{1+\omega^{2} \tau_{c}^{2}}+\frac{S_{f}^{2}\left(1-S_{s}^{2}\right) \tau_{s}^{\prime}}{1+\omega^{2} \tau_{s}^{\prime 2}}\right]$ \\
\hline where $\tau^{-1}=\tau_{c}^{-1}+\tau_{e}^{-1}$ and $\tau_{s}^{\prime}=\frac{\tau_{c} \tau_{s}}{\tau_{c}+\tau_{s}}$.
\end{tabular}

The squared generalized order parameter $S^{2}$ can be given by the angle $\theta$ between the bond vector and the diffusing cone:

$$
S^{2}=\left[\frac{\cos \theta(1+\cos \theta)}{2}\right]^{2}
$$

The theory can be extended to include motions on two different time scales using two sets of $S^{2}$ values $\left(S_{f}^{2}\right.$ and $\left.S_{s}{ }^{2}\right)$ and correlation times $\tau_{f}$ and $\tau_{s}$. ${ }^{a}$ 
Table A2. NMR techniques for the detection and characterization of binding of ligands to proteins. Based on [a10, a11]

\begin{tabular}{|c|c|c|c|c|c|}
\hline Technique & $\begin{array}{l}\text { Sample } \\
\text { requirements }\end{array}$ & $K_{d}$ limit & MW limit & Information content & Comment \\
\hline \multicolumn{6}{|l|}{ Ligand-detected } \\
\hline $\begin{array}{l}\text { Change in }{ }^{1} \mathrm{H} \text { relaxation rates (line } \\
\text { broadening, signal intensity loss) }\end{array}$ & & & for large proteins $(>30 \mathrm{kDa})$ & might indicate ligand epitope & \\
\hline Diffusion editing & & $100 \mathrm{nM}-1 \mathrm{mM}$ & for small proteins & $\begin{array}{c}\text { change in diffusion constant indicates } \\
\text { binding }\end{array}$ & \\
\hline Chemical shift perturbation & & & no limit & might indicate ligand epitope & not a robust technique \\
\hline \multicolumn{6}{|l|}{ NOE-based techniques } \\
\hline Transferred NOE & ligand excess* & $100 \mathrm{nM}-10 \mathrm{mM}$ & $\begin{array}{l}\text { small ligand (max. } 1-2 \mathrm{kDa}), \\
\text { large protein }\end{array}$ & binding comformation of the ligand & \\
\hline NOE pumping & & & for large proteins $(>30 \mathrm{kDa})$ & & $\begin{array}{l}\text { uses intermolecular } \\
\text { cross-relaxation }\end{array}$ \\
\hline Inverse NOE pumping & & $1 \mathrm{nM}-1 \mathrm{mM}$ & for large proteins $(>30 \mathrm{kDa})$ & ligand binding epitope & \\
\hline STD & ligand excess* & $100 \mathrm{nM}-10 \mathrm{mM}$ & $\begin{array}{l}\text { small ligand (max. } 1-2 \mathrm{kDa}), \\
\text { large protein }\end{array}$ & ligand binding epitope & \\
\hline Water-LOGSY ${ }^{\text {a12 }}$ & ligand excess* & $100 \mathrm{nM}-10 \mathrm{mM}$ & $\begin{array}{l}\text { small ligand (max. } 1-2 \mathrm{kDa}), \\
\text { large protein }\end{array}$ & ligand binding epitope & $\begin{array}{c}\text { for hydrophilic targets } \\
\text { and/or ligands }\end{array}$ \\
\hline \multicolumn{6}{|l|}{ Target-detected } \\
\hline Chemical shift perturbation & & & & & $\begin{array}{l}\text { signal assignment } \\
\text { necessary }\end{array}$ \\
\hline $\begin{array}{l}{ }^{15} \mathrm{~N} \text { HSQC titration } \\
\text { (SAR by NMR) }\end{array}$ & \multirow{3}{*}{$\begin{array}{l}\text { isotope-labelled } \\
\text { protein } \\
\text { (or small protein at } \\
\text { high } \\
\text { concentrations) }\end{array}$} & \multirow{3}{*}{$\begin{array}{l}\text { no lower limit- } \\
\text { max. } 10 \mathrm{mM}\end{array}$} & \multirow{3}{*}{$\begin{array}{l}\text { proteins below } \\
30-100 \mathrm{kDa}^{* *}\end{array}$} & binding epitope of the protein & \\
\hline${ }^{13} \mathrm{C}$ methyl group titration & & & & $\begin{array}{l}\text { binding epitope of the protein, to map } \\
\text { hydrophobic interactions }\end{array}$ & \\
\hline $\begin{array}{l}{ }^{15} \mathrm{~N} \text { relaxation measurements and } \\
\text { model-free analysis }\end{array}$ & & & & $\begin{array}{c}\text { dynamical characterization of the } \\
\text { protein }\end{array}$ & \\
\hline
\end{tabular}

* protein concentration in the $\mathrm{nM}$ to $\mu \mathrm{M}$ range, 10-400-fold excess of the ligand

**depending on the deuteration of the protein and the applied techniques, e.g. Transverse Relaxation Optimized Spectroscopy (TROSY) 


\section{Theoretical Section B: Equations for ITC theory}

In the case of one binding site:

$$
K_{a}=\frac{\Theta}{(1-\Theta)[L]}
$$

where $[\mathrm{L}]$ is the concentration of the free ligand, which can be calculated from the total ligand $\mathrm{L}_{\mathrm{T}}$ and macromolecule concentration $\mathrm{M}_{\mathrm{T}}$ :

$$
[L]=L_{T}-n \Theta M_{T}
$$

Combining (B1) and (B2):

$$
\Theta^{2}-\Theta\left(1+\frac{1}{n K_{a} M_{T}}+\frac{L_{T}}{n M_{T}}\right)+\frac{L_{T}}{n M_{T}}=0
$$

whose only meaningful root is

$$
\Theta=\frac{1}{2}\left(1+\frac{1}{n K_{a} M_{T}}+\frac{L_{T}}{n M_{T}}-\sqrt{\left(\frac{1}{n K_{a} M_{T}}+\frac{L_{T}}{n M_{T}}\right)^{2}-\frac{4 L_{T}}{n M_{T}}}\right)
$$

The differential heat of the $i$ th injection can be expressed as

$$
q_{i}=n M_{T} V_{0} \Delta H_{b}\left(\Theta_{i}-\Theta_{i-1}\right)
$$

In the case of two independent binding sites:

$$
\begin{aligned}
K_{a} & =\frac{\Theta}{(1-\Theta)[L]} \text { and } K_{a}{ }^{\prime}=\frac{\Theta^{\prime}}{\left(1-\Theta^{\prime}\right)[L]} \\
L_{T} & =[L]+M_{T}\left(n \Theta+n^{\prime} \Theta^{\prime}\right)
\end{aligned}
$$

Combining Equations (B6) and (B7):

$$
L_{T}=[L]+\frac{n M_{T}[L] K_{a}}{1+[L] K_{a}}+\frac{n^{\prime} M_{T}[L] K_{a}{ }^{\prime}}{1+[L] K_{a}{ }^{\prime}}
$$

which leads to a cubic equation:

$$
[L]^{3}+p[L]^{2}+q[L]+r=0
$$

where

$$
\begin{aligned}
& p=\frac{1}{K_{a}}+\frac{1}{K_{a}{ }^{\prime}}+\left(n+n^{\prime}\right) M_{T}-L_{T} \\
& q=\left(\frac{n}{K_{a}{ }^{\prime}}+\frac{n^{\prime}}{K_{a}}\right) M_{T}-\left(\frac{1}{K_{a}}+\frac{1}{K_{a}{ }^{\prime}}\right) L_{T}+\frac{1}{K_{a} K_{a}{ }^{\prime}} \\
& r=\frac{-L_{T}}{K_{a} K_{a}{ }^{\prime}}
\end{aligned}
$$


Table A2. The assigned chemical shifts of Gal-1 at pH 7.4 without lactose.

\begin{tabular}{|c|c|c|c|c|c|c|c|}
\hline & $\mathrm{H}$ & $\mathrm{N}$ & $\mathrm{C}$ & $\mathrm{CA}$ & $\mathrm{CB}$ & HA & $\mathrm{HB}$ \\
\hline $\mathrm{C} 2$ & 9.05 & 127.6 & 172.1 & 53.4 & 39.0 & 4.90 & $3.11 / 3.35$ \\
\hline G3 & 8.41 & 112.2 & 170.1 & 42.5 & - & $4.43 / 4.03$ & - \\
\hline L4 & 7.64 & 121.5 & 171.7 & 54.2 & 41.0 & 4.32 & 1.61 \\
\hline V5 & 8.05 & 123.6 & 172.1 & 58.6 & 32.0 & 4.75 & 1.98 \\
\hline A6 & 9.61 & 129.8 & 171.9 & 47.5 & 18.6 & 5.69 & 1.30 \\
\hline S7 & 9.35 & 114.5 & 171.1 & 54.2 & 63.3 & 5.66 & 4.00 \\
\hline N8 & 8.31 & 115.1 & 172.9 & 51.6 & 34.0 & 4.48 & $3.27 / 3.04$ \\
\hline L9 & 7.91 & 114.9 & 174.2 & 55.1 & 40.1 & 3.80 & 1.60 \\
\hline N10 & 8.55 & 114.7 & 170.6 & 50.8 & 35.5 & 4.16 & $3.09 / 2.36$ \\
\hline L11 & 8.09 & 120.2 & 173.9 & 53.1 & 41.2 & 4.58 & 1.41 \\
\hline K12 & 8.67 & 127.4 & 171.2 & 51.6 & & & \\
\hline P13 & & & 175.0 & 61.3 & 29.0 & & \\
\hline G14 & 8.43 & 112.3 & 171.5 & 42.5 & - & $4.34 / 3.63$ & - \\
\hline E15 & 7.98 & 120.9 & 172.9 & 53.9 & 28.0 & 4.56 & 2.11 \\
\hline $\mathrm{C} 16$ & 9.02 & 122.1 & 169.7 & 52.2 & 41.8 & 5.27 & 3.10 \\
\hline L17 & 9.11 & 129.6 & 171.6 & 50.9 & 42.3 & 4.99 & 1.77 \\
\hline R18 & 9.07 & 127.0 & 172.0 & 52.0 & 30.4 & 5.09 & 1.68 \\
\hline V19 & 8.79 & 121.8 & 171.1 & 58.2 & 31.9 & 4.87 & 2.00 \\
\hline R20 & 8.98 & 126.3 & 173.5 & 51.3 & 32.0 & 5.71 & 1.92 \\
\hline G21 & 9.24 & 114.1 & 167.5 & 43.3 & - & $4.36 / 2.85$ & - \\
\hline E22 & 8.46 & 119.2 & 173.5 & 52.2 & 29.2 & 4.60 & 1.85 \\
\hline V23 & 8.98 & 129.3 & 174.2 & 59.8 & 29.2 & 4.24 & 2.44 \\
\hline A24 & 7.90 & 132.7 & & 49.4 & & & \\
\hline $\mathrm{P} 25$ & & & 173.3 & 61.9 & 28.8 & 4.07 & $2.35 / 1.93$ \\
\hline D26 & 8.28 & 116.5 & 173.0 & 49.8 & 36.7 & 4.57 & 2.65 \\
\hline A 27 & 6.77 & 118.7 & 173.7 & 50.9 & 17.8 & 3.79 & 0.98 \\
\hline K28 & 9.59 & 118.6 & 176.7 & 54.8 & 30.7 & 4.63 & 2.01 \\
\hline S29 & 8.40 & 114.3 & 170.6 & 55.1 & 61.9 & 5.28 & 3.88 \\
\hline F30 & 8.21 & 118.4 & 169.0 & 54.8 & 40.0 & 5.26 & $3.5 / 2.95$ \\
\hline V31 & 8.85 & 120.3 & 172.5 & 58.1 & 34.6 & 4.99 & 1.75 \\
\hline L32 & 8.81 & 124.0 & 171.5 & 51.8 & 43.4 & 5.27 & 1.61 \\
\hline N33 & 9.62 & 123.5 & 172.3 & 48.5 & 39.2 & 6.19 & 2.91 \\
\hline L34 & 9.63 & 120.1 & 175.2 & 50.4 & 43.8 & 5.73 & 1.57 \\
\hline G35 & 9.13 & 107.3 & 167.8 & 45.3 & - & 5.07 & 4.32 \\
\hline K36 & 9.00 & 127.9 & 172.5 & 55.5 & 32.5 & 4.74 & $1.98 / 1.83$ \\
\hline D37 & 7.93 & 114.1 & 172.3 & 50.1 & 37.6 & 3.50 & 2.94 \\
\hline S38 & 7.93 & 109.6 & 171.8 & 58.8 & 60.3 & 3.49 & 3.80 \\
\hline N39 & 7.90 & 117.4 & 171.4 & 50.3 & 38.3 & 4.60 & 2.41 \\
\hline N40 & 7.48 & 122.6 & 170.6 & 50.1 & 38.8 & 5.53 & 2.60 \\
\hline L41 & 9.66 & 122.6 & 174.0 & 50.5 & & 5.05 & \\
\hline $\mathrm{C} 42$ & 8.84 & 118.5 & 171.3 & 53.8 & 26.3 & 4.97 & $2.82 / 3.34$ \\
\hline L43 & 8.20 & 120.4 & 169.6 & 54.0 & 42.9 & 4.76 & 1.67 \\
\hline H44 & 9.18 & 129.7 & 172.2 & 52.9 & 37.0 & & \\
\hline F45 & 8.63 & 128.2 & 169.8 & 53.5 & 37.5 & 4.60 & \\
\hline N46 & 8.44 & 122.7 & 172.9 & 46.6 & & 4.72 & \\
\hline R48 & 8.70 & 126.0 & 172.1 & 53.0 & & & \\
\hline F49 & 8.05 & 123.6 & 175.4 & 57.6 & 35.5 & 4.05 & \\
\hline N50 & 8.05 & 115.2 & 170.5 & 50.9 & 35.9 & 4.96 & 2.85 \\
\hline A51 & 8.39 & 124.3 & 173.8 & 50.2 & - & 4.75 & 1.40 \\
\hline H52 & & & 172.2 & 54.0 & 25.2 & 4.28 & 3.31 \\
\hline G53 & 8.54 & 106.7 & 171.2 & 42.5 & & $4.24 / 3.57$ & - \\
\hline D54 & 8.11 & 120.2 & 171.6 & 51.4 & 42.0 & 4.85 & $2.61 / 2.20$ \\
\hline A55 & 8.10 & 121.4 & 173.9 & 47.9 & 18.0 & 4.66 & 1.22 \\
\hline N56 & 8.16 & 125.8 & 170.3 & 50.2 & 34.6 & 4.68 & 2.38 \\
\hline T57 & 7.61 & 111.6 & 169.9 & 58.8 & 70.8 & 4.60 & 3.40 \\
\hline I58 & 9.15 & 126.8 & 171.1 & 59.3 & 36.5 & 3.95 & 1.71 \\
\hline V59 & 7.35 & 129.1 & 172.1 & 59.4 & 30.5 & 4.40 & 1.76 \\
\hline C60 & 8.94 & 122.4 & 171.1 & 53.4 & 28.5 & 6.01 & \\
\hline N61 & 8.94 & 118.2 & 169.6 & 48.5 & 40.2 & 5.29 & 2.88 \\
\hline
\end{tabular}




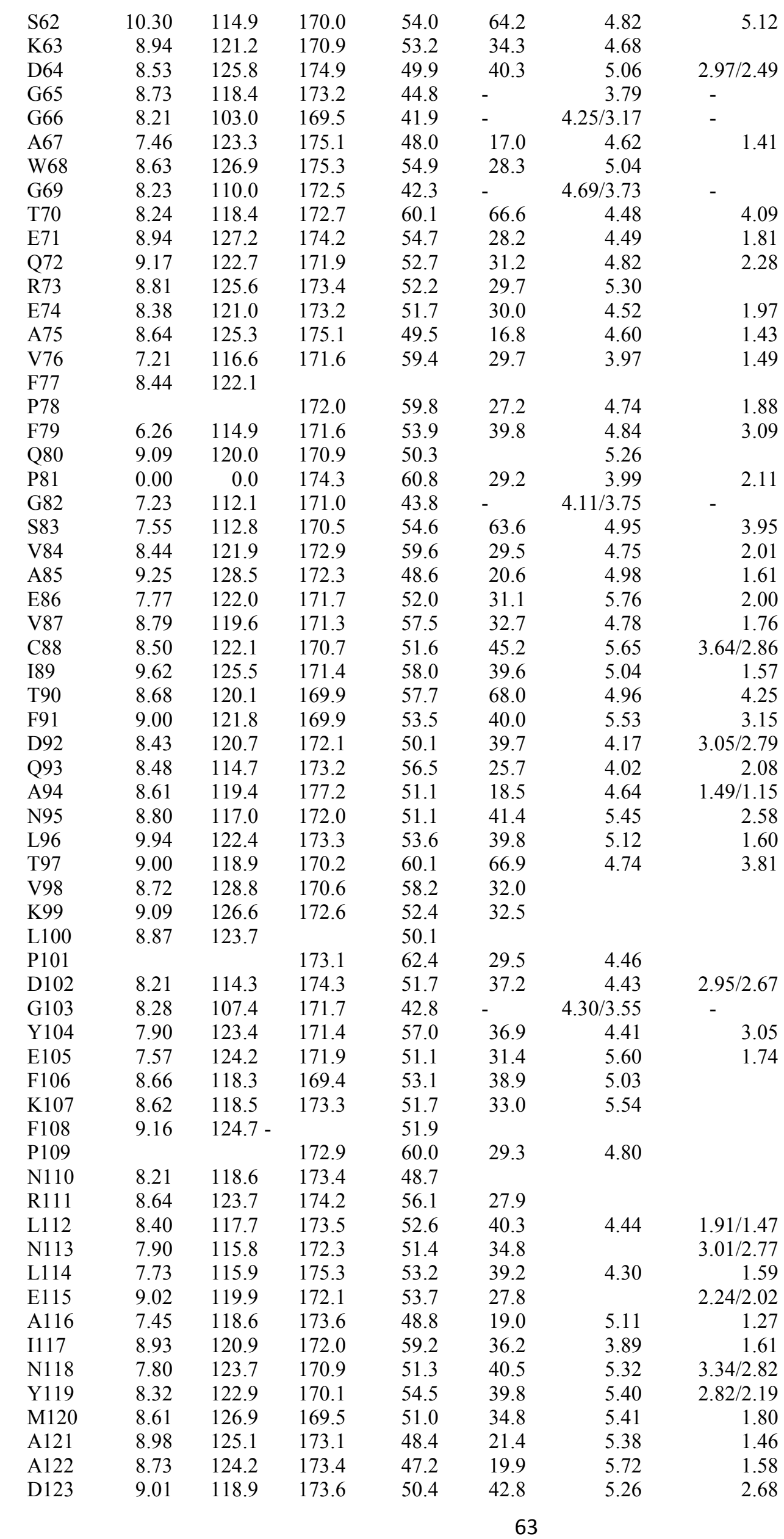




$\begin{array}{lrrrrrrr}\text { G124 } & 8.63 & 107.8 & 174.0 & 43.2 & - & 4.05 / 4.44- & \\ \text { D125 } & 8.76 & 123.4 & 171.8 & 53.0 & 39.0 & 4.91 & 2.94 / 2.69 \\ \text { F126 } & 8.18 & 122.6 & 170.1 & 53.0 & 40.8 & 5.06 & 2.48 / 2.11 \\ \text { K127 } & 8.17 & 127.7 & 173.0 & 51.6 & 31.7 & 4.53 & 1.73 \\ \text { I128 } & 8.51 & 127.1 & 172.2 & 60.4 & 34.1 & 3.40 & 1.75 \\ \text { K129 } & 9.33 & 124.7 & 173.9 & 52.4 & 30.3 & & \\ \text { C130 } & 8.26 & 118.0 & 169.1 & 53.5 & 42.0 & 5.39 & 3.35 / 3.14 \\ \text { V131 } & 9.00 & 124.2 & 169.9 & 58.2 & 32.2 & & \\ \text { A132 } & 9.05 & 127.0 & 172.0 & 47.7 & 21.0 & 4.91 & 1.38 \\ \text { F133 } & 8.25 & 119.6 & 172.1 & 52.9 & 37.0 & 5.21 & 3.33 / 2.96 \\ \text { D134 } & 8.62 & 128.2 & & 53.3 & & & \end{array}$

\section{Particle size, morphology and electrostatic stability changes of the Aß1-42 fibril samples in the presence of LPFFD or ThT}

In order to prove the sedimentation and flocculation hypothesis, samples were prepared for DLS, TEM and $\zeta$-potential measurements, with the same protocol as used for the NMR. The diffuse back-scattering decreases with increasing particle size (e.g. caused by flocculation). ${ }^{\text {a13 }}$ The time-dependent changes in the back-scattered (BS) light intensity were monitored photographically and were plotted against sample height and time (Figure A1). ${ }^{\text {a14-a16 }}$ The analysis revealed slow sedimentation for pure fibrillar A $1-42$. For the LPFFD $+A \beta 1-42$ sample, a ligand-induced flocculation phenomenon was indicated. After $3 \mathrm{~h}$, spikes appeared in the BS intensity which are related to the precipitated material attached to the test tube wall. For the ThT $+\mathrm{A} \beta 1-42$ sample, the steep BS intensity fall over the whole height of the sample in the first $3 \mathrm{~h}$ suggested a significant particle size increase due to flocculation. The final low BS intensity was attained after $3 \mathrm{~h}$, and the fluctuation in the BS intensity revealed that large sediments adhered to the tube wall. These findings pointed to a rapid ThT-induced self-association of the fibrillar A $\beta 1-42$.
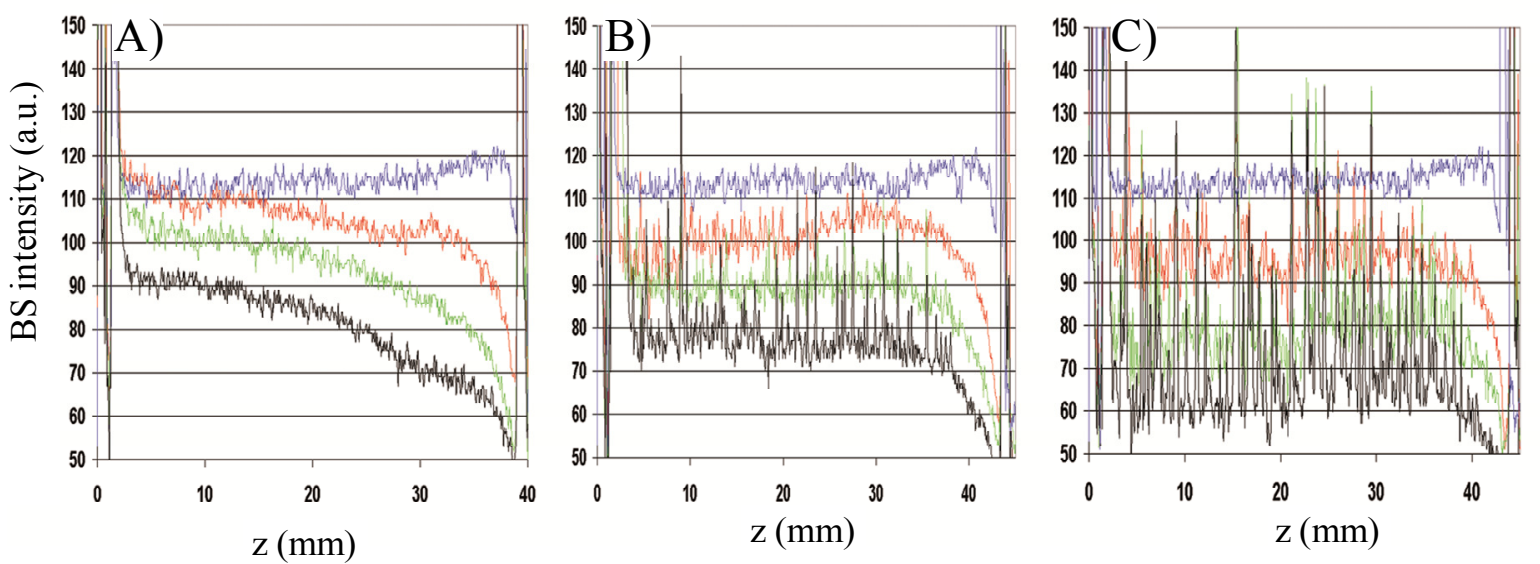

Figure A1. Diffuse light-scattering results obtained on freshly prepared samples of fibrillar A $\beta 1-42$ (A), LPFFD $+A \beta 1-42$ (B) and ThT $+A \beta 1-42$ (C); measured at $\mathrm{t}=0$ (blue), 1 (red), 2 (green) and $3 \mathrm{~h}$ (black). The samples were prepared in phosphate buffer $(10 \mathrm{mM}, \mathrm{pH} 7.4)$. 
In TEM measurements, only separate (non-flocculated) mature fibrils were observed for pure fibrillar A $\beta 1-42$ during the studied $24 \mathrm{~h}$. Immediately after the sample preparation for the LPFFD $+A \beta 1-42$ mixture, large floccules of A $\beta 1-42$ fibrils appeared, which subsequently displayed a further increase in particle size. Addition of ThT to the fibrillar A $\beta 1-42$ resulted in large interfibrillar assemblies, and after $3 \mathrm{~h}$ large particles were formed by the flocculated fibrils. Electrokinetic potential ( $\zeta$-potential) measurements revealed a slightly increased electrostatic stability of the A $\beta 1-42$ fibrils upon LPFFD and/or ThT binding, which indicates that the interfibrillar assembly is driven by specific non-covalent cross-linking interactions.

A)

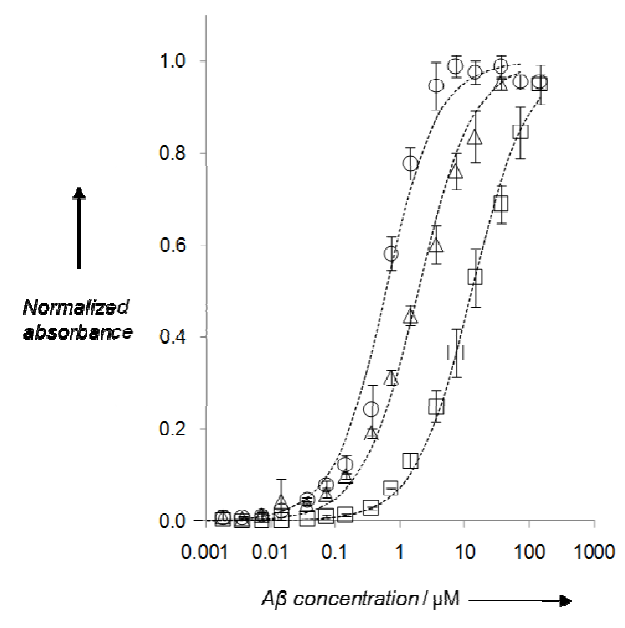

B)

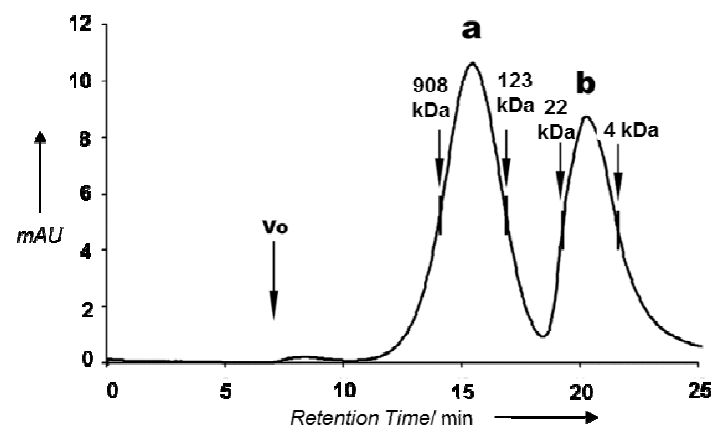

C)

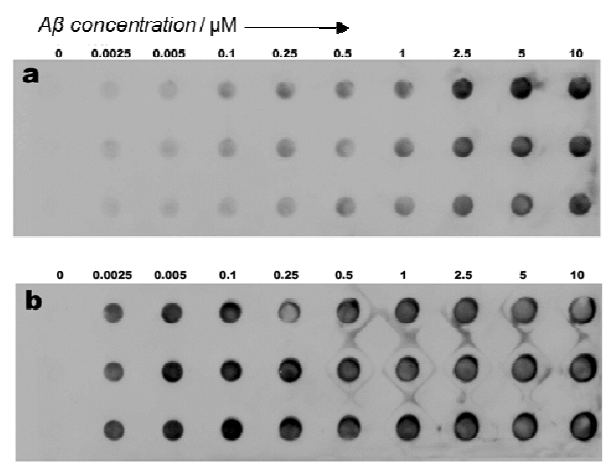

Figure A2. A) Normalized absorbances recorded in capture ELISA experiments, where the biotinyl-10 (circles), $-\mathbf{9}$ (triangles) or $\mathbf{- 5}$ (squares) are attached to the avidin-functionalized plate and the increasing surface concentration of A $\beta$ is observed through the BAM10 antibody. Fitted curves are given (dashed). B) Size exclusion chromatographic separation of the HMW (a) and LMW (b) fractions of the A $\beta$ oligomeric sample. C) Concentration-dependent dot blot experiments performed with the HMW (a) and the LMW fractions (b).

\section{Appendix references}

a1. Solomon, I., Phys Rev 1955, 99, 559-565.

a2. Overhauser, A. W., Phys Rev 1953, 89, 689-700.

a3. Teng, Q., Protein dynamics. In Structural Biology: Practical NMR Applications. Springer: 2005.

a4. Rule, S. G., Hitchens, K. T., Nuclear spin relaxation and molecular dynamics. In Fundamentals of Protein NMR Spectroscopy, Springer: 2006.

a5. Abragam, A., Principles of Nuclear Magnetism, Clarendon Press, Oxford, 1961.

a6. Kay, L.E., Torchia, D.A., Bax, A., Biochemistry 1989, 28, 8972-79. Lipari, G.; Szabo, A., $J$ Am Chem Soc 1982, 104, 4546-59. 
a7. Lipari, G.; Szabo, A., J Am Chem Soc 1982, 104, 4546-59.

a8. Lipari, G.; Szabo, A., J Am Chem Soc 1982, 104, 4559-70.

a9. Clore, G. M.; Szabo, A.; Bax, A.; Kay, L. E.; Driscoll, P. C., et al., J Am Chem Soc 1990, 112, 4989-91.

a10. Meyer, B.; Peters, T., Angew Chem Int Ed 2003, 42, 864-90.

a11.Zerbe, O., BioNMR in Drug Research. Wiley-VCH: Weinheim, 2003.

a12.Dalvit, C.; Pevarello, P.; Tato, M.; Veronesi, M.; Vulpetti, A., et al., J Biomol NMR 2000, $18,65-8$.

a13. Mengual, O.; Meunier, G.; Cayre, I.; Puech, K.; Snabre, P., Colloids and Surfaces 1999, 152, $111-23$.

a14. Mengual, O.; Meunier, G.; Cayre, I.; Puech, K.; Snabre, P., Talanta 1999, 50, 445-56.

a15.Lemarchand, C.; Couvreur, P.; Besnard, M.; Costantini, D.; Gref, R., Pharm Res 2003, 20, 1284-92.

a16.Lemarchand, C.; Couvreur, P.; Vauthier, C.; Costantini, D.; Gref, R., Int J Pharm 2003, 254, $77-82$. 